Marília Chaves Vieira de Campos

\title{
Análise crítica e estimativa dos valores preditivos positivos das calcificações de aspecto mamográfico não benigno
}

Tese apresentada à Faculdade de Medicina da Universidade de São Paulo para obtenção do título de Doutor em Ciências

Área de concentração: Radiologia Orientador: Dr. Nestor de Barros

São Paulo

2006 

A meus pais Ivan e Lia,

exemplos de amor, perseverança e de coragem para enfrentar desafios.

A Ana Cecília e Mariana, dois raios de Sol que enchem minha vida de luz e alegria.

A Antonio Carlos,

que há vinte anos me apóia e impulsiona em direção a novas conquistas. 


\section{AgRADECIMENTOS}

Os mais sinceros agradecimentos a todas as pessoas que colaboraram na execução desse trabalho, em especial:

ao Dr. Nestor de Barros, pela sua paciência e disponibilidade como orientador

ao Dr. Luciano Chala, que contribuiu com preciosas sugestões,

e às amigas que participaram da leitura das mamografias,

Dra. Adriana Padovan Ferreira,

Dra. Cristina César Conti e

Dra. Daniela Stanzani.

Também gostaria de agradecer aos professores que participaram da Banca do Exame de Qualificação:

Profa. Dra. Filomena Marino Carvalho,

Prof. Dr. Ayrton Pastore e

Dra. Maria Cristina Chammas.

Meu carinho a duas pessoas que fazem com que a vida seja bem melhor, e que, indiretamente, colaboraram muito para esse trabalho ter se concretizado:

\section{Ilka Regina Chaves e}

Dra. Renata Rudge Telles de Aquino.

Um agradecimento especial às pessoas que incentivaram meus primeiros passos na Radiologia Mamária:

Dra. Vera Nunes Aguillar,

Dr. Cláudio Rossi,

Dra. Elvira Marques e

Dr. Aron J. Belfer.

Agradeço ainda ao apoio dos amigos

do Instituto de Radiologia do Hospital das Clínicas da Faculdade de Medicina da Universidade de São Paulo,

do Fleury Centro de Diagnósticos e

da Unidade Radiológica Paulista. 


\section{SUMÁRIO}

Lista de abreviaturas........................................................ vi

Lista de tabelas ................................................................... vii

Lista de figuras.................................................................. viii

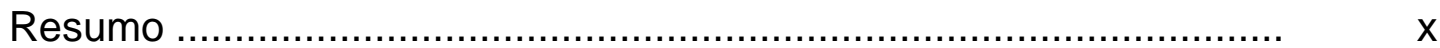

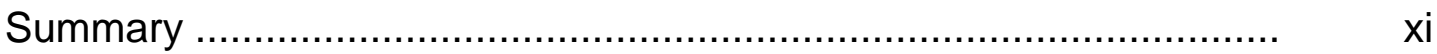

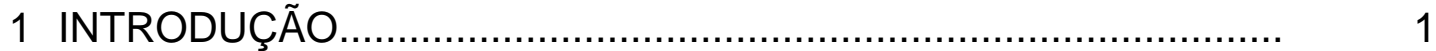

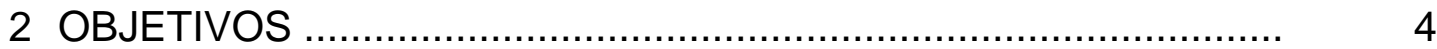

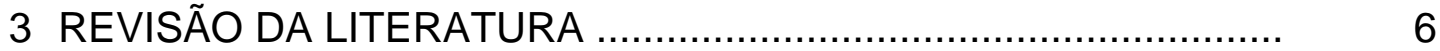

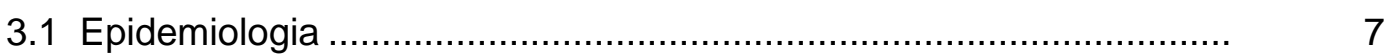

3.2 Detecção, diagnóstico e valor preditivo positivo (VPP) ..................... 8

3.3 Classificação do BI-RADS ........................................................... 18

3.4 Biópsias percutâneas orientadas pela estereotaxia ........................ 32

3.5 Técnicas em biópsias percutâneas mamárias................................... 34

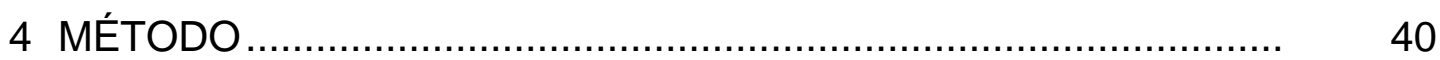

4.1 Participantes e critérios de inclusão e exclusão ................................. 41

4.2 Método ................................................................................... 42

4.3 Análise estatística dos dados ..................................................... 47

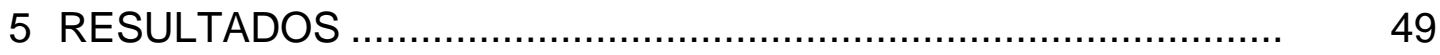

5.1 Casuística - população estudada..................................................... 50

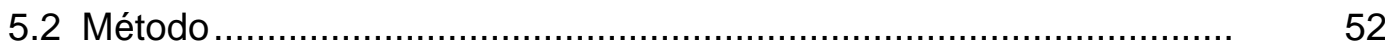

5.3 Análise estatística.................................................................... 56

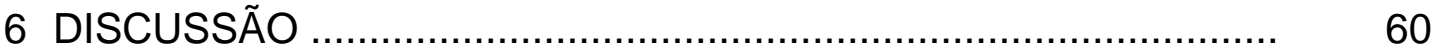

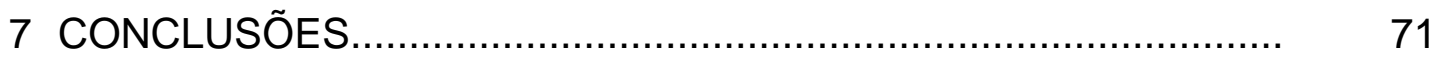

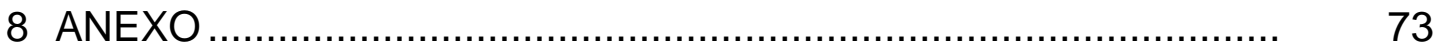

9 REFERÊNCIAS ......................................................... 89 


\section{LISTA DE ABREVIATURAS}

$\begin{array}{ll}\text { AP } & \text { anatomopatológico } \\ \text { BPAG } & \text { biópsia por agulha grossa } \\ \text { CDI } & \text { carcinoma ductal invasivo } \\ \text { CDIS } & \text { carcinoma ductal "in situ" } \\ \text { FA } & \text { fibroadenoma } \\ \text { HDA } & \text { hiperplasia ductal atípica } \\ \text { HDT } & \text { hiperplasia ductal típica } \\ \text { PAAF } & \text { punção aspirativa por agulha fina } \\ \text { VPP } & \text { valor preditivo positivo }\end{array}$




\section{LISTA DE TABELAS}

Tabela 1. Magnitude dos fatores de risco conhecidos para câncer de mama

Tabela 2. Resultados anatomopatológicos

Tabela 3. Resultados anatomopatológicos e proporção na população estudada.

Tabela 4. Freqüência e incidência de malignidade de acordo com a morfologia das calcificações

Tabela 5. Freqüência e incidência de malignidade de acordo com a distribuição das calcificações.

Tabela 6. Combinação morfologia e distribuição como determinantes do VPP das calcificações mamárias

Tabela 7. Associação da morfologia e da distribuição das calcificações e respectivos VPP

Tabela 8. VPP das calcificações segundo a morfologia, nas pacientes abaixo dos 60 anos e acima dos 60 anos 


\section{LISTA DE FIGURAS}

Figura 1. Mamografia de paciente, com 55 anos, evidenciando calcificação grosseira, "em pipoca", e calcificações de morfologia heterogênea grosseira com distribuição segmentar - AP: CDI

Figura 2. Mamografia de paciente, com 43 anos, demonstrando calcificações de morfologia heterogênea grosseira com distribuição agrupada - AP: fibroesclerose

Figura 3. Mamografia de paciente, com 52 anos, apresentando calcificações de morfologia puntiforme/arredondada, com distribuição agrupada - AP: adenose simples

Figura 4. Mamografia de paciente, com 59 anos, apresentando calcificações de morfologia amorfa com distribuição linear - AP: HDT

Figura 5. Mamografia de paciente, com 53 anos, apresentando calcificações de morfologia pleomorfa e distribuição agrupada - AP: CDIS.

Figura 6. Mamografia de paciente, com 64 anos, apresentando calcificações de morfologia amorfa e distribuição agrupada - AP: FA.

Figura 7. Mamografia de paciente, com 72 anos, apresentando calcificações de morfologia linear e distribuição segmentar - AP: CDI

Figura 8. Mamografia de paciente, com 39 anos, apresentando calcificações de morfologia arredondada/puntiforme e distribuição agrupada - AP: adenose simples 
Figura 9. Mamografia de paciente, com 51 anos, apresentando calcificações de morfologia pleomorfa fina e distribuição

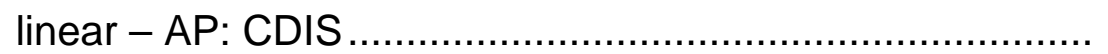

Figura 10. Mamografia de paciente, com 73 anos, apresentando calcificações de morfologia heterogênea grosseira e distribuição segmentar - AP: adenose simples 


\section{RESUMO}

Campos MCV. Análise crítica e estimativa de valores preditivos positivos das calcificações de aspecto mamográfico não benigno [tese]. São Paulo: Faculdade de Medicina, Universidade de São Paulo; 2006. 97p.

Foram avaliadas algumas características das calcificações e sua associação com o câncer de mama. Estudou-se a densidade, morfologia, distribuição, extensão e número de calcificações em 507 mamografias, correlacionando-as ao achado anatomopatológico pós-biópsia. Os valores preditivos positivos encontrados para cada tipo de calcificação foram utilizados para categorizá-las de acordo com as categorias do sistema BI-RADS em subcategorias $4 \mathrm{~A}$ (2 a 11\%), 4B (11,1 a 50\%) e 4C (50,1 a 70,0\%) e categoria 5 (acima de 70\%). Todas as características se mostraram importantes na diferenciação das calcificações em benignas e malignas, em menor grau a densidade e em maior grau a morfologia e a distribuição. A distribuição linear ou segmentar, e a morfologia pleomorfa ou linear apresentaram as mais altas taxas de malignidade.

Descritores: 1.MAMOGRAFIA/classificação 2.NEOPLASIAS MAMÁRIAS 3. VALOR PREDITIVO 4.CALCINOSE/diagnóstico 


\section{SUMMARY}

Campos MCV. Critical analysis and estimative of positive preditive values of non benign mamographic aspect calcifications [thesis]. São Paulo: "Faculdade de Medicina, Universidade de São Paulo"; 2006. 97p.

Some characteristics of the calcifications and its association with the breast cancer had been evaluated. It was studied density, morphology, distribution, extension and number of calcification in 507 mammographies, correlating them with the biopsies. The positive preditive values for each type of calcification had been used in accordance with the categories of the BI-RADS. In the study BI-RADS 4 was divided in: 4A ( PPV 2 to 11\%), 4B (11,1 to 50\%) and $4 \mathrm{C}(50,1$ to $70.0 \%)$ and category 5 (above of $70 \%$ ). All the characteristics was important in the caracterization of the calcifications in benign or malignant; in lesser degree the density and bigger degree the morphology and distribution. A linear or segmentary distribution, and the pleomorfic or linear morphology had presented the highest taxes of malignity.

Descriptors: 1.MAMMOGRAPHY/ classification 2.BREAST CANCER 3.PREDICTIVE VALUE 4.CALCIFICATION/diagnosis 
1 INTRODUÇÃO 
O câncer de mama é a neoplasia maligna mais comum nas mulheres, quando excluído o câncer de pele e, no Brasil, é a segunda causa de morte por câncer no sexo feminino ${ }^{1,2}$. A maneira mais eficaz de reduzir a mortalidade por esta doença é a sua detecção precoce por meio do rastreamento mamográfico, atualmente recomendado para todas as mulheres assintomáticas com mais de 40 anos $^{3}$.

Focos de calcificações mamárias são freqüentemente detectados nas mamografias de rastreamento e, embora, a maioria deles seja tipicamente benigna $^{3}$, podem representar um câncer de mama, que nesta circunstância, mais freqüentemente é "in situ" e sem comprometimento ganglionar axilar" 4,5 Assim, muitas biópsias mamárias originadas nos programas de rastreamento mamográfico visam investigar focos de calcificações que não são tipicamente benignos e apresentam graus variados de suspeição para malignidade; a maioria destas biopsias resultam em diagnósticos benignos ${ }^{3}$.

Em 1993, o Colégio Americano de Radiologia (ACR) publicou a primeira edição do BI-RADS (Breast Imaging Reporting and Data System) que visava uniformizar a estrutura, a terminologia, as conclusões e as recomendações de conduta nos laudos mamográficos ${ }^{6,7}$. A avaliação e a conduta em relação às calcificações propostas no BI-RADS baseiam-se principalmente na morfologia e distribuição delas. Se o aspecto radiológico for indeterminado ou sugestivo de malignidade, elas são classificadas nas 
categorias de avaliação final 4 ou 5 do BI-RADS e a biópsia, recomendada. Na quarta edição do BI-RADS, publicada em 2003, foi proposta a subdivisão da categoria 4 em três subcategorias denominadas de 4A, 4B e 4C, de acordo com um grau crescente de suspeição para malignidade. Entretanto, não foram definidos critérios para a subdivisão dessa categoria, assim como, de divisão entre as categorias 4 e 5, incluindo quais tipos calcificações pertencem a cada categoria. Aperfeiçoar tais critérios e colaborar na classificação das calcificações mamárias dentro das categorias 4 e 5 de avaliação do BIRADS é a proposta deste trabalho, e pode contribuir para uniformizar a conclusão dos laudos mamográficos, para melhorar a seleção da técnica de biópsia e para aperfeiçoar a conduta pós-biópsia. 
2 OBJETIVOS 
Determinar o valor preditivo positivo (VPP) para malignidade dos diferentes tipos de calcificações de acordo com as suas características mamográficas.

Classificar as calcificações mamárias nas categorias de avaliação final 4 (A, B e C) e 5 do BI-RADS. 
3 REVISÃO DA LITERATURA 


\subsection{EPIDEMIOLOGIA}

Nos Estados Unidos a American Cancer Society coloca o câncer de mama como a neoplasia maligna mais comum em mulheres, quando excluído o câncer de pele não melanoma, e como segunda causa de morte por câncer, superada apenas pelo câncer de pulmão ${ }^{9}$.

No Brasil, o câncer de mama também é a segunda neoplasia mais freqüente, precedida pelo câncer de pele não melanoma, porém, entre as mulheres é a principal causa de morte por câncer².

A análise epidemiológica do câncer mamário é extensa, sendo que são vários os fatores associados com o maior risco de câncer de mama, como menarca precoce, menopausa tardia, nuliparidade ou primiparidade em idade avançada, obesidade, exposição a altas doses de radiação, o fato de nunca ter amamentado, história pessoal de doença mamária benigna ou de câncer mamário, consumo de álcool, dieta rica em gorduras animais e história familiar de câncer mamário em um ou mais parentes de primeiro grau (Tabela 1). 
Tabela 1 - Magnitude dos fatores de risco conhecidos para câncer de mama

\begin{tabular}{|c|c|c|}
\hline \multicolumn{3}{|c|}{ RISCO RELATIVO } \\
\hline Menor que 2 & De 2 a 4 & Maior que 4 \\
\hline Menarca precoce & $\begin{array}{l}\text { Um parente de } 1^{\circ} \text { grau } \\
\text { com câncer de mama }\end{array}$ & $\begin{array}{l}\text { Dois parentes de } 1^{\circ} \text { grau } \\
\text { com câncer de mama }\end{array}$ \\
\hline Menopausa tardia & Radiação & Mutação genética \\
\hline Nuliparidade & Mamas densas & Câncer de mama prévio \\
\hline$>35$ anos no $1^{\circ}$ parto & & LCIS \\
\hline TRH & & DCIS \\
\hline Obesidade & & Atipia \\
\hline Uso de álcool & & \\
\hline $\begin{array}{l}\text { Biópsia prévia com diagnóstico de } \\
\text { doença epitelial proliferativa benigna }\end{array}$ & & \\
\hline
\end{tabular}

FONTE: Tchou, J - J Am Coll Surg ${ }^{10}$

A associação entre fatores de risco e câncer de mama não explica grande parte dos casos dessa patologia, por isso ela é, em geral, considerada hormônio dependente. Por esse motivo, do ponto de vista de saúde pública, todas as mulheres devem ser rastreadas dentro das orientações para cada faixa etária.

\subsection{DetecçÃo, diagnóstico e VAlor PREDitiVo Positivo (VPP)}

É importante distinguir os termos detecção e diagnóstico, pois o uso inapropriado dos mesmos tem confundido a utilização da mamografia e de outros métodos de imagem na avaliação do câncer de mama ${ }^{11}$.

Detecção é a capacidade de encontrar anormalidades, enquanto que diagnóstico é a capacidade de classificar uma anomalia como benigna ou maligna. A detecção deve preceder o diagnóstico e no caso do câncer mamário é a função mais importante de um exame de imagem. 
A mamografia é uma excelente técnica para detecção, mas não é diagnóstica, a menos que uma lesão tenha características típicas de processo maligno ou benigno.

Outro termo utilizado com freqüência nesse trabalho é "valor preditivo positivo (VPP)". Valor preditivo positivo é um dado que estabelece, na presença de um resultado de exame positivo, qual é a probabilidade da pessoa realmente ter a doença, que no caso desse estudo é o câncer de mama.

O cálculo do VPP pode ser feito através da divisão do número de casos verdadeiramente positivos pelo número total de exames positivos ${ }^{12}$.

\section{A. Mamografia e rastreamento}

O principal papel da mamografia é o rastreamento de mulheres assintomáticas, na tentativa de detectar o câncer em estágio mais precoce do que a própria mulher ou seu médico possam detectar durante o autoexame ou exame clínico.

A mamografia tem se mostrado um método eficiente na detecção de lesões muito pequenas e é o único exame de rastreamento que provou ser capaz de reduzir as mortes por câncer de mama. Esse decréscimo na mortalidade está quase que inteiramente associado à diminuição do tamanho da lesão no momento do diagnóstico do câncer de mama ${ }^{3}$.

As primeiras evidências que sustentam a recomendação do rastreamento periódico mamográfico derivam de sete estudos controlados randomizados $^{13}$. Esses estudos compararam mortes por câncer de mama 
entre mulheres de 40-70 anos submetidas a mamografia de rotina e mulheres de grupo controle. Em seis deles observou-se que a mamografia de rotina reduziu a mortalidade por câncer de mama dentro de todas as faixas etárias estudadas. Em apenas um deles os investigadores foram incapazes de demonstrar qualquer benefício do rastreamento ${ }^{14,15}$

Nos acompanhamentos iniciais desses estudos nenhum deles mostrou muitos benefícios para o subconjunto de mulheres que entraram no programa de rastreamento à idade de 40-49 anos $^{14}$. A vantagem do rastreamento nesses casos só apareceu depois, porque mulheres mais jovens têm taxas de crescimento de câncer de mama mais rápidas, para as quais intervalos de exame de dois anos são excessivamente longos ${ }^{16,17}$.

HUMPHREY recentemente revisou seis desses sete estudos, além de dois de auto-exame das mamas. Observou uma mortalidade por câncer de mama de $22 \%$ em mulheres na faixa etária de 50 anos, e de $15 \%$ em mulheres dos 40 aos 49 anos, em 14 anos de observação ${ }^{15}$. Com base nos achados desses trabalhos, todos os municípios suecos e norte-americanos, e muitos na Finlândia, agora oferecem mamografia de rotina como um serviço de saúde pública para mulheres de 40 anos ou mais.

Em grande parte por causa do uso difundido da mamografia de rotina, o paciente comum com câncer de mama nos Estados Unidos hoje tem 39\% menos chance de morrer da doença do que teria no início da década de $80^{18}$.

Apesar de a mamografia de rastreamento começando aos 40 anos ser consenso nos Estados Unidos, a periodicidade ideal para a realização dos 
exames na faixa etária dos 40 aos 49 anos ainda é discutida ${ }^{19}$. Todas as organizações aconselham mamografias anuais para mulheres a partir dos 50 anos.

O exame físico e a mamografia são estudos complementares e embora nenhum teste isolado ou combinado seja perfeito, se utilizados juntos podem alcançar benefício máximo.

Infelizmente, detecção precoce não garante uma evolução favorável, devido a fatores não conhecidos e que têm relação com a potencialidade para metastatisar de alguns tumores e com as variações de resposta do hospedeiro ao tumor ${ }^{20}$. Então, mesmo o mais exato programa de rastreamento não salvará todas as mulheres; a redução de mortalidade esperada com bases no HIP e dados suecos é de $25 \%$ a $40 \%$ e não de $100 \%$.

\section{B. Mamografia digital e outros métodos usados na detecção e diagnóstico das lesões mamárias}

Considerando que a mamografia apresenta alta sensibilidade nas mamas de constituição predominantemente adiposa, concluímos que o problema maior na detecção precoce são as mamas radiograficamente densas, onde geralmente o câncer é encontrado num estágio mais avançado ${ }^{21}$.

Em estudo recente coordenado pelo ACR estudou-se a acurácia diagnóstica da mamografia digital versus a da mamografia tradicional, em mulheres assintomáticas que realizaram mamografia de rotina. Observou-se certa superioridade da mamografia digital na análise de mamas densas, o que pode representar benefícios nos exames de rastreamento de câncer de mama em mulheres jovens e na pré menopausa, que geralmente apresentam maior densidade mamária ${ }^{22}$. 
A mamografia digital apresenta ainda vantagens no que diz respeito a mamografia diagnóstica, devido à possibilidade da utilização de métodos adicionais para a avaliação de lesões, como: 1. a mamografia digital contrastada, que estuda a angiogênese da lesão; 2. a tomosíntese, que permite a avaliação tridimensional da lesão; 3. a telemamografia, que permite a transmissão das imagens da mamografia de um local remoto para um centro de especialistas; 4. e a detecção computadorizada (Computer-aided Diagnosis and Detection - CAD), que, associada aos métodos de obtenção de mamografia digital, tem um desempenho melhor do que quando associada aos métodos tradicionais de mamografia.

O sistema CAD, em estudo apresentado em 2001 no encontro anual da Sociedade Norte Americana de Radiologia mostrou uma taxa de detecção de 84\% para massas e 97\% para agrupamento de calcificações ${ }^{23}$.

Com relação à ultra-sonografia mamária, sabemos que não é o método indicado no rastreamento de mamas assintomáticas porque apresenta alta taxa de falso-negativo, devido, principalmente, a sua limitação na detecção de microcalcificações não associadas a nódulos, de distorções arquiteturais e de pequenos nódulos localizados de permeio ao tecido adiposo ${ }^{24-28}$. A taxa de falso positivos também é alta ${ }^{27}$.

A ultra-sonografia apresenta ainda limitações na avaliação de calcificações tais como alta dependência do operador e do equipamento, não permitindo avaliação adequada do número e morfologia das calcificações ${ }^{24}$. Assim sendo, até que essas questões sejam resolvidas, a ultra-sonografia não deve ser utilizada no rastreamento populacional de mulheres assintomáticas ${ }^{24}$. 
A imagem por ressonância magnética $(R M)$ das mamas tem se mostrado uma ferramenta muito útil na avaliação de várias doenças mamárias. O seu uso para rastreamento, no entanto, não foi ainda validado. Deve-se lembrar que atualmente a RM ainda está associada a desvantagens importantes para o uso como método de rastreamento, como alto custo e baixa especificidade.

\section{Mamografia: questão dos falso-positivos}

A redução dos exames de mamografia falso-positivos pode ser fundamental para a ampliação dos programas de rastreamento mamográfico ${ }^{29,30}$. Consideramos como exames falso positivos aqueles nos quais a biópsia foi indicada e o resultado foi benigno ${ }^{29}$.

SICKLES e VARAS ${ }^{29,31}$ deram um importante passo para a redução do número de exames falso positivos ao determinar na mamografia um grupo de lesões não palpáveis com probabilidade de malignidade inferior a 2\%, em que a vigilância mamográfica e clínica pode ser considerada como alternativa a biópsia. Essas lesões foram denominadas de provavelmente benignas $^{29-34}$

No entanto ainda se realiza um número substancial de biópsias com resultados benignos em lesões de caráter indeterminado. O VPP desejável para as biópsias indicadas pela mamografia é de $25 \%$ a 40\%. Nos Estados Unidos esses valores tem estado entre $15 \%$ e $40 \%{ }^{35}$.

$\mathrm{HALL}^{36}$ acredita que a obtenção de uma segunda opinião antes de biopsiar uma lesão não palpável deve ser encorajada. HALL é um grande 
defensor do rastreamento mamográfico, mas acredita que será difícil manter a aceitação pública e a manutenção do método, sem que ocorra diminuição do número de alterações benignas biopsiadas.

KOPANS $^{37}$ ressalta que embora deva haver uma redução no número de biópsias realizadas em alterações benignas, isso deve ser feito com cuidado para que não se coloque em risco a detecção e o diagnóstico precoce do câncer de mama através da mamografia.

Atualmente realiza-se biópsia em um amplo espectro de lesões mamográficas, desde algumas lesões provavelmente benignas cujas pacientes têm características pessoais que tornam desfavorável a vigilância clínica e mamográfica, como desejo de engravidar, história pessoal prévia de câncer de mama e outros, até as lesões altamente suspeitas de malignidade, com VPP maior que $95 \%{ }^{34}$.

Desta maneira, apesar do avanço representado pela determinação das lesões provavelmente benignas na mamografia, há um enorme interesse em se encontrar novos subgrupos de lesões com baixa suspeita de malignidade, onde a vigilância clínica e por métodos de imagem seja uma alternativa segura à biópsia ${ }^{27}$, particularmente nas lesões de aspecto indeterminado ${ }^{20}$.

\section{Mamografia na detecção de calcificações suspeitas}

Considera-se como definição de um agrupamento de calcificações aquele em que três ou mais calcificações menores de $1 \mathrm{~mm}$ de diâmetro estejam agrupadas em um pequeno volume de tecido, e projetadas em uma área de $0,5 \mathrm{~cm} \times 0,5 \mathrm{~cm}$ na mamografia ${ }^{38}$. 
As calcificações, sem outros achados mamográficos associados, foram relacionadas ao câncer de mama pela primeira vez há mais de 50 anos. Em 1954, LE BORNE descreveu que as calcificações finas, alongadas, numerosas e irregularmente agrupadas em uma área da mama estavam, muito freqüentemente, associadas ao câncer de mama. Essa descoberta levou a um aumento significativo no diagnóstico do carcinoma ductal "in situ" (CDIS), já que esse tipo de câncer de mama se manifesta mais freqüentemente através do achado mamográfico de calcificações.

Em estudo multicêntrico JACKMAN ${ }^{39}$, em 2001, avaliou 1326 casos de carcinomas ductais "in situ" e demonstrou que $89,1 \%$ deles manifestaram-se como calcificações.

Até a década de 70 , as calcificações ainda eram poucas vezes diagnosticadas, devido ao baixo contraste dos filmes e a compressão relativamente pobre. Quando detectadas, todas eram submetidas à cirurgia, pois não era possível diferenciar microcalcificações benignas de malignas ${ }^{30}$.

Em 1967, pela primeira vez observou-se que a densidade das calcificações no carcinoma de mama não é uniforme ${ }^{40}$.

Em 1972, ROGERS e POWELL ${ }^{41}$ concluíram que a análise do tamanho das calcificações não contribuiu para a diferenciação das mesmas em benignas ou malignas, exceto quando elas já são consideradas grosseiras, e que o aumento na concentração de calcificações por $\mathrm{cm}^{2}$ está associado a um aumento no seu VPP.

Em 1976, MILLIS ${ }^{42}$ também observou associação entre o câncer de mama e o tamanho (<500 micrometros), o número (alto) e a concentração (alta) de calcificações em um agrupamento. 
Em 1976, LE GAL propôs uma categorização das calcificações mamárias de acordo com o número, distribuição e morfologia das mesmas:

- Tipo 1: anelares

- Tipo 2: puntiformes, arredondadas, regulares

- Tipo 3: muito tênues para se precisar a forma, mesmo com o auxílio de lupa

- Tipo 4: puntiformes e irregulares

- Tipo 5: vermiformes.

A proporção de malignidade encontrada nesse estudo foi, respectivamente, de $0 \%, 33 \%, 40 \%, 100 \%$ e 100\% para os tipos de 1 a 5 . Essa classificação foi consagrada como classificação de Le Gal e utilizada em diversos $\operatorname{artigos}^{43}$

Em 1984, LE GAL, em novo estudo de calcificações, novamente correlacionou os seus cinco tipos morfológicos com porcentagens de malignidade, a saber:

- Tipo 1: todas são benignas

- Tipo 2: descritas como puntiformes e regulares: 22\% são malignas

- Tipo 3: descritas como semelhantes à poeira, de difícil identificação morfológica: 40\% são malignas

- Tipo 4: 66\% são malignas

- Tipo 5: todas são malignas. As calcificações polimórficas foram incluídas nesse tipo. ${ }^{44}$ 
Nos dias atuais, muitos casos de calcificações agrupadas são diagnosticados, principalmente nos programas de rastreamento. Com o avanço tecnológico, filmes de alto contraste e incidências complementares como as magnificadas, temos a possibilidade de classificar focos de calcificações ora considerados suspeitos, em categorias de benignidade, evitando morbidade e diminuindo custos $^{18}$.

Calcificações que não sejam tipicamente benignas exigem estudo com magnificação em duas incidências diferentes (crânio caudal e perfil absoluto). São essenciais filmes de alta qualidade, obtidos com foco de 0,1 mm, exposição de 2 segundos ou menos e sem artefatos de movimento para a avaliação de características mamográficas como morfologia, distribuição e número das calcificações.

As diferentes morfologias das calcificações refletem diferentes graus de suspeita de malignidade. $\operatorname{TABAR}^{45}$ descreveu como valor preditivo positivo das calcificações lineares $94 \%$, das granulares $57 \%$ e das amorfas $45 \%$.

VIANNA e MARCHIORI ${ }^{46}$, em 2002 estudaram 30 casos de tumores malignos cujas mamografias apresentaram calcificações relacionadas com as lesões, avaliando a morfologia e a distribuição das calcificações. Concluíram que $80 \%$ dos casos apresentavam calcificações com a forma esperada para o padrão histológico arquitetural do tumor, dado que reforça a importância do estudo morfológico das calcificações.

Atualmente, a classificação usada para a categorização das calcificações é a classificação do sistema BI-RADS de laudos mamográficos. 


\subsection{ClassificAÇÃo do BI-RADS}

O Colégio Americano de Radiologia adotou modelo de normatização de laudos mamográficos em 1992, denominado de BI-RADS (Breast Imaging Reporting and Data System), realizado em conjunto com o Instituto Americano do Câncer, o Centro de Prevenção e Controle de Doenças do FDA (Food and Drug Administration) e o Colégio Americano de Cirurgiões e de Patologistas.

Este modelo preconiza laudo mamográfico conciso, descrição dos achados com terminologia padronizada, impressão diagnóstica e conduta preconizada.

Em relação à composição e distribuição do tecido fibroglandular, a descrição do padrão da mama pode variar desde predominantemente adiposa até acentuadamente densa. Esta variação está relacionada à sensibilidade da mamografia, pois se sabe que o câncer de mama é normalmente radiodenso e a sensibilidade mamográfica é menor nas mamas densas ${ }^{47}$.

No que diz respeito à análise das calcificações, a classificação é dividida em relação à morfologia em:

\section{TIPICAMENTE BENIGNAS:}

a. Calcificações cutâneas: pequenas, de paredes finas, com centro radioluscente

b. Calcificações vasculares: em linhas paralelas, claramente associadas a estruturas tubulares

c. Calcificações grosseiras ou "em pipoca": grandes (> 2-3 mm de diâmetro), lobulares, típicas dos fibroadenomas 
d. Calcificações grandes, em bastão: geralmente maiores que um mm de diâmetro, podem formar bastões contínuos ou descontínuos, seguindo uma distribuição ductal, convergindo para o mamilo. Geralmente são bilaterais, vistas em mulheres acima dos 60 anos, representando calcificações secretórias

e. Calcificações redondas: podem ser múltiplas e variar em tamanho, geralmente formadas em ácinos ou lóbulos

f. Calcificações puntiformes: redondas ou ovais, com menos de 0,5 mm de diâmetro e margens bem definidas

g. Calcificações com centro radioluscente: redondas ou ovais, com centro radioluscente e paredes mais espessas do que as calcificações "em casca de ovo". Estão associadas a áreas de esteatonecrose

h. Calcificações "em casca de ovo": arredondadas, porém com paredes finas

i. Calcificações em "leite de cálcio": são arredondadas na incidência crânio-caudal e ficam lentiformes na incidência em perfil absoluto

j. Calcificações em fios de sutura: lineares ou tubulares, com nós freqüentemente aparentes

k. Calcificações distróficas: geralmente aparecem em mamas irradiadas ou que sofreram trauma. Apesar de terem forma irregular são grosseiras e têm mais de 0,5 mm de tamanho. Freqüentemente têm centro radioluscente.

\section{CALCIFICAÇÕES DE CARÁTER INTERMEDIÁRIO DE SUSPEITA:}

a. Amorfas: são tão tênues e diminutas que não é possível determinar a sua morfologia

b. Calcificações heterogêneas grosseiras: geralmente são bilaterais e se apresentam em múltiplos focos. 


\section{CALCIFICAÇÕES COM ALTA PROBABILIDADE DE MALIGNIDADE:}

a. Calcificações finas e pleomorfas: variam em tamanho e formato, geralmente são menores que 0,5 mm em diâmetro

b. Calcificações finas e lineares: são finas, lineares ou curvilíneas, descontínuas e têm menos que 0,5 mm de espessura.

Quanto à distribuição, são assim descritas:

a. Agrupadas: quando pelo menos cinco calcificações ocupam um volume menor que um $\mathrm{cm}^{3}$ de tecido

b. Lineares: arranjadas em linha nas duas incidências

c. Segmentares: sugere acompanhar o ducto e seus lóbulos

d. Regionais: distribuídas em grande volume de tecido, não respeitando a distribuição ductal

e. Difusas: distribuídas randomicamente nas mamas. 


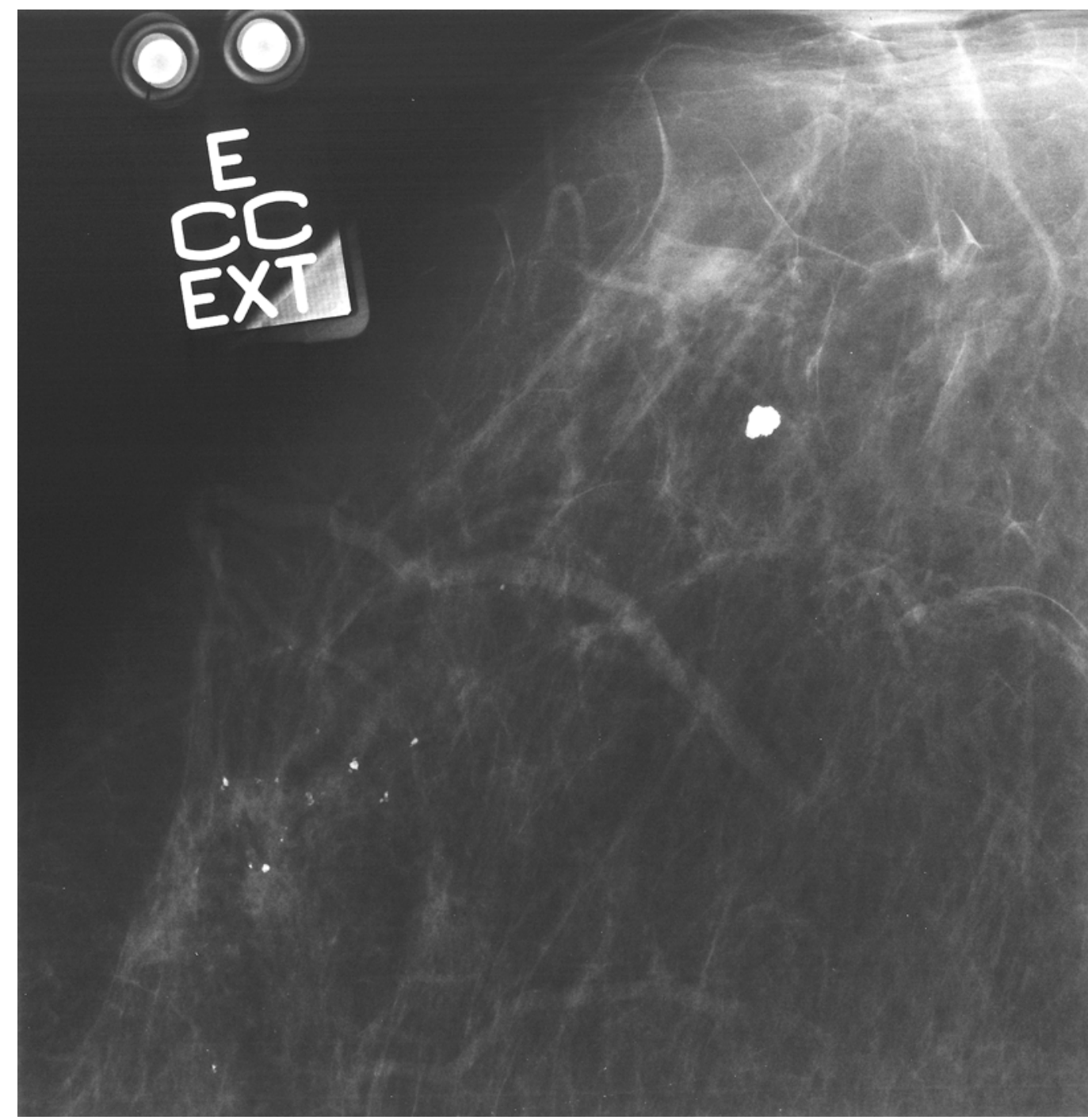

Figura 1. Mamografia de paciente, com 55 anos, evidenciando calcificação grosseira, "em pipoca", e calcificações de morfologia heterogênea grosseira com distribuição segmentar - AP: CDI 


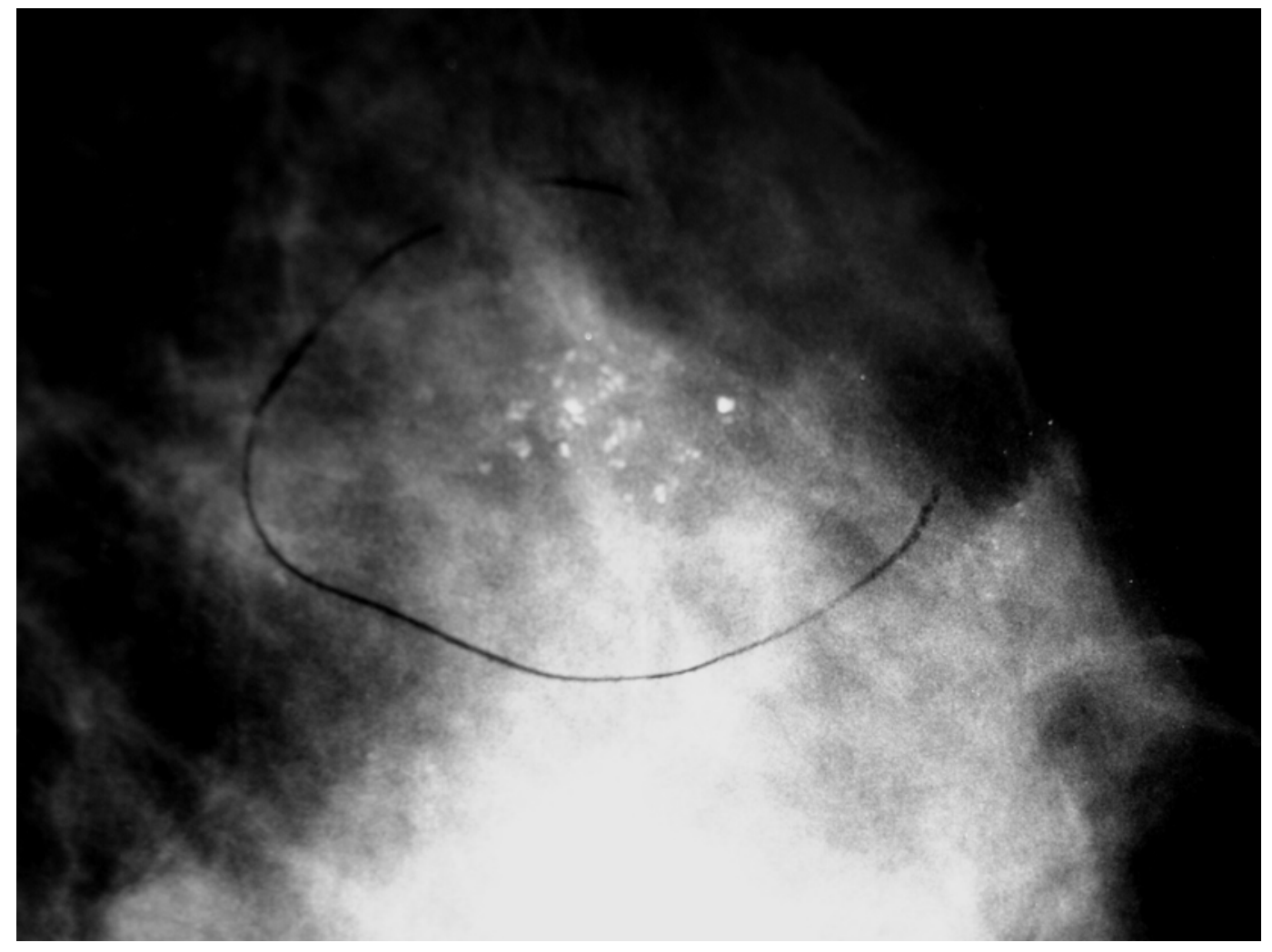

Figura 2. Mamografia de paciente, com 43 anos, demonstrando calcificações de morfologia heterogênea grosseira com distribuição agrupada - AP: fibroesclerose 


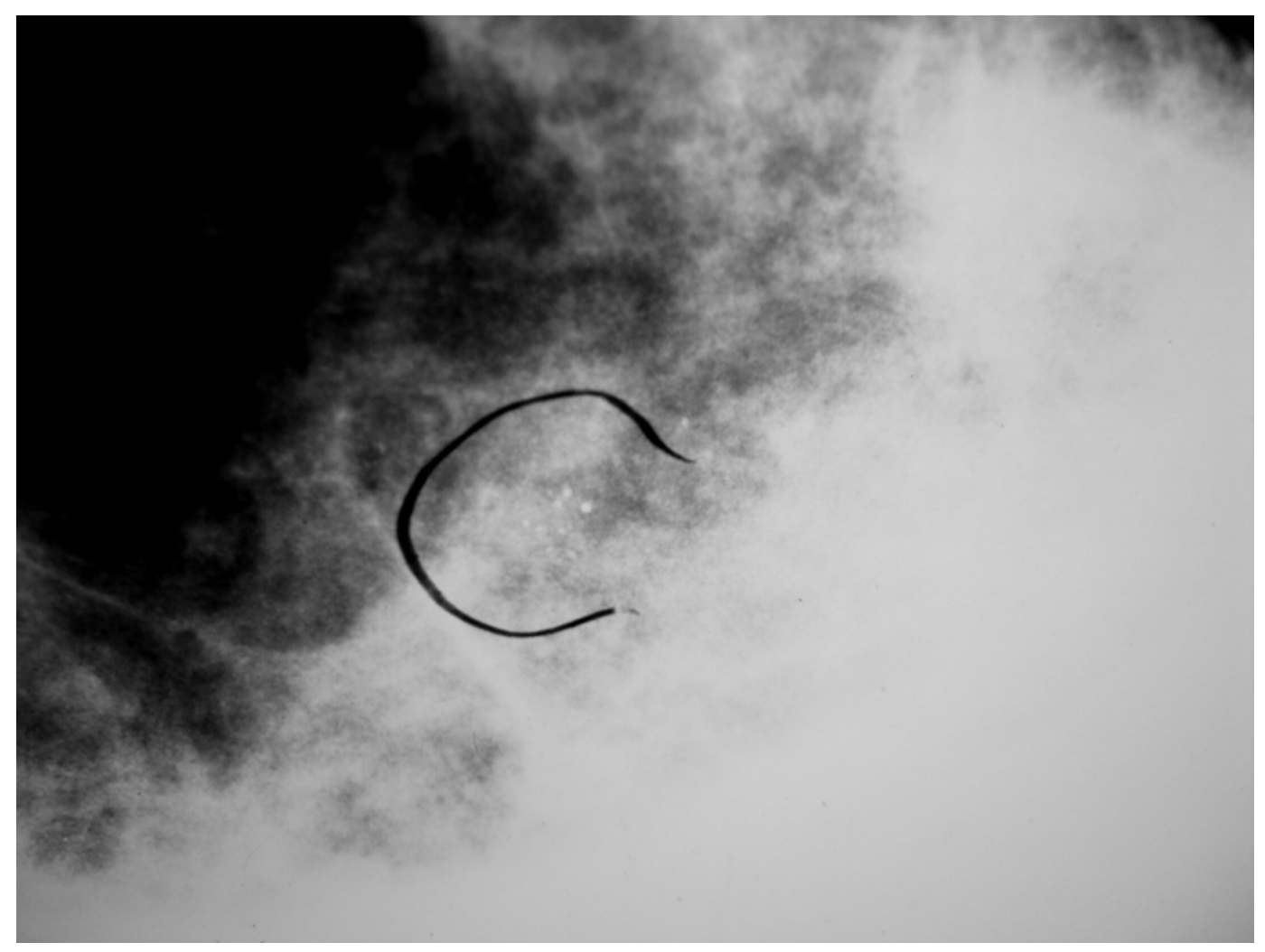

Figura 3. Mamografia de paciente, com 52 anos, apresentando calcificações de morfologia puntiformelarredondada, com distribuição agrupada - AP: adenose simples 


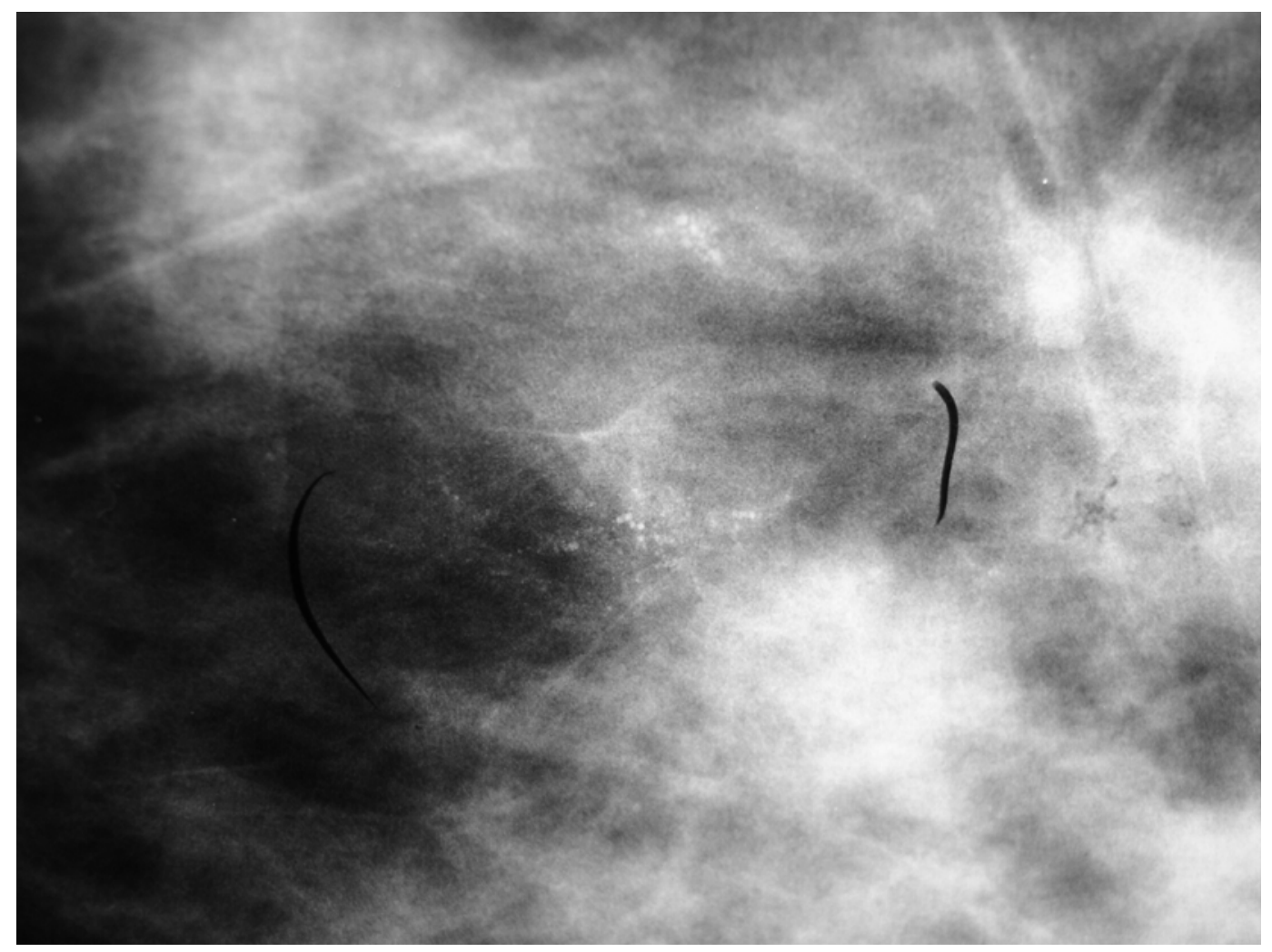

Figura 4. Mamografia de paciente, com 59 anos, apresentando calcificações de morfologia amorfa com distribuição linear - AP: HDT 


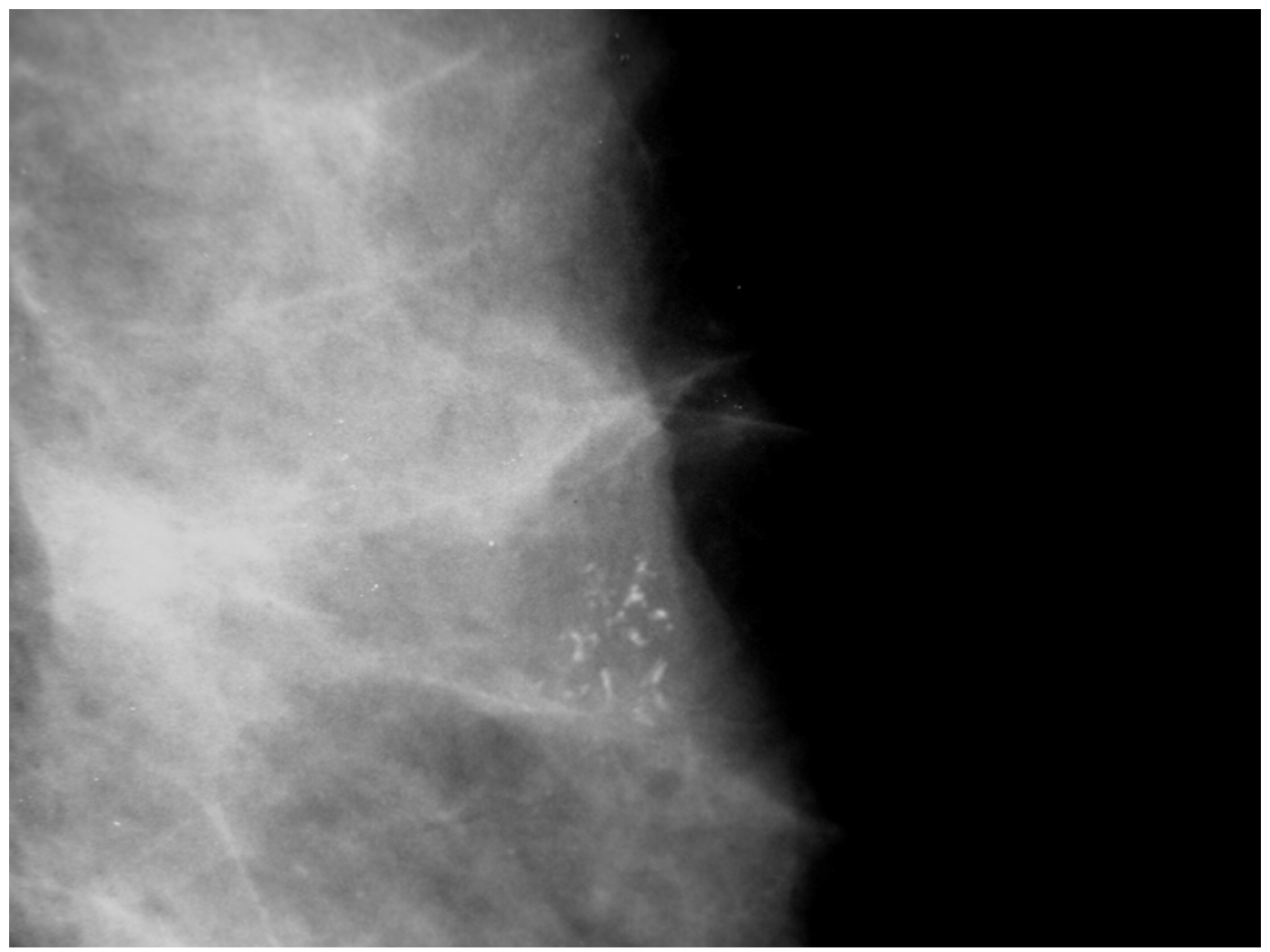

Figura 5. Mamografia de paciente, com 53 anos, apresentando calcificações de morfologia pleomorfa e distribuição agrupada - AP: CDIS 


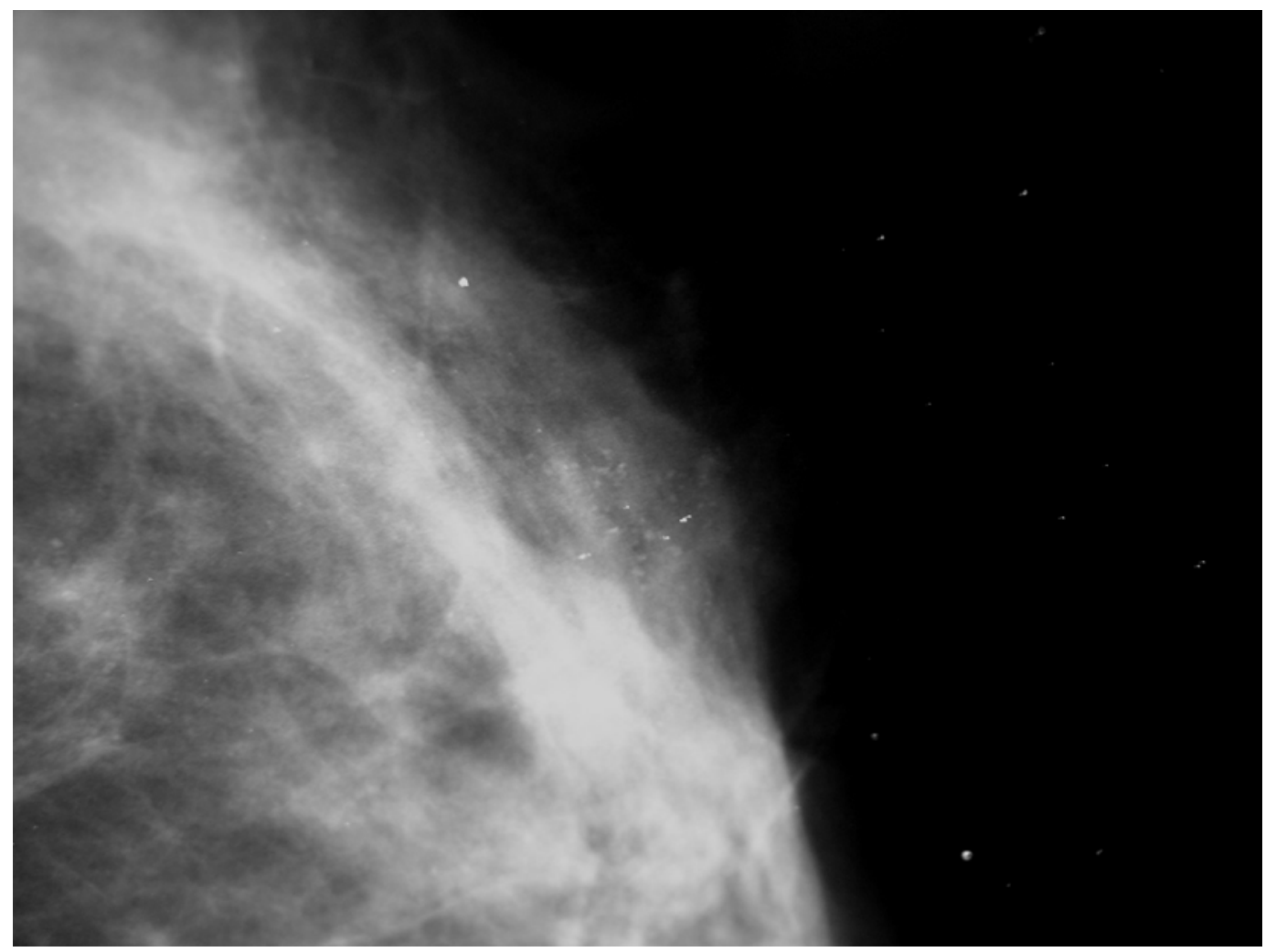

Figura 6. Mamografia de paciente, com 64 anos, apresentando calcificações de morfologia amorfa e distribuição agrupada - AP: FA 


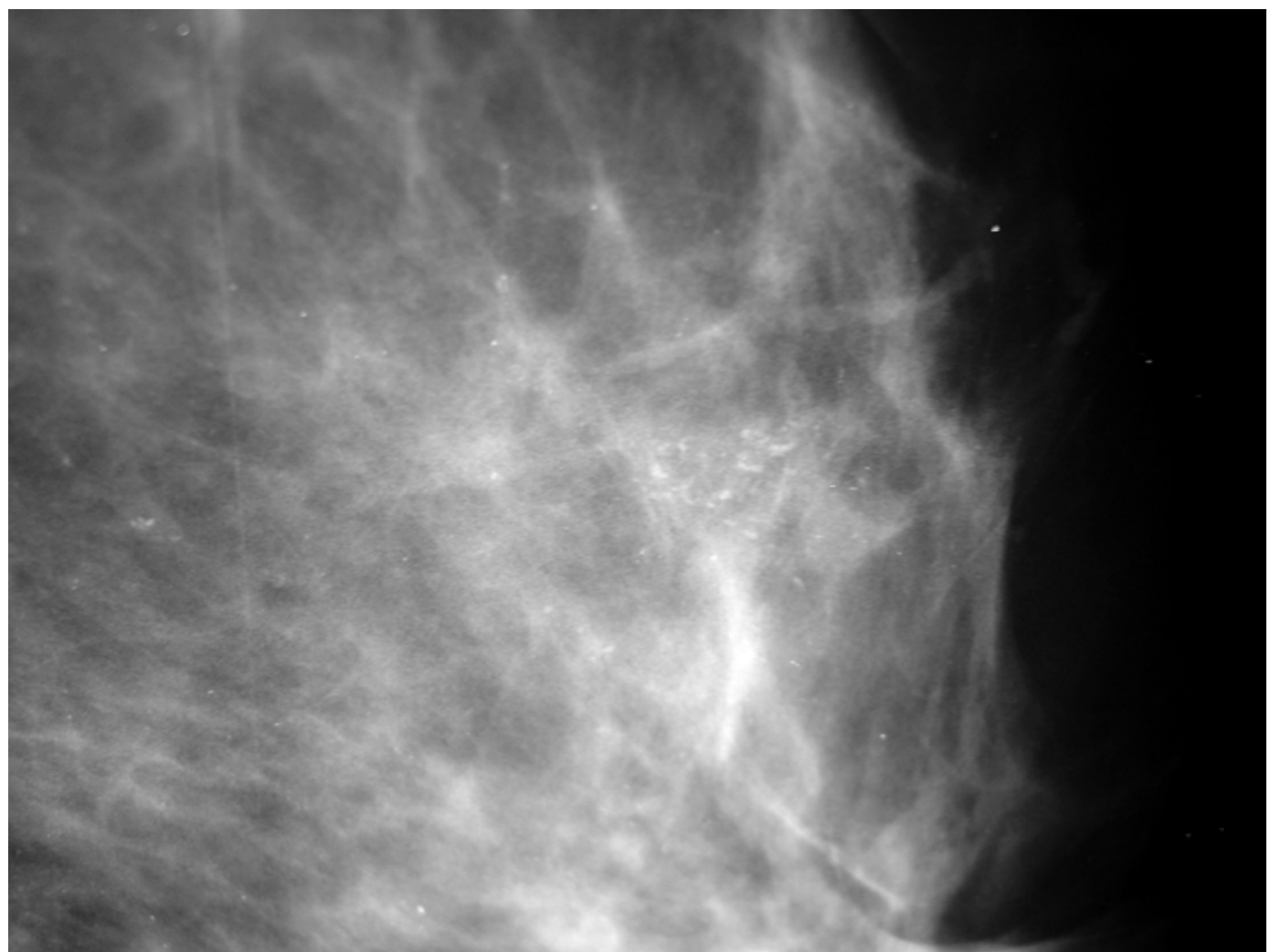

Figura 7. Mamografia de paciente, com 72 anos, apresentando calcificações de morfologia linear e distribuição segmentar - AP: CDI 


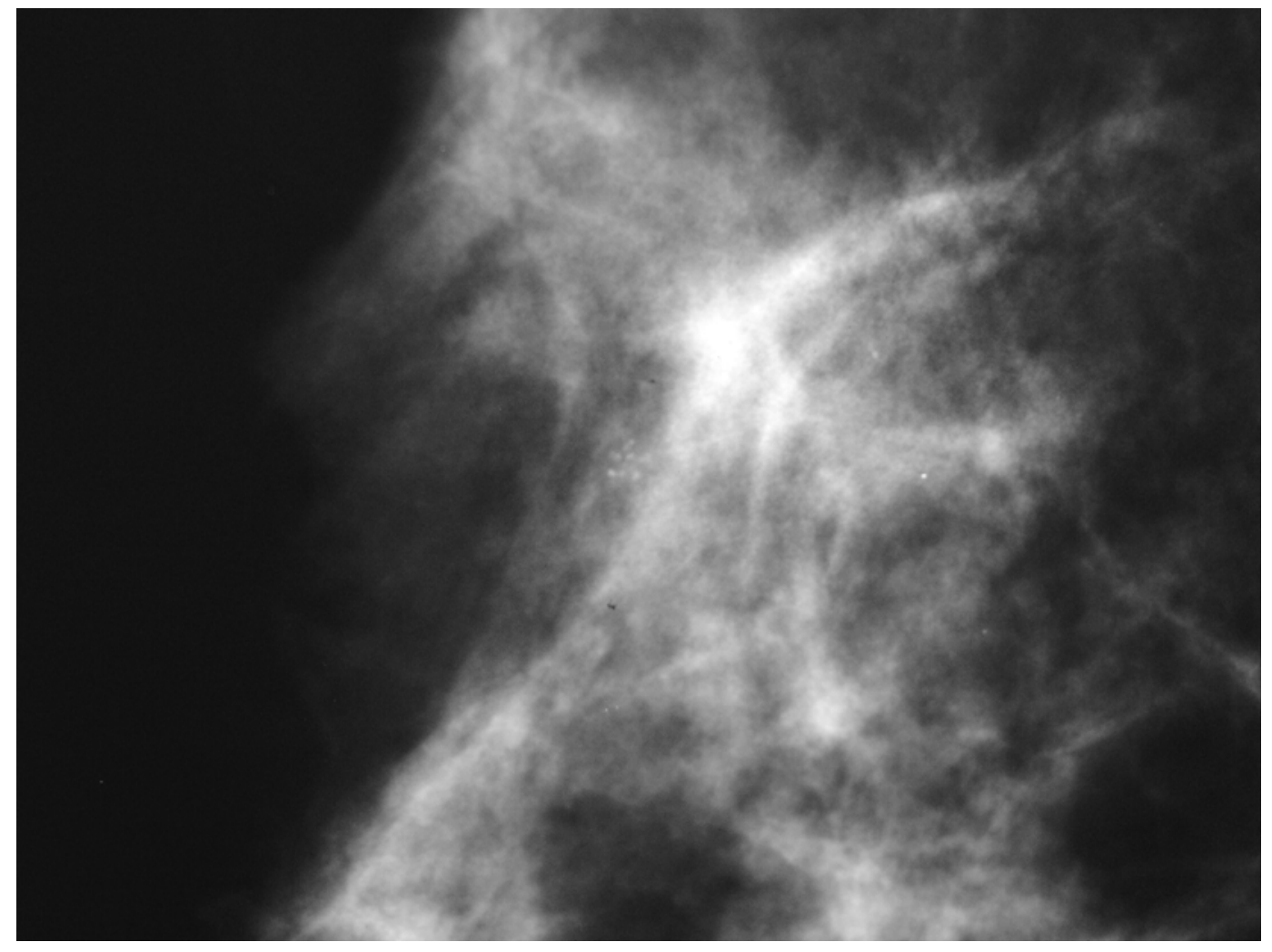

Figura 8. Mamografia de paciente, com 39 anos, apresentando calcificações de morfologia arredondada/puntiforme e distribuição agrupada - AP: adenose simples 


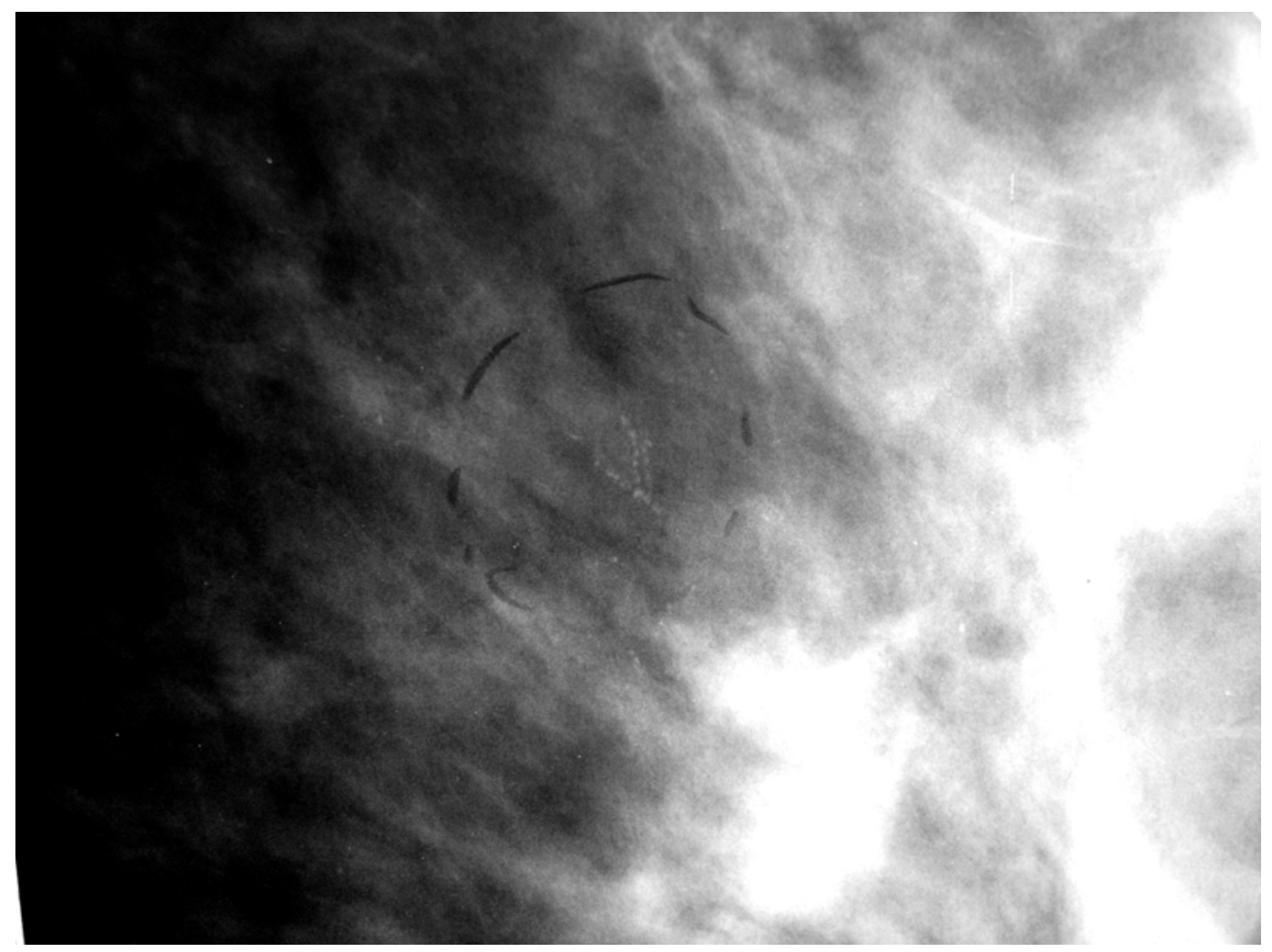

Figura 9. Mamografia de paciente, com 51 anos apresentando calcificações de morfologia pleomorfa fina e distribuição linear - AP: CDIS 


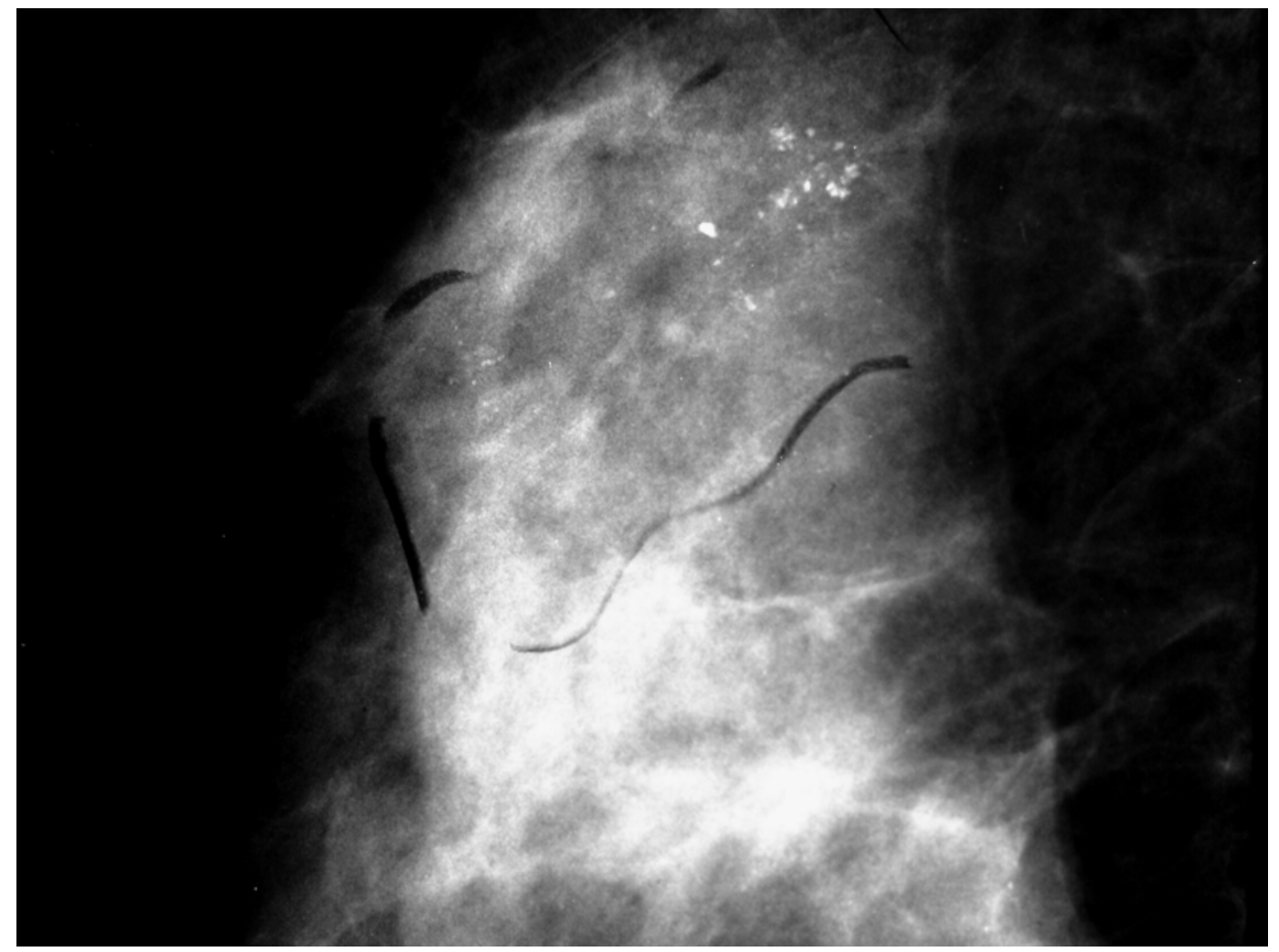

Figura 10. Mamografia de paciente, com 73 anos apresentando calcificações de morfologia heterogênea grosseira e distribuição segmentar - AP: adenose simples 
A conclusão diagnóstica é expressa em categorias, a saber:

- Categoria zero: mamografia que necessita de estudo adicional por imagem

- Categoria 1: mamografia normal

- Categoria 2: mamografia com achados radiológicos benignos

- Categoria 3: mamografia com achados radiológicos provavelmente benignos

- Categoria 4: mamografia com achados radiológicos suspeitos para malignidade

- Categoria 5: mamografia com achados altamente suspeitos para malignidade.

A última fase do laudo mamográfico se refere à recomendação de conduta, que é inerente a cada categoria do BI-RADS:

- Categoria 1 e 2: seguimento anual ou bianual

- Categoria 3: seguimento mamográfico em seis meses

- Categoria 4 e 5: sugestão/indicação de investigação cito-histológica. ${ }^{7,8}$

Na quarta edição do BI-RADS, de 2003, foi mantido o critério descritivo das calcificações abrangendo tamanho, morfologia e distribuição. Estabeleceu-se apenas uma diferença no que se refere à descrição da morfologia das calcificações, unificando as calcificações arredondadas e puntiformes em uma mesma descrição, pois ficou evidente que a diferença de tamanho entre ambas não é significativa.

Ainda nessa quarta edição, foi proposta a subdivisão da categoria 4 em três subcategorias: 4A, 4B e 4C. Essa subdivisão tem como objetivos: 1. proporcionar ao médico que recebe o laudo do radiologista uma opinião mais precisa quanto ao grau de suspeita que a lesão sugere; 2. facilitar indicação do seguimento mamográfico mais indicado após o resultado do estudo 
anatomopatológico (AP) e 3. sugerir ao patologista uma maior atenção ao encontrar um resultado benigno em achado mamográfico classificado como $4 C^{8}$

A sugestão feita pelo manual do BI-RADS para efetuar essa subdivisão é a seguinte:

- Categoria 4A: pode ser usada para um achado que sugira a necessidade de intervenção, mas que tenha uma baixa suspeita de malignidade, já que não é esperado um achado anatomopatológico maligno. Se o resultado AP for benigno pode-se proceder a um controle mamográfico em seis meses ou de rotina.

- Categoria 4B: inclui lesões com uma suspeita intermediária de malignidade. Os achados demonstram que é necessário estar atento à correlação antomopatológica e radiológica.

- Categoria 4C: inclui achados de moderada malignidade, mas ainda não clássicos de malignidade. Exemplos: agrupamento novo de finas calcificações pleomorfas. Nessa categoria espera-se um resultado anatomopatológico maligno. $^{8}$

\subsection{BIÓPSIAS PERCUTÂNEAS ORIENTADAS PELA ESTEREOTAXIA}

Os programas de rastreamento do câncer de mama provocaram um aumento considerável no número de diagnósticos de lesões não palpáveis, normalmente menores de 1,0 cm, entre elas as calcificações agrupadas. Os esforços na categorização destas lesões permitiram que inúmeras cirurgias 
fossem evitadas. Porém, um número grande de lesões classificadas como suspeitas e altamente suspeitas para malignidade, demanda verificação histológica ${ }^{48}$.

As alternativas disponíveis para evitar a biópsia cirúrgica são o seguimento imagenológico periódico para as lesões provavelmente benignas e a biópsia percutânea com estudo histológico para as lesões que necessitam prosseguimento na investigação da sua natureza.

O seguimento periódico para lesões provavelmente benignas à mamografia pode ser uma conduta adequada, baseada nos trabalhos de SICKLES $^{24}$ que encontrou menos de $1 \%$ de malignidade em 1000 casos de calcificações redondas ou ovais agrupadas; de MOSKOWITZ ${ }^{11}$, que reviu 593 casos de nódulos não calcificados com margens bem definidas, maiores que $1,0 \mathrm{~cm}$, onde apenas $2 \%$ eram malignos e de $\mathrm{KOPANS}^{37}$, que mostrou que em apenas $1 \%$ dos 227 casos de áreas de densidade assimétrica do parênquima mamário foi encontrado malignidade. Consolidam ainda esses achados os estudos de WOLFE $^{49}$, que em uma série de 1356 lesões provavelmente benignas, encontrou menos que $1 \%$ de malignidade e, novamente SICKLES ${ }^{34}$ que em 4533 lesões classificadas como "provavelmente benignas", encontrou câncer em menos de 1,5\% dos casos.

Nos casos das lesões suspeitas para malignidade (categoria 4 do BI-RADS) e lesões provavelmente malignas (categoria 5 do BI-RADS), há a indicação de estudo anatomopatológico da lesão. Esse estudo pode ser feito através de biópsias percutâneas (punção aspirativa com agulha fina - PAAF, biópsia por agulha grossa - BPAG e mamotomia) ou de biópsia excisional. 
O uso da biópsia percutânea de fragmento, orientada por métodos de imagem, apresenta um papel importante no diagnóstico de lesões mamárias. Ela é mais rápida, menos invasiva e de custo mais baixo que uma biópsia excisional. Quantidade menor de tecido é retirada, sem problemas estéticos para a paciente e também sem alterações cicatriciais em exames mamográficos posteriores. Quando este tipo de biópsia demonstra a presença

de um câncer, pode-se programar a cirurgia definitiva com a paciente. Em casos de achados anatomopatológicos benignos, com exames de imagens concordantes, a paciente, salvo em algumas situações especiais, pode realizar controles mamográficos periódicos ${ }^{50}$.

\subsection{TÉCNICAS EM BIÓPSIAS PERCUTÂNEAS MAMÁRIAS}

\section{A. Punção aspirativa com agulha fina (PAAF)}

CIATTO $^{51}$, em 1987 avaliou a precisão diagnóstica da citologia por PAAF estereotáxica na previsão da presença de câncer, mostrando a necessidade de treinamento do médico com o método para que o material seja adequado. As lesões benignas e as calcificações apresentaram maior taxa de material inadequado, talvez pelo excesso de tecido fibroso e o baixo número de células em lesões benignas. O autor concluiu que a contribuição da citologia estereotáxica na taxa de detecção do câncer de mama subclínico não foi grande, sendo limitada a ajudar na decisão da conduta em casos de anormalidades mamográficas de baixa suspeita. 
PISANO $^{52}$, em 2001, apresentou estudo a respeito de PAAF com sensibilidade de 85 a 88\% e especificidade de 55,6 a 90,5\% para a detecção de câncer de mama.

Em função das suas limitações quanto a sensibilidade e a especificidade e da necessidade de se contar com patologista especializado em citopatologia, atualmente a PAAF têm sido menos utilizada para alguns tipos de lesões, e não é mais indicada para o diagnóstico de lesões configuradas por agrupamentos de calcificações.

\section{B. Biópsia percutânea por agulha grossa (BPAG)}

Devido às limitações da PAAF, desenvolveu-se nova alternativa para a biópsia percutânea: a biópsia percutânea com agulha grossa, onde o material pode ser avaliado histologicamente, à semelhança da biópsia excisional, porém, em espécimes menores.

Em 1988, PARKER ${ }^{53}$ possibilitou uma evolução na BPAG, ao utilizar uma pistola constituída por um sistema de molas que impulsiona a agulha rapidamente nos tecidos, simplificando o método. Este sistema automático reduziu o risco de deslocamento da lesão, o problema da fragmentação do material e da hemorragia.

PARKER iniciou sua investigação utilizando, além da pistola com sistema automático de molas, agulhas de calibre 18 e unidade de estereotaxia adaptada ao mamógrafo convencional, com a paciente sentada. Devido à observação de reações vaso-vagais e/ou de movimentação da paciente, PARKER e seus colaboradores no final de 1988 começaram a utilizar, para 
biópsias mamárias, uma unidade de estereotaxia dedicada somente a esse propósito, com a paciente deitada em decúbito ventral, evitando as desvantagens da unidade adaptada.

Em 1990, PARKER ${ }^{53}$ publicou um trabalho correlacionando os achados da BPAG mamária com os da cirurgia, tendo havido concordância entre os métodos em $87 \%$ dos casos. Os autores concluíram que a BPAG, pode ser uma alternativa aceitável à biópsia excisional em mulheres com lesões suspeitas à mamografia, sendo mais fácil, retirando mínima quantidade de tecido, causando menos trauma e não deixando cicatrizes ou qualquer outra alteração arquitetural do parênquima, além de apresentar menor custo.

Ainda nesse trabalho de 1990, PARKER descreve que os patologistas não estavam inteiramente satisfeitos com a quantidade e consistência dos fragmentos obtidos com agulhas de calibre 18, passando então a utilizar agulhas de calibre 16 e, posteriormente, de calibre 14 e 12, quando os patologistas sentiram que poderiam fornecer diagnósticos mais precisos. Para minimizar a possibilidade de não amostrar calcificações, PARKER realizava a radiografia dos espécimes, nos casos de calcificações, para se certificar de que as mesmas encontravam-se nos fragmentos.

Sobre esse assunto, MEYER ${ }^{54}$, em 1993, observou que é necessário um mínimo de três fragmentos e que a radiografia do espécime contendo as calcificações é a chave para o diagnóstico histológico das mesmas, e LIBERMAN $^{55}$, em 1995, descreveu que a radiografia do espécime deve ser realizada rotineiramente em biópsias estereotáxicas de calcificações, para se ter certeza de que foi obtido o tecido desejado e para orientar o diagnóstico histológico ${ }^{47}$. 
Em 1993, PAKER ${ }^{56}$ comparou a concordância entre os achados histológicos da BPAG com a agulha 14 e da cirurgia, mostrando melhora na concordância com os achados cirúrgicos.

Alguns anos depois que a BPAG foi introduzida, tornou-se evidente que uma alta porcentagem de lesões diagnosticadas como hiperplasia ductal atípica eram câncer à biópsia excisional. BURBANK introduziu então o termo "subestimado" para tais casos e a terminologia tem sido desde então adotada por outros autores ${ }^{49}$.

A quantidade de casos subestimados é um dos fatores negativos neste tipo de biópsia. Estes valores variam de 15 a 36\%, sendo os casos mais comuns os carcinomas ductais "in situ" que tornam-se carcinomas invasivos na cirurgia e as hiperplasias ductais com atipias, que na análise da peça cirúrgica mostram corresponder a carcinomas ductais "in situ".

Em 2001, JACKMAN ${ }^{39}$ encontrou uma taxa de 20,4\% de casos subestimados em biópsias com agulha de 14 gauge.

BURBANK e PARKER ${ }^{57}$ em um trabalho sobre métodos para avaliação da qualidade em um programa de biópsia mamária dirigida por imagem, afirmaram que o "padrão-ouro" para estabelecer um diagnóstico histológico para lesões não palpáveis é o agulhamento seguido da exerese cirúrgica da lesão. Entretanto o "padrão-ouro" não é perfeito: a melhor taxa estimada atualmente de não-diagnóstico de câncer, para agulhamento seguido de exerese cirúrgica, é de $2 \%$.

PARKER $^{53}$, avaliando a evolução da BPAG da mama mostrou que conforme ele e seus colaboradores utilizavam o método, puderam perceber a necessidade de aumentar o número de fragmentos obtidos para 
no mínimo cinco, de nódulos e densidades e para no mínimo dez, de região de microcalcificações.

Apesar de ser um método rápido e eficaz é importante reconhecer que a BPAG tem algumas limitações. Sendo uma delas a pequena quantidade de tecido retirada, em situações específicas esta restrição impede um diagnóstico patológico preciso (atipia ductal, lesão esclerosante radial, diagnósticos questionáveis de tumor phyllodes e outras lesões raras, como tumores vasculares da mama).

Após a realização de BPAG é recomendado que se faça o seguimento radiológico após seis, doze, vinte e quatro e trinta e seis meses.

\section{Mamotomia}

Na década de 90, foi desenvolvida nova técnica de biópsia percutânea, especialmente para a mama (Mammotome; Biopsys Medical, Irvine, Califórnia), que possibilita a retirada de fragmentos de tecido através de uma única punção, com quantidades e dimensões bem superiores a aquelas obtidas com BPAG convencional. Esta técnica foi introduzida nos EUA em agosto de 1994, tendo sido aprovada pelo Food and Drug Administration - FDA.

Na mamotomia são usadas agulhas de maior calibre, oito e onze gauge, obtendo-se maiores fragmentos, que resultam em diminuição das taxas de diagnósticos subestimados ${ }^{58}$. Em 2001, JACKMAN ${ }^{39}$, em estudo multicêntrico, encontrou uma taxa de $20,4 \%$ de casos subestimados usando agulhas tradicionais, contra $11,2 \%$ utilizando a mamotomia. 
A mamotomia têm sido usada, preferencialmente, em lesões pequenas, especialmente nas calcificações, através da estereotaxia. Para as lesões maiores, a biópsia tradicional está indicada, com menores custos e preocupações com diagnóstico subestimado.

Em estudo realizado em 1997, BURBANK ${ }^{57}$ observou que a mamotomia não promoveu complicações clínicas ou a criação de posteriores lesões mamográficas cicatriciais. 
4 MÉTOdo 


\subsection{Participantes E CRITÉRIOS de INCLUSÃo E EXCLUSÃo}

Este estudo retrospectivo incluiu 1700 mulheres assintomáticas cujas mamografias de rastreamento, realizadas entre abril de 1991 e junho de 2004, demonstraram focos de calcificações que foram submetidos à biópsia percutânea ou cirúrgica e cuja retirada foi comprovada através de radiografia dos fragmentos ou da peça cirúrgica e da descrição do laudo anatomopatológico. Tais pacientes foram provenientes de três serviços médicos, a saber: Instituto de Radiologia do Hospital das Clínicas da Faculdade de Medicina da Universidade de São Paulo ( $n=1313)$, Unidade Radiológica Paulista $(n=144)$ e Laboratório Fleury $(n=243)$. O trabalho foi submetido à análise do Comitê de Ética Médica da Universidade de São Paulo, tendo sido aprovado sem a necessidade de consentimento pós-informação das pacientes. Foram excluídas do estudo pacientes com história pessoal de câncer de mama $(n=8)$; pacientes cujas mamografias disponíveis nos arquivos não constavam de pelo menos duas incidências mamográficas distintas, incluindo incidências magnificadas ( $n=388$ ); pacientes com múltiplos focos de calcificações ( $n=14)$; pacientes cujo foco de calcificações associava-se a outros achados mamográficos $(n=351)$; pacientes cujo foco submetido à biópsia apresentava menos do que 5 calcificações $(n=9)$; pacientes cujo resultado da análise histológica da amostra obtida pela biópsia percutânea 
foi considerada discordante do aspecto radiológico e que ate o término do estudo não haviam sido submetidas à biópsia cirúrgica $(n=5)$; pacientes que não preenchessem os critérios estabelecidos para controle clínico e mamográfico pós-biópsia ( $n=385)$; pacientes cujo diagnóstico histológico na biópsia cirúrgica foi de hiperplasia ductal atípica $(n=15)$, de hiperplasia lobular atípica $(n=3)$ ou de carcinoma lobular "in situ" $(n=3)$; e pacientes com diagnóstico de malignidade na biópsia percutânea sem confirmação cirúrgica até o término do estudo $(n=12)$.

As 507 mulheres remanescentes com 507 focos de calcificações compuseram o grupo final de estudo. A idade destas mulheres variou de 33 a 85 anos, com média de 52,8 anos e mediana de 52,0 anos. Destas 507 mulheres, $61,9 \%(314 / 507)$ provenieram do Instituto de Radiologia do Hospital das Clínicas da Faculdade de Medicina da Universidade de São Paulo, 17,9\% (91/507) da Unidade Radiológica Paulista e 20,1\% (102/507) do Laboratório Fleury.

\subsection{MÉTodo}

\section{A. Equipamentos}

As radiografias foram realizadas em mamógrafos MAMMOMAT (Siemens Medical Solutions, New York, NY), SENOGRAPHE 600T, SENOGRAPHE DMR ou SENOGRAPHE 700T (General Eletric Medical Systems, Milwaukee, WI) e incluíram as incidências médio lateral oblíqua ou perfil absoluto e crânio caudal da mama a ser biopsiada, complementadas 
com radiografias de magnificação localizada das calcificações em questão, além de outras incidências adicionais, quando pertinentes.

\section{B. Biópsias}

Todos os procedimentos de localização pré-operatória, biópsia com pistola automática e biópsia com pistola a vácuo foram realizados por médico especializado em imagenologia mamária.

As localizações pré-operatórias foram realizadas com fio metálico do tipo Kopans (Cook, Bloomington, IN - USA), de 21 gauge, orientadas pelo sistema biplanar.

As biópsias com pistola a vácuo foram feitas em mesa dedicada LORAD (Hologic Inc, Bedford, Massachusetts) com sistema de orientação estereotáxica, por imagem digital e agulha de 11 G.

As biópsias com pistola automática foram realizadas com orientação estereotáxica, por imagem analógica e pistola BARD MAGNUM (Bard Radiology, Convington, Geórgia) e agulhas de 12 G.

\section{Classificação anatomopatológica e conduta pós biópsia}

Nos casos em que a paciente foi submetida apenas à biópsia de fragmento as calcificações foram classificadas de acordo com o resultado do estudo histológico dos fragmentos.

Os resultados encontrados foram divididos em duas categorias: benignos ou malignos. Foram consideradas como benignas as seguintes 
alterações: alterações fibrocísticas, adenose (simples ou esclerosante), fibroesclerose, fibroadenoma, mastite, hiperplasia ductal sem atipias (HDT), papiloma (como achado de biópsia excisional), metaplasia apócrina, esteatonecrose e reação de corpo estranho (reação de CE). Foram consideradas como alterações malignas o carcinoma ductal "in situ" (CDIS), carcinoma ductal invasivo (CD Invasivo), carcinoma lobular invasivo (CL Invasivo).

Os casos com resultado anatomopatológico maligno foram submetidos a tratamento apropriado, incluindo exerese cirúrgica, e os casos benignos foram submetidos a controle clínico e mamográfico de um ano para as biópsias de fragmento feitas com pistola à vácuo e de dois anos para as feitas com pistola de molas.

\section{Critérios de Interpretação}

A análise das mamografias foi realizada por dois médicos radiologistas experientes, no período compreendido entre janeiro/2004 e outubro/2005, em datas distintas e ambientes separados e sem conhecimento prévio dos resultados anatomopatológicos.

Consideramos como radiologista experiente aquele com mais de oito anos de experiência em laudos mamográficos, durante os quais analisou entre 500 e 1000 mamografias por mês, e detentor de título do Colégio Brasileiro de Radiologia.

Antes da análise foi realizada uma revisão das diretrizes do sistema BI-RADS, e do léxico por ele utilizado no que diz respeito às características morfologia e distribuição, a fim de uniformizar a descrição 
dessas características à semelhança dos achados descritos nas páginas 56 a 119 do manual do BI-RADS (Illustrated Breast Imaging Reporting and Data System $-4^{\mathrm{a}}$ ed).

Nos casos de divergência entre as classificações aplicadas pelos dois radiologistas, um terceiro com a mesma experiência avaliou esses exames e classificou-os. A classificação considerada foi a indicada por dois entre os três radiologistas avaliadores.

As calcificações foram caracterizadas segundo os seguintes critérios analíticos:

1. Quanto à morfologia, foi considerada para fins de categorização apenas a calcificação mais supeita do agrupamento. Foram classificadas em:

a. Puntiformes/arredondadas, quando puntiformes, redondas ou ovais, com margens bem definidas e menos de 0,5 mm de diâmetro (págs. 68, 69, 84 e 85 do manual do BI-RADS).

b. Grosseiras heterogêneas, definidas como irregulares, variando em forma e em tamanho, algumas com mais de $0,5 \mathrm{~mm}$ de diâmetro, com maior densidade e mais grosseiras, associadas a outras diminutas calcificações menos densas, com morfologias amorfa ou pleomorfa (págs. 63 e 64 do manual do BI-RADS).

c. Amorfas ou indistintas, quando de baixa densidade, tênues e diminutas, sem que tivesse sido possível definir uma forma, semelhantes a poeira fina, grãos de areia ou com aspecto em sal e pimenta (págs. 88 a 92 do manual do BI-RADS).

d. Pleomorfas finas, quando variaram em tamanho e forma, tendo geralmente menos de 0,5 mm de diâmetro (págs. 94 a 97 do manual do BI-RADS). 
e. Lineares, quando de formato linear, finas e alongadas, descontínuas e irregulares em densidade, tamanho e contornos (págs. 98 e 99 do manual do BI-RADS).

2. Quanto à distribuição foram classificadas em:

a. Agrupadas, quando da presença de um foco de configuração arredondada ocupando espaço com extensão máxima de $1,5 \mathrm{~cm}$ na mamografia (págs. 102 e 103 do manual do BI-RADS).

b. Com distribuição linear, quando dispostas em linha nas duas incidências ortogonais (págs. 104 a 106 do manual do BI-RADS).

c. Com distribuição segmentar, quando em trajeto que sugerisse acompanhar um ducto e seus respectivos lóbulos em direção ao mamilo, podendo assumir configuração triangular, com vértice retroareolar, ou configuração ovalada, ou em formato retangular (págs. 108 a 110 do manual do BIRADS).

d. Com distribuição regional, quando da presença de um foco com múltiplas calcificações ocupando um espaço com extensão maior que 1,5 cm na mamografia, sem distribuição ductal ou segmentar (págs. 112 a 114 do manual do BI-RADS).

3. Quanto à densidade as classificamos como tendo densidades iguais ou diferentes.

4. Quanto à extensão utilizamos para a classificação a medida em centímetros $(\mathrm{cm})$ da maior extensão ocupada pelo agrupamento, independente da incidência mamográfica. 
5. Quanto ao número, quantificamos o número absoluto de calcificações no agrupamento até o máximo de 30 e a partir desse número as mesmas foram denominadas como "mais de 30 ".

\subsection{AnÁlise Estatística dos Dados}

Inicialmente estudamos isoladamente os dados das pacientes de cada um dos três serviços de onde elas procederam, até que fosse concluído que a população dos mesmos era homogênea para a finalidade deste estudo, e portanto poderia ser avaliada como um grupo único.

Depois, ao fazer a análise descritiva dos achados nos casos selecionados, resumimos as variáveis quantitativas (idade, extensão e número) em médias, medianas, valores mínimos e máximos. As variáveis categóricas (densidade, morfologia e distribuição) foram expressas em freqüências simples e relativas (porcentagens).

Estudamos o grupo completo das pacientes, sem distingui-las em faixas etárias. Posteriormente fizemos a análise separada dos casos de pacientes acima dos 60 anos em relação à freqüência das calcificações de acordo com a classificação morfológica, para avaliar se esse grupo apresentava comportamento diferente do grupo completo.

Para avaliar a associação entre as variáveis categóricas e a malignidade foi utilizado o teste Qui-quadrado de Pearson ou o teste exato de Fisher, quando havia valores esperados inferiores a cinco. 
Para analisar a influência da extensão e do número, foram comparados os grupos de pacientes com biópsias positivas e negativas em relação às médias dessas variáveis. O teste utilizado foi o teste $\mathrm{t}$ de Student para amostras independentes. Com o intuito de corrigir possíveis erros de medida e facilitar a interpretação, as variáveis extensão e número foram categorizadas. A escolha do ponto de corte foi baseada em curvas ROC.

Com o intuito de analisar o efeito conjunto das variáveis, foi ajustado um modelo de Regressão Logística.

Os resultados foram expressos em "odds ratio" e respectivos intervalos de confiança de 95\%.

O programa estatístico utilizado foi o SPSS versão 11.0. O nível de significância adotado foi de 0,05 $5^{59-63}$. 


\subsection{Casuística - POPULAÇÃo ESTUdAdA}

Da população inicial de 1700 exames foram excluídos os exames das pacientes com história pessoal de câncer de mama (8), que não apresentassem condições técnicas adequadas (388), com calcificações multifocais (14) e os que apresentassem algum outro achado radiológico associado às calcificações (351). Foram também excluídos os exames em que houvessem menos de cinco calcificações na área a ser estudada (9), aqueles com achado anatomopatológico discordante do aspecto radiológico das calcificações (5) e os casos de hiperplasia ductal atípica (15), hiperplasia lobular atípica (3) e de carcinoma lobular "in situ" (3).

Excluímos, ainda, doze casos em que a biópsia de fragmento teve resultado histológico maligno e não tivemos acesso ao resultado anatomopatológico da peça cirúrgica e os casos em que a biópsia de fragmento teve resultado histológico benigno, porém não houve o seguimento clínico e mamográfico a que nos propusemos neste estudo (385). O processo de seleção de casos para o estudo esta demonstrado no Diagrama 1. 
Diagrama 1 - Diagrama mostrando o processo de busca e seleção dos casos para o estudo

\begin{tabular}{|c|c|}
\hline \multicolumn{2}{|c|}{$\mathrm{n}=1700$ casos de calcificações submetidas à biópsia } \\
\hline \multicolumn{2}{|c|}{ Retirados os casos de pacientes com história prévia de câncer de mama } \\
\hline & Excluídos $n=8$ casos \\
\hline \multicolumn{2}{|c|}{$(n=1692)$ Retirados os casos de calcificações multifocais } \\
\hline & Excluídos $n=14$ casos \\
\hline \multicolumn{2}{|c|}{$(n=1678)$ Retirados os casos de calcificações associadas a outros achados radiológicos } \\
\hline & Excluídos $n=351$ casos \\
\hline \multicolumn{2}{|c|}{$(n=1327)$ Retirados os casos com menos de cinco calcificações } \\
\hline & Excluídos $n=9$ casos \\
\hline \multicolumn{2}{|c|}{$\begin{array}{c}(\mathrm{n}=1318) \text { Retirados os casos tecnicamente inadequados para estudo e aqueles com } \\
\text { resultado AP que não pudesse ser atribuído ao achado de calcificações. Retirados os } \\
\text { casos de HDA, HLA e CLIS. }\end{array}$} \\
\hline & Excluídos $n=414$ casos \\
\hline \multicolumn{2}{|c|}{$\begin{array}{c}\text { (n=904) Retiramos os casos em que não houvesse comprovação cirúrgica do resultado AP } \\
\text { ou seguimento de dois anos (para biópsias de fragmento assistidas por pistola de molas) } \\
\text { ou um ano (para biópsias de fragmento assistidas à vácuo) }\end{array}$} \\
\hline & \\
\hline & Excluídos n=397 casos \\
\hline Total de casos incluídos $n$ & 10 estudo $(n=507 \mathrm{cc}$ \\
\hline
\end{tabular}

HDA: hiperplasia ductal atípica

HLA: hiperplasia lobular atípica

CLIS: carcinoma lobular "in situ"

Deste modo foi obtida a amostra estudada de 507 exames, que correspondem a 507 pacientes. A idade das pacientes variou de 33 a 85 anos, com média de 52,8 anos e mediana de 52,0 anos.

Entre as 507 pacientes que foram estudadas 61,9\% foram provenientes do hospital público, $17,9 \%$ do serviço privado A e $20,1 \%$ do serviço privado $\mathrm{B}$. 


\subsection{MÉTODO}

\section{A. Biópsias}

Em 61,1\% dos casos (310/507) foi utilizada a biópsia excisional precedida pelo agulhamento da lesão, em $29,2 \%$ dos casos (148/507) foi utilizada a biópsia de fragmento assistida por pistola automática e a biópsia de fragmento assistida à vácuo em 9,7\% dos casos (49/507).

Após a análise anatomopatológica, 63,5\% (322/507) agrupamentos de calcificações apresentaram resultado anatomopatológico benigno e 36,5\% (185/507) apresentaram resultado anatomopatológico maligno conforme demonstra a Tabela 2.

Tabela 2 - Resultados anatomopatológicos

\begin{tabular}{cc|c}
\hline & $\mathbf{N}$ & $\mathbf{\%}$ \\
\cline { 2 - 3 } Benigno & 322 & 63,5 \\
Maligno & 185 & 36,5 \\
\hline TOTAL & 507 & 100,0 \\
\hline
\end{tabular}

\section{B. Exames anatomopatológicos}

O achado anatomopatológico mais comum foi o de adenose simples $(28,4 \%$ - 144/507), seguido do de CDIS (25,8\% - 131/507). Entre as 322 lesões benignas o achado mais comum foi o de adenose simples (44,7\%), seguido da hiperplasia ductal típica $(18,0 \%)$, da fibroesclerose $(12,4 \%)$, do papiloma $(8,7 \%)$, dos fibroadenomas $(7,1 \%)$, da adenose esclerosante $(6,5 \%)$, da reação de corpo estranho (1,5\%) e da esteatonecrose (0,9\%). Entre os 
carcinomas, 70,8\% foram carcinomas ductais "in situ" (131/185), 27,6\% foram carcinomas ductais invasivos (51/185) e 1,6\% (3/185) foram carcinomas lobulares invasivos, conforme demonstrado na Tabela 3.

Tabela 3 - Resultados anatomopatológicos e proporção na população estudada

\begin{tabular}{c|c|c}
\hline AP & $\mathbf{N}$ & $\%$ \\
\hline Adenose & 144 & 28,4 \\
CDIS & 131 & 25,8 \\
HDT & 58 & 11,4 \\
CD Invasivo & 51 & 10,1 \\
Fibroesclerose & 40 & 7,9 \\
Papilomatose & 28 & 5,5 \\
Fibroadenoma & 23 & 4,5 \\
Adenose esclerosante & 21 & 4,1 \\
Reação CE & 5 & 1,0 \\
CL Invasivo & 3 & 0,6 \\
Esteatonecrose & 3 & 0,6 \\
\hline TOTAL & 507 & 100,0
\end{tabular}

As pacientes com biópsias positivas para câncer de mama tinham, em média, quase dois anos a mais que as pacientes com biópsias negativas. Essa diferença foi estatisticamente significante $(p=0,038)$.

\section{Critérios de interpretação}

1. Morfologia

A freqüência das diferentes morfologias entre os casos estudados foi:

a. pleomorfas finas $(31,6 \%-160 / 507)$,

b. amorfas $(28,4 \%-144 / 507)$,

c. puntiformes $(19,3 \%-98 / 507)$,

d. heterogêneas grosseiras $(17,0 \%$ - 86/507) e

e. lineares $(3,7 \%-19 / 507)$. 
A morfologia pleomorfa fina, além de ter sido a mais freqüente, foi a que mais esteve associada ao câncer de mama, apresentando VPP de 76,3\% (122/160). As demais morfologias apresentaram VPP de 57,9\% (11/19), para a morfologia linear; 20,8\% (30/144), para a morfologia amorfa; $13,3 \%$ (13/98), para a morfologia puntiforme e 10,5\% (9/86) para a morfologia heterogênea grosseira, conforme mostra a Tabela 4.

Tabela 4 - Freqüência e incidência de malignidade de acordo com a morfologia das calcificações

\begin{tabular}{ccc|c|c}
\hline MORFOLOGIA & $\mathbf{N}$ & $\begin{array}{c}\text { FREQÜÊNCIA } \\
(\%)\end{array}$ & $\begin{array}{c}\text { N DE CASOS } \\
\text { MALIGNOS }\end{array}$ & $\begin{array}{c}\text { VPP } \\
(\%)\end{array}$ \\
\hline Pleomorfas finas & 160 & $\begin{array}{c}31,6 \\
(160 / 507)\end{array}$ & 122 & $\begin{array}{c}76,3 \\
(122 / 160)\end{array}$ \\
\hline Amorfas & 144 & $\begin{array}{c}28,4 \\
(144 / 507)\end{array}$ & 30 & $\begin{array}{c}20,8 \\
(30 / 144)\end{array}$ \\
\hline Puntiformes & 98 & $\begin{array}{c}19,3 \\
(98 / 507)\end{array}$ & 13 & $\begin{array}{c}13,3 \\
(13 / 98)\end{array}$ \\
\hline Heterogêneas grosseiras & 86 & $\begin{array}{c}17,0 \\
(86 / 507)\end{array}$ & 9 & $\begin{array}{c}10,5 \\
(9 / 86)\end{array}$ \\
\hline Lineares & 19 & $\begin{array}{c}3,7 \\
(19 / 507)\end{array}$ & 11 & $\begin{array}{c}57,9 \\
(11 / 19)\end{array}$ \\
\hline TOTAL & 507 & & 185 & $\begin{array}{c}35,4 \\
(185 / 507)\end{array}$ \\
\hline
\end{tabular}

A significância estatística da característica morfologia foi de $p<0,001$.

2. Distribuição

A freqüência dos diferentes tipos de distribuições foi:
a. agrupada $(75,9 \%-385 / 507)$,
b. segmentar $(14,0 \%-71 / 507)$,
c. linear $(8,5 \%-43 / 507)$ e
d. regional $(1,6 \%-8 / 507)$.

A distribuição mais associada à malignidade foi a segmentar, que apresentou um VPP de 77,5\% (55/71), seguida da distribuição linear, que teve VPP de 58,1\% (25/43) e da agrupada, com VPP de 27,3\% (105/385), conforme ilustra a Tabela 5. 
Tabela 5 - Freqüência e incidência de malignidade de acordo com a distribuição das calcificações

\begin{tabular}{cccccc}
\hline DISTRIBUIÇÃO & N & $\begin{array}{c}\text { FREQÜÊNCIA } \\
(\%)\end{array}$ & $\begin{array}{c}\text { N DE CASOS } \\
\text { MALIGNOS }\end{array}$ & $\begin{array}{c}\text { VPP } \\
(\%)\end{array}$ \\
\hline Agrupada & 385 & $\begin{array}{c}75,9 \\
(385 / 507)\end{array}$ & 105 & $\begin{array}{c}27,3 \\
(105 / 385)\end{array}$ \\
\hline Segmentar & 71 & $\begin{array}{c}14,0 \\
(71 / 507)\end{array}$ & 55 & $\begin{array}{c}77,5 \\
(55 / 71)\end{array}$ \\
\hline Linear & 43 & $\begin{array}{c}8,5 \\
(43 / 507)\end{array}$ & 25 & $\begin{array}{c}58,1 \\
(25 / 43)\end{array}$ \\
\hline Regional & 8 & $\begin{array}{c}1,6 \\
(8 / 507)\end{array}$ & 0 & 0 \\
\hline TOTAL & 507 & & 185 & $\begin{array}{c}35,4 \% \\
(185 / 507)\end{array}$ \\
\hline
\end{tabular}

A significância estatística da característica distribuição foi de $p<0,001$.

3. Densidade, extensão e número

A grande maioria das calcificações $(95,1 \%$ - 482/507) apresentou densidades diferentes e apenas 4,9\% das calcificações (25/507) apresentava densidades iguais. Entre as calcificações de densidades diferentes 37,6\% eram malignas (181/482) e entre as de densidades iguais $16,0 \%$ eram malignas (4/25).

As variáveis extensão e número, que são numéricas, foram transformadas em variáveis dicotômicas a partir da determinação de um ponto de corte entre a maioria de casos benignos e a maioria de casos malignos.

A extensão média dos grupos de calcificações foi 1,3 cm (dp=1,1, mediana=0,7). O ponto de corte escolhido foi $0,6 \mathrm{~cm}$, que apresentou $72,4 \%$ de sensibilidade $(72,4 \%)$ e $52,8 \%$ de especificidade. Tiveram resultado AP maligno $46,9 \%$ dos casos com extensão maior que $0,6 \mathrm{~cm}(134 / 286)$ e $23,1 \%$ dos casos com extensão menor que $0,6 \mathrm{~cm}(51 / 221)$. 
O número médio de calcificações em cada lesão foi 13,8 $(d p=7,6)$, variando de 2 a 45 . A escolha do ponto de corte 10 para número foi baseada na curva ROC, e apresentou a melhor combinação de sensibilidade $(78,9 \%)$ e especificidade (50,6\%). Apenas 19,3\% dos casos com menos de 10 calcificações foram malignos (39/202), enquanto que 47,9\% dos casos com mais de dez calcificações corresponderam a câncer de mama (146/305).

A densidade, o número de calcificações e o tamanho do agrupamento de calcificações foram fatores que apresentaram significância estatística, com valores de $p<0,001$.

\subsection{ANÁLISE Estatística}

\section{A. Regressão logística}

Ao combinarmos as diferentes características das calcificações observamos que a densidade, a extensão e o número, apesar de isoladamente terem demonstrado importância estatística, apresentaram em comum a ocorrência de um fenômeno estatístico conhecido como colinearidade, que ocorre quando duas variáveis têm o mesmo comportamento. A densidade apresentou colinearidade em relação à morfologia, e a extensão e o numero de calcificações apresentaram colinearidade em relação à distribuição. Devido a esse comportamento não consideramos as associações dessas características, associando apenas a morfologia e a distribuição na nossa análise multivariada. 


\section{B. Combinação morfologia $x$ distribuição}

Modificando as combinações de morfologia e distribuição calculamos as variações de VPP, conforme demonstrado na Tabela 6.

Tabela 6 - Combinação morfologia e distribuição como determinantes do VPP das calcificações mamárias

\begin{tabular}{|c|c|}
\hline COMBINAÇÃO MORFOLOGIA E DISTRIBUIÇÃO & \% MALIGNOS \\
\hline Lineares, Segmentar $(n=5)$ & 100,0 \\
\hline Pleomorfas finas, Segmentar $(n=37)$ & 94,6 \\
\hline Pleomorfas finas, Linear $(n=17)$ & 76,5 \\
\hline Lineares, Linear $(n=7)$ & 71,4 \\
\hline Pleomorfas finas, Agrupadas $(n=105)$ & 70,5 \\
\hline Puntiformes, Segmentar $(n=9)$ & 55,6 \\
\hline Amorfas, Segmentar $(n=15)$ & 53,3 \\
\hline Heterogêneas grosseiras, Linear $(n=5)$ & 40,0 \\
\hline Heterogêneas grosseiras, Segmentar $(n=5)$ & 40,0 \\
\hline Puntiformes, Linear $(n=11)$ & 36,4 \\
\hline Amorfas, Linear $(n=3)$ & 33,3 \\
\hline Amorfas, Agrupadas $(n=124)$ & 16,9 \\
\hline Lineares, Agrupadas $(n=7)$ & 14,3 \\
\hline Heterogêneas grosseiras, Agrupadas $(n=72)$ & 6,9 \\
\hline Puntiformes, Agrupadas $(n=77)$ & 5,1 \\
\hline
\end{tabular}

Essas associações estão também exemplificadas na Tabela 7. 
Tabela 7 - Associação da morfologia e da distribuição das calcificações e respectivos VPP

\begin{tabular}{|c|c|c|c|c|c|}
\hline & \multicolumn{3}{|c|}{ DISTRIBUIÇÃO } \\
\hline & & & Agrupada & Linear & Segmentar \\
\hline & & & $\begin{array}{l}(385) \\
\text { VPP } 27,3 \% \\
\quad(105)\end{array}$ & $\begin{array}{c}(43) \\
\text { VPP } 58,1 \% \\
\quad(25)\end{array}$ & $\begin{array}{c}(71) \\
\text { VPP } 77,5 \% \\
\quad(55)\end{array}$ \\
\hline \multirow{5}{*}{ 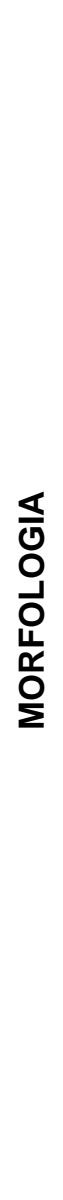 } & 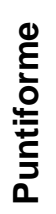 & 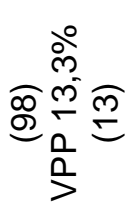 & $\begin{array}{c}(77) \\
\text { VPP } 5,2 \% \\
(4)\end{array}$ & $\begin{array}{c}(11) \\
\text { VPP } 36,4 \% \\
\quad(4)\end{array}$ & $\begin{array}{c}(9) \\
\text { VPP } 55,6 \% \\
(5)\end{array}$ \\
\hline & $\begin{array}{l}\frac{\pi}{t} \\
\frac{0}{\grave{L}}\end{array}$ & 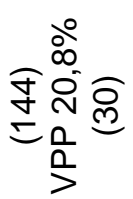 & $\begin{array}{c}(124) \\
\text { VPP } 16,9 \% \\
\quad(21)\end{array}$ & $\begin{array}{c}(3) \\
\text { VPP } 33,3 \% \\
(1)\end{array}$ & $\begin{array}{c}(15) \\
\operatorname{VPP} 53,3 \% \\
(8)\end{array}$ \\
\hline & 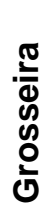 & 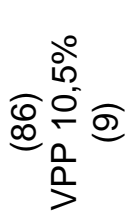 & $\begin{array}{c}(72) \\
\text { VPP } 6,9 \% \\
(5)\end{array}$ & $\begin{array}{c}(5) \\
\text { VPP } 40,0 \% \\
(2)\end{array}$ & $\begin{array}{c}(5) \\
\operatorname{VPP} 40,0 \% \\
(2)\end{array}$ \\
\hline & 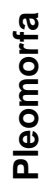 & 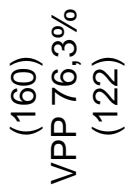 & $\begin{array}{c}(105) \\
\text { VPP } 70,5 \% \\
(74)\end{array}$ & $\begin{array}{c}(17) \\
\text { VPP } 76,5 \% \\
(13)\end{array}$ & $\begin{array}{c}(37) \\
\text { VPP } 94,6 \% \\
\quad(35)\end{array}$ \\
\hline & لِّ & 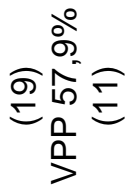 & $\begin{array}{c}(7) \\
\text { VPP } 14,3 \% \\
(1)\end{array}$ & $\begin{array}{c}(7) \\
\operatorname{VPP} 71,4 \% \\
(5)\end{array}$ & $\begin{array}{l}(5) \\
\text { VPP } 100,0 \% \\
(5)\end{array}$ \\
\hline
\end{tabular}

\section{Análise do comportamento do VPP das diferentes morfologias das} calcificações de acordo com a idade das pacientes

Após o estudo dos VPP para o grupo completo das pacientes, analisamos os VPP das calcificações nas pacientes com mais de 60 anos de idade. Inicialmente observamos que a taxa de biópsias com resultado 
positivo para câncer foi maior nas pacientes acima de 60 anos $(46,9 \%)$ e menor nas pacientes abaixo de 60 anos $(34,1 \%)$, com significância estatística de $p=0,019$. Porém, ao associar a influência dos diferentes tipos de morfologia de calcificações aos VPP encontrados, observamos que o VPP das calcificações de morfologia heterogênea grosseira chegou a zero nas pacientes com mais de 60 anos, conforme demonstrado na Tabela 8.

Tabela 8 - VPP das calcificações segundo a morfologia, nas pacientes abaixo dos 60 anos e acima dos 60 anos

\begin{tabular}{|c|c|c|c|c|}
\hline \multirow{2}{*}{ MORFOLOGIA } & \multirow{2}{*}{ AP } & \multicolumn{2}{|c|}{ VPP x IDADE } & \multirow[t]{2}{*}{ TOTAL } \\
\hline & & $<=60$ anos & $>60$ anos & \\
\hline Amorfas & & $\begin{array}{c}21,3 \% \\
(27 / 127)\end{array}$ & $\begin{array}{l}17,6 \% \\
(3 / 17)\end{array}$ & $\begin{array}{c}20,8 \% \\
(30 / 144)\end{array}$ \\
\hline Lineares & & $\begin{array}{l}46,7 \% \\
(7 / 15)\end{array}$ & $\begin{array}{l}100 \% \\
(4 / 4)\end{array}$ & $\begin{array}{l}57,9 \% \\
(11 / 19)\end{array}$ \\
\hline Pleomorfas finas & & $\begin{array}{c}71,3 \% \\
(87 / 122)\end{array}$ & $\begin{array}{l}92,1 \% \\
(35 / 38)\end{array}$ & $\begin{array}{c}76,3 \% \\
(122 / 160)\end{array}$ \\
\hline $\begin{array}{c}\text { Heterogêneas } \\
\text { Grosseiras }\end{array}$ & & $\begin{array}{l}14,5 \% \\
(9 / 62)\end{array}$ & & $\begin{array}{l}10,5 \% \\
(9 / 86)\end{array}$ \\
\hline Puntiformes & & $\begin{array}{c}11,8 \% \\
(10 / 85)\end{array}$ & $\begin{array}{l}23,1 \% \\
(3 / 13)\end{array}$ & $\begin{array}{l}13,3 \% \\
(13 / 98)\end{array}$ \\
\hline
\end{tabular}

$p=0,019$ 
6 DISCUSSÃO 
As calcificações são a indicação mais freqüente de biópsia mamária, pois tratam-se do achado mais comum no carcinoma ductal "in situ"4,6.

A maioria das calcificações encaminhadas para estudo anatomopatológico é do tipo indeterminada, sem características tipicamente malignas, tem baixo VPP para malignidade e grande taxa de discordância entre os radiologistas, notadamente nas lesões que se mostram benignas após a biópsia ${ }^{64}$.

O sistema BI-RADS sugere que os achados mamográficos sejam divididos em categorias de acordo com o valor preditivo positivo de cada um, porém não define os valores característicos de cada categoria, nem os pontos de corte entre elas. A única definição de VPP até o momento é o valor de $2 \%$, que delimita as categorias 3 e 4 . Esse valor surgiu em conseqüência de estudos feitos sobre a categoria 3, que é aceita, atualmente, para definir lesões que apresentam VPP menor que $2 \%{ }^{29-33}$.

Nesse estudo procuramos descrever as características das calcificações de acordo com o léxico do BI-RADS, e depois, confrontando-as com os resultados anatomopatológicos, caracterizá-las segundo os valores preditivos positivos encontrados. Ao longo do trabalho verificamos que o léxico do $\mathrm{BI}$ RADS ainda suscita dúvidas de utilização, podendo ser aprimorado, e que a subcategorização da categoria 4 em 4A, 4B e 4C pode ser feita, melhorando os aspectos de comunicação com a paciente e com o médico patologista. 
Essa subcategorização não deve afetar, por enquanto, a conduta indicada para as calcificações de aspecto indeterminado, que permanece sendo a biópsia.

Nosso trabalho, após estudar as características das calcificações e suas interações, irá sugerir esses VPP, aplicáveis apenas ao estudo das calcificações como achados isolados, com base nos VPP encontrados na nossa pesquisa e nos trabalhos já publicados sobre esse tema.

Na casuística estudada foram excluídos os casos de calcificações associadas a outros achados radiológicos para evitar que o VPP das calcificações fosse influenciado pela natureza do achado radiológico associado. Esse aspecto do estudo é importante para a compreensão de certas diferenças nos VPP encontrados nesse e em outros estudos, assim como para salientar que os VPP aqui sugeridos para divisão de categorias e subcategorias do BI-RADS se referem unicamente ao achado de calcificações.

A determinação do tempo de 24 meses para o controle das pacientes com resultado anatomopatológico benigno na biópsia de fragmento por pistola automática foi realizada com base no trabalho de $\operatorname{SICKLES}^{34}$, que sugere que lesões provavelmente benignas, sem biópsia, que permaneçam radiologicamente estáveis por 24 a 36 meses podem ser consideradas como lesões benignas. Para os casos de biópsia à vácuo com agulha 11G, que apresentam taxa de subestimação mais baixa, e índices de eficácia semelhantes aos da biópsia cirúrgica ${ }^{58}$, fizemos o acompanhamento de 12 meses, por considerar esse período suficiente. 
Ao estudar as calcificações submetidas à biópsia, nossa casuística apresentou o número de neoplasias malignas esperado segundo comparação com outros trabalhos descritos na literatura ${ }^{55-58}$. As altas taxas de CDIS, em detrimento do carcinoma ductal invasivo são explicadas em virtude do nosso objeto de estudo serem apenas as calcificações, achado mamográfico classicamente associado ao CDIS.

Os casos com achado anatomopatológico de CLIS após biópsia excisional foram excluídos, porque a apresentação deste tipo de carcinoma como calcificações ainda é muito incomum, e pouco relatada na literatura ${ }^{65}$. Pela mesma razão foram excluídos os casos de HLA. Também foram excluídos deste estudo 15 casos de hiperplasia ductal atípica, pelo fato de ser tênue o limite entre a HDA e o CDIS, e ser muito dependente do observador.

A interpretação das mamografias é outra fase do trabalho muito dependente do observador. Em estudo realizado em 2000, BERG demonstrou que as calcificações são o achado mamográfico mais sujeito a variações descritivas, sendo a morfologia a característica que mais mostrou variação interobservadores ${ }^{64}$. As calcificações amorfas foram as mais problemáticas, apresentando o menor índice de concordância (índice Kappa de 0,25), sendo muitas vezes denominadas de pleomorfas, e outras vezes de puntiformes ${ }^{64}$. Esse pode ser um dos fatores que determina os diferentes VPP encontrados na literatura para cada tipo de morfologia de calcificação. As calcificações amorfas apresentam valores de VPP de $20,0 \%{ }^{66}$ a $45,0 \%{ }^{3}$, sendo que o valor encontrado no nosso estudo, de $20,8 \%$ encontra-se dentro da variação 
esperada. Procurando minimizar a discordância entre os observadores, fizemos um treinamento teórico-prático prévio à análise das radiografias, baseado na quarta edição do manual do BI-RADS, relembrando os critérios utilizados pelo sistema BI-RADS na classificação das calcificações.

As calcificações de morfologia linear, caracteristicamente descritas como categoria 5 do BI-RADS, apresentam variações de VPP na literatura de $81 \%$ a $94 \%^{6,35,45,50}$. No nosso estudo as calcificações de morfologia linear apresentaram um VPP que consideramos baixo - 57,9\%. Acreditamos que um dos fatores que determinou esse baixo VPP foi o estabelecimento de rigorosos critérios para a categorização da morfologia linear na $4^{\mathrm{a}}$ edição do BI-RADS, que não eram ainda definidos pelo BI-RADS na época dos trabalhos supra citados, como de LIBERMAN e TABAR. Seguimos esses critérios, só considerando como calcificações de morfologia linear aquelas que apresentassem partículas lineares nas duas incidências mamográficas ortogonais, não se associando a nenhum outro tipo de morfologia, já que nesse caso poderiam ser denominadas de pleomorfas. Outro fator a ser considerado é que nos trabalhos anteriores nem sempre houve diferenciação entre a morfologia e a distribuição linear, aspecto pelo qual buscamos primar no nosso trabalho em função da preocupação do léxico BI-RADS na diferenciação dessas duas características.

Em trabalho apresentado em novembro de 2005 em Chicago, no RSNA, onde apresenta os achados decorrentes do estudo morfológico de 112 casos de calcificações e seus respectivos VPP, BURNSIDE ${ }^{67}$ descreve ter achado VPP de 7,1\% para as calcificações grosseiras, 13,3\% para as 
amorfas, 27,6\% para as pleomorfas finas e 55\% para as lineares finas. Esse estudo, já realizado após a $4^{\mathrm{a}}$ edição do BI-RADS, apresenta VPP próximo ao do nosso estudo para as calcificações de morfologia linear, o que corrobora a nossa hipótese para compreender as diferenças de VPP nos estudos prévios à $4^{a}$ edição do BI-RADS e nos estudos posteriores a ela, como este e o de BURNSIDE.

Outro fator que demonstrou ser importante na determinação do valor preditivo positivo das calcificações foi a distribuição. No nosso estudo nenhuma calcificação com distribuição regional foi maligna, o que é concordante com a descrição do BI-RADS, porém o pequeno número de casos com esse tipo de distribuição pode ter comprometido a avaliação do seu VPP, por isso achamos mais prudente não considerar esse achado como definidor de conduta. Um dos fatores que pode ter contribuído para a pequena amostra de casos de calcificações com distribuição regional na nossa casuística é que poucas calcificações com esse tipo de distribuição têm indicação de biópsia, e portanto, encontramos poucos casos com essa distribuição e confirmação anatomopatológica.

Observamos que ao manter-se a associação das distribuições dos tipos linear e segmentar obtivemos maiores índices de valores preditivos positivos, independentemente da morfologia das calcificações, o que justifica, por si só, a indicação de biópsia em calcificações com esses tipos de distribuição.

Em 1980, EGAN ${ }^{38}$ concluiu que agrupamentos de calcificações com densidades diferentes estavam mais associados ao câncer. No nosso estudo, em $97,8 \%$ dos casos de câncer de mama as calcificações tinham 
densidades diferentes, o que corrobora a afirmação feita por EGAN. No entanto, observamos nesse estudo que a densidade das calcificações preferencialmente deve ser utilizada como característica descritiva e não como atributo de suspeita, assim como é atualmente utilizada pelo sistema BIRADS, por apresentar comportamento de colinearidade com a morfologia.

As características extensão e número apresentaram comportamento de colinearidade em relação à distribuição. Isso pode ser mais bem compreendido ao lembrarmos que a distribuição segmentar, relacionada pelo BI-RADS à categoria 5, é, por definição, uma distribuição de grande extensão, e conseqüentemente de maior número de calcificações e que portanto grande número e extensão estarão associados a maior VPP. Por isso concluímos nesse estudo que a utilização das características número e extensão deve ser preferencialmente como descritores da distribuição, mas não como atributos de suspeita, assim como é preconizado pelo manual do BI-RADS.

Estudamos os VPP de cada característica, buscando classificar as calcificações de acordo com esses VPP e depois associamos a morfologia à distribuição e calculamos novos VPP, que imaginamos ser de maior valor na categorização das calcificações dentro das categorias do BI-RADS. No entanto, contamos com poucos dados disponíveis na literatura que possam utilizar como referência para sugerir essa divisão de categorias.

O início da categorização partiu da premissa estipulada pelo BIRADS, baseada nos trabalhos de SICKLES, VARAS e VIZCAINO, de que as lesões com VPP menor que $2 \%$ são BI-RADS 3, e portanto, lesões com VPP maior que $2 \%$ já seriam BI-RADS 4A. 
Baseamo-nos ainda na afirmação do BI-RADS de que as calcificações amorfas são calcificações de caráter intermediário de suspeita de malignidade, o que as incluiria na categoria 4B.

O BI-RADS exemplifica ainda, a categoria 5 com calcificações lineares com distribuição linear ou segmentar, o que nos leva a inferir que esse tipo de calcificação seria categoria 5 do BI-RADS.

Dirigimo-nos então à literatura em busca de trabalhos que houvessem buscado esses VPP e pudessem nos auxiliar como referência. Em vários estudos foram encontrados VPP ao redor de $20 \%$ para as calcificações $\operatorname{amorfas}^{34,35,66}$, e iniciamos neste valor a categoria de suspeição intermediária (4B), estendendo-a até 50\%, por considerar que lesões com mais de 50\% de VPP já devem ser tomadas como lesões de alta suspeita para malignidade.

Para a categoria $4 \mathrm{C}$, que abrangeria lesões mais suspeitas que a média, consideramos VPP de 50 a 70\%. O VPP de $70 \%$ sugerido como limite entre as categorias 4 e 5 baseia-se em estudos que evidenciaram que calcificações com morfologia linear e pleomorfa fina, e as calcificações com distribuição linear e segmentar, que são as mais associadas a maior suspeita de câncer de mama, apresentaram VPP a partir de 70\%. Os VPP observados nesses estudos foram de 68\% para as calcificações de distribuição linear, de $74 \%$ para as de distribuição segmentar ${ }^{66}$ e de $81 \%$ a $94 \%{ }^{6,3}$ para as calcificações de morfologia linear. Podemos ainda encontrar na literatura outros estudos que apresentaram VPP ao redor de $70 \%$, como os de BALL ${ }^{71}$ onde o VPP para as lesões classificadas como categoria 5 foi de $77,4 \%$ e o de GÜLSÜN ${ }^{72}$, em que o VPP para essas lesões foi de $68 \%$. 
Acreditamos que ter valores de corte estabelecidos entre as subcategorias $4 \mathrm{~A}, 4 \mathrm{~B}$, e $4 \mathrm{C}$ e a categoria 5 pode ser um instrumento a mais para auxiliar o mastologista a interpretar o resultado do anatomopatológico das calcificações da sua paciente como suficiente ou não, e para orientá-lo quanto ao melhor seguimento indicado caso a caso. Além disso, categorizações como essas auxiliam na auditoria dos casos de calcificações submetidas a biópsias, o que nos ajudará a compreender melhor, com o passar do tempo, o comportamento de cada tipo de patologia que determina o achado mamográfico de calcificações.

Considerando os dados encontrados nesse trabalho e a nossa sugestão de divisão de categorias do BI-RADS teríamos a seguinte classificação:

- BI-RADS 3 (VPP menor que 2\%) nenhuma característica isolada ou combinação de distribuição e morfologia resultou em VPP menor que $2 \%$ nesse estudo.

- BI-RADS 4 A (VPP de 2,0 a 11\%) aplicável a calcificações com distribuição agrupada e morfologia puntiforme (VPP=5,1\%); distribuição agrupada e morfologia heterogênea grosseira (VPP=6,9\%); e de calcificações de morfologia heterogênea grosseira (VPP=10,5\%).

- BI-RADS 4B (VPP de 11,1 a 50\%), aplicável a calcificações de distribuição linear e morfologia amorfa (VPP=33,3\%), de distribuição linear e morfologia puntiforme (VPP=36,4\%), de distribuição linear e morfologia heterogênea grosseira (VPP=40,0\%), de distribuição segmentar e morfologia heterogênea grosseira (VPP=40,0\%), de distribuição agrupada e morfologia linear (VPP=14,3\%), de distribuição agrupada e morfologia amorfa (VPP=16,9\%), de morfologia amorfa (VPP=20,8\%), de morfologia puntiforme (VPP=13,3\%) e de distribuição agrupada (VPP=27,3\%). 
- BI-RADS 4C (VPP de 50,1 a 70\%) para as calcificações de distribuição segmentar e morfologia amorfa (VPP= 53,3\%), de distribuição segmentar e morfologia puntiforme (VPP= 55,6\%) e de distribuição linear (VPP=58,1\%).

- BI-RADS 5 (VPP maior que 70\%) para as calcificações de distribuição agrupada e morfologia pleomorfa fina (VPP=70,5\%), calcificações de distribuição linear e morfologia linear (VPP=71,4\%), de distribuição linear e morfologia pleomorfa fina (VPP=76,5\%), de distribuição segmentar e morfologia pleomorfa fina (VPP=94,6\%), de distribuição segmentar e morfologia linear (VPP=100\%), de distribuição segmentar (VPP=77,5\%) e de morfologia linear, apesar do VPP encontrado nesse trabalho de 57,9\%.

Um dado interessante encontrado neste estudo foi a ausência de casos de câncer de mama em pacientes com calcificações de morfologia grosseira associada a indeterminadas, com idade maior de 60 anos. Em geral a taxa de câncer de mama aumentou após os sessenta anos, o que é considerado como normal para a faixa etária. No entanto nesse tipo de calcificação, que já é considerado como indeterminado, porém com padrão mais sugestivo de benignidade, não se observou nenhum caso de câncer após os sessenta anos. Esse achado sugere que o tema deve ser mais bem estudado, pois com mais evidências talvez possamos passar a fazer apenas os controles mamográficos semestrais em mulheres com mais de 60 anos e esse tipo de calcificações, e não mais a biópsia.

Uma deficiência observada no nosso estudo é o fato de termos apenas oito casos de calcificações com distribuição regional. Outros estudos com amostras maiores talvez possam ser mais categóricos na caracterização desse tipo de distribuição como benigna, como já é sugerido pelo manual do BI-RADS. 
Podemos ainda questionar o tipo de seguimento feito aos casos do estudo que não tiveram biópsia excisional. Nos casos de biópsia a vácuo com agulha de $11 \mathrm{G}$ estabelecemos um tempo de controle de um ano por esse grupo apresentar taxas de sub estimação mais baixas (cerca de 11,2\%), em relação às pacientes submetidas a biópsia com agulha $14 G$ (cerca de 20,3\%), conforme demonstrou JACKMAN ${ }^{34}$, em 2001. É aceito que ao compararmos as biópsias de fragmento com agulha 14 G e a biópsia a vácuo com agulha 11 G, a eficácia da biópsia a vácuo em obter um resultado anatomopatológico efetivo é maior ${ }^{57,58}$, porém estudos com tempo de seguimento maior para todos os tipos de biópsia seriam interessantes, para tentar neutralizar possíveis efeitos da subestimação de lesões. Vale frisar que as biópsias incluídas no estudo apresentaram sempre fragmentos contendo as calcificações em questão, o que visa aumentar a representatividade da amostra da biópsia.

Alguns sub grupos de classificação de morfologia associada a distribuição mostraram um número de amostra pequeno, que provocou índices de confiança inadequados. Nesses casos acreditamos que novos estudos com amostra ampliada poderão ter maior significância estatística. 
7 CONCLUSÕES 
Neste trabalho observamos que:

1. Morfologia e distribuição foram as características mais significativas na determinação do VPP das calcificações. As características densidade, número e extensão tiveram importância secundária.

2. Características como morfologia linear ou pleomorfa e distribuição linear ou segmentar foram associadas a maior suspeita de câncer de mama.

3. As calcificações de morfologia grosseira associada a indeterminadas, em mulheres com mais de 60 anos não estiveram associadas a nenhum caso de câncer de mama.

4. Associando as características distribuição e morfologia obtivemos VPP mais precisos do que considerando cada característica isoladamente.

5. Nossa definição de valores preditivos positivos para a divisão da categoria 4 é a seguinte: VPP de $2 \%$ a $11 \%$ para $4 \mathrm{~A}$, de $11,1 \%$ a $50 \%$ para $4 \mathrm{~B}$ e de $50,1 \%$ a $70 \%$ para $4 \mathrm{C}$.

6. Calcificações com VPP $>70 \%$ e calcificações de morfologia linear foram consideradas como categoria 5 do BI-RADS. 


\begin{tabular}{|c|c|c|c|c|c|c|c|c|}
\hline Nome & Idade & Distribuição & Morfologia & Área & Quantidade & Método & Origem & AP \\
\hline AVG & 72 & Regional & $\begin{array}{c}\text { heterogêneas } \\
\text { grosseiras }\end{array}$ & 4,0 & $>30$ & Core & $\mathrm{HC}$ & Fibroesclerose \\
\hline MJS & 57 & Linear & $\begin{array}{c}\text { heterogêneas } \\
\text { grosseiras }\end{array}$ & 1,6 & 10 & Core & $\mathrm{HC}$ & CAD "in situ" \\
\hline GB & 53 & Agrupadas & puntiformes & 0,8 & 10 & Agulhama & $\mathrm{HC}$ & Adenose \\
\hline MRN & 49 & Agrupadas & amorfas & 0,5 & 10 & Agulhama & $\mathrm{HC}$ & HDT \\
\hline NFF & 66 & Agrupadas & amorfas & 0,6 & 10 & Agulhama & Fleury & HDT \\
\hline JGG & 70 & Linear & $\begin{array}{c}\text { heterogêneas } \\
\text { grosseiras }\end{array}$ & 0,5 & 10 & Agulhama & $\mathrm{HC}$ & Fibroesclerose \\
\hline LBS & 64 & Agrupadas & amorfas & 0,5 & 10 & Agulhama & $\mathrm{HC}$ & Reação CE \\
\hline AR & 51 & Agrupadas & puntiformes & 0,5 & 10 & Agulhama & $\mathrm{HC}$ & Adenose \\
\hline MGS & 46 & Agrupadas & $\begin{array}{l}\text { pleomorfas } \\
\text { finas }\end{array}$ & 0,8 & 10 & Core & $\mathrm{HC}$ & Fibroesclerose \\
\hline TJVF & 49 & Agrupadas & amorfas & 0,5 & 10 & Core & $\mathrm{HC}$ & Papiloma \\
\hline LCLJ & 59 & Agrupadas & amorfas & 0,5 & 10 & Agulhama & $\mathrm{HC}$ & HDT \\
\hline ALAS & 43 & Agrupadas & $\begin{array}{c}\text { heterogêneas } \\
\text { grosseiras }\end{array}$ & 0,9 & 10 & MAMOTOMIA & Fleury & Adenose \\
\hline MLBS & 54 & Agrupadas & amorfas & 0,5 & 10 & MAMOTOMIA & Fleury & Adenose \\
\hline TG & 44 & Agrupadas & $\begin{array}{c}\text { heterogêneas } \\
\text { grosseiras }\end{array}$ & 0,5 & 10 & MAMOTOMIA & Fleury & Adenose \\
\hline LLP & 53 & Agrupadas & amorfas & 1,9 & 10 & Agulhama & $\mathrm{HC}$ & Papiloma \\
\hline EMNABC & 50 & Linear & puntiformes & 2,0 & 10 & Agulhama & URP & CAD "in situ" \\
\hline DLMN & 60 & Agrupadas & $\begin{array}{c}\text { heterogêneas } \\
\text { grosseiras }\end{array}$ & 0,6 & 10 & Core & Fleury & Fibroesclerose \\
\hline AMF & 53 & Agrupadas & $\begin{array}{c}\text { heterogêneas } \\
\text { grosseiras }\end{array}$ & 0,5 & 10 & Agulhama & $\mathrm{HC}$ & HDT \\
\hline JBS & 58 & Agrupadas & puntiformes & 0,5 & 10 & Agulhama & $\mathrm{HC}$ & Papiloma \\
\hline MÊS & 55 & Agrupadas & $\begin{array}{c}\text { heterogêneas } \\
\text { grosseiras }\end{array}$ & 0,5 & 10 & Core & $\mathrm{HC}$ & Adenose \\
\hline CLP & 68 & Linear & puntiformes & 1,3 & 10 & Agulhama & $\mathrm{HC}$ & Fibroesclerose \\
\hline MSB & 49 & Agrupadas & amorfas & 1,0 & 10 & Agulhama & $\mathrm{HC}$ & Adenose \\
\hline MAS & 60 & Agrupadas & $\begin{array}{c}\text { heterogêneas } \\
\text { grosseiras }\end{array}$ & 0,5 & 10 & Core & $\mathrm{HC}$ & Adenose \\
\hline MAMG & 41 & Agrupadas & $\begin{array}{l}\text { pleomorfas } \\
\text { finas }\end{array}$ & 0,8 & 11 & Agulhama & URP & CAD Invasivo \\
\hline MR & 53 & Agrupadas & $\begin{array}{c}\text { heterogêneas } \\
\text { grosseiras }\end{array}$ & 0,8 & 11 & Agulhama & URP & Adenose \\
\hline TMN & 46 & Agrupadas & amorfas & 1,0 & 11 & Agulhama & $\mathrm{HC}$ & Adenose \\
\hline MAC & 39 & Agrupadas & amorfas & 2,0 & 11 & Agulhama & $\mathrm{HC}$ & Adenose \\
\hline NF & 52 & Agrupadas & $\begin{array}{c}\text { heterogêneas } \\
\text { grosseiras }\end{array}$ & 0,5 & 11 & Agulhama & $\mathrm{HC}$ & Fibroesclerose \\
\hline SAA & 40 & Agrupadas & puntiformes & 1,5 & 11 & Agulhama & $\mathrm{HC}$ & Adenose \\
\hline $\mathrm{NI}$ & 72 & Agrupadas & $\begin{array}{l}\text { pleomorfas } \\
\text { finas }\end{array}$ & 0,7 & 11 & Agulhama & URP & CAD "in situ" \\
\hline GE & 65 & Agrupadas & $\begin{array}{l}\text { pleomorfas } \\
\text { finas }\end{array}$ & 0,5 & 11 & Agulhama & URP & CAD "in situ" \\
\hline CFF & 72 & Linear & lineares & 1,8 & 11 & Agulhama & URP & CAD Invasivo \\
\hline TMRP & 49 & Agrupadas & amorfas & 0,5 & 11 & Agulhama & URP & Adenose \\
\hline EGF & 55 & Agrupadas & $\begin{array}{c}\text { pleomorfas } \\
\text { finas }\end{array}$ & 0,5 & 11 & Agulhama & URP & Adenose \\
\hline GLF & 44 & Agrupadas & $\begin{array}{l}\text { pleomorfas } \\
\text { finas }\end{array}$ & 0,8 & 11 & Agulhama & URP & CAD "in situ" \\
\hline ESM & 47 & Agrupadas & amorfas & 0,8 & 11 & Agulhama & URP & Adenose \\
\hline
\end{tabular}




\begin{tabular}{|c|c|c|c|c|c|c|c|c|}
\hline Nome & Idade & Distribuição & Morfologia & Área & Quantidade & Método & Origem & AP \\
\hline MGAM & 44 & Agrupadas & amorfas & 0,5 & 11 & Core & Fleury & Fibroesclerose \\
\hline SRB & 47 & Agrupadas & puntiformes & 0,5 & 11 & Agulhama & $\mathrm{HC}$ & Adenose \\
\hline RALN & 38 & Agrupadas & puntiformes & 0,7 & 11 & Agulhama & $\mathrm{HC}$ & HDT \\
\hline AP & 51 & Agrupadas & puntiformes & 0,6 & 11 & Agulhama & $\mathrm{HC}$ & Adenose \\
\hline LMG & 37 & Agrupadas & $\begin{array}{l}\text { pleomorfas } \\
\text { finas }\end{array}$ & 0,8 & 11 & Agulhama & URP & CAD "in situ" \\
\hline JCA & 47 & Agrupadas & amorfas & 1,5 & 11 & Agulhama & $\mathrm{HC}$ & Adenose \\
\hline MÊS & 61 & Agrupadas & $\begin{array}{l}\text { pleomorfas } \\
\text { finas }\end{array}$ & 0,6 & 11 & Agulhama & URP & CAD "in situ" \\
\hline IB & 53 & Agrupadas & puntiformes & 0,7 & 12 & Core & $\mathrm{HC}$ & CAL Invasivo \\
\hline GLCM & 53 & Agrupadas & amorfas & 0,6 & 12 & Agulhama & URP & Adenose \\
\hline SEM & 45 & Agrupadas & puntiformes & 0,5 & 12 & Core & Fleury & HDT \\
\hline ES & 34 & Linear & lineares & 0,6 & 12 & Agulhama & URP & CAD "in situ" \\
\hline ANMN & 39 & Agrupadas & amorfas & 1,1 & 12 & Agulhama & URP & CAD "in situ" \\
\hline $\mathrm{RL}$ & 44 & Linear & $\begin{array}{l}\text { pleomorfas } \\
\text { finas }\end{array}$ & 0,9 & 12 & Agulhama & URP & CAD "in situ" \\
\hline MIB & 49 & Agrupadas & $\begin{array}{l}\text { pleomorfas } \\
\text { finas }\end{array}$ & 0,5 & 12 & Agulhama & URP & CAD "in situ" \\
\hline SPC & 39 & Agrupadas & amorfas & 0,8 & 12 & Agulhama & URP & CAD Invasivo \\
\hline LGM & 46 & Agrupadas & $\begin{array}{l}\text { heterogêneas } \\
\text { grosseiras }\end{array}$ & 2,5 & 12 & MAMOTOMIA & Fleury & FA \\
\hline HK & 60 & Linear & $\begin{array}{l}\text { pleomorfas } \\
\text { finas }\end{array}$ & 1,3 & 12 & Agulhama & URP & CAD "in situ" \\
\hline MLDS & 56 & Agrupadas & amorfas & 1,9 & 12 & Agulhama & $\mathrm{HC}$ & Adenose \\
\hline LR & 51 & Agrupadas & puntiformes & 0,5 & 12 & Agulhama & $\mathrm{HC}$ & HDT \\
\hline SEM & 50 & Agrupadas & amorfas & 1,0 & 12 & Agulhama & $\mathrm{HC}$ & Papiloma \\
\hline IK & 72 & Agrupadas & $\begin{array}{c}\text { heterogêneas } \\
\text { grosseiras }\end{array}$ & 0,9 & 12 & MAMOTOMIA & Fleury & FA \\
\hline IFB & 47 & Agrupadas & $\begin{array}{l}\text { pleomorfas } \\
\text { finas }\end{array}$ & 0,5 & 12 & Agulhama & $\mathrm{HC}$ & CAD "in situ" \\
\hline AMACR & 49 & Agrupadas & $\begin{array}{l}\text { heterogêneas } \\
\text { grosseiras }\end{array}$ & 0,8 & 12 & Agulhama & URP & HDT \\
\hline SOR & 82 & Agrupadas & $\begin{array}{l}\text { heterogêneas } \\
\text { grosseiras }\end{array}$ & 0,9 & 12 & MAMOTOMIA & Fleury & FA \\
\hline RCDG & 50 & Agrupadas & $\begin{array}{c}\text { heterogêneas } \\
\text { grosseiras }\end{array}$ & 0,7 & 12 & MAMOTOMIA & Fleury & Adenose \\
\hline ASS & 55 & Agrupadas & $\begin{array}{c}\text { heterogêneas } \\
\text { grosseiras }\end{array}$ & 1,3 & 12 & Agulhama & $\mathrm{HC}$ & HDA \\
\hline RSC & 50 & Agrupadas & $\begin{array}{l}\text { heterogêneas } \\
\text { grosseiras }\end{array}$ & 0,7 & 12 & Core & $\mathrm{HC}$ & CAD "in situ" \\
\hline MGPN & 47 & Agrupadas & $\begin{array}{l}\text { pleomorfas } \\
\text { finas }\end{array}$ & 1,3 & 12 & Agulhama & $\mathrm{HC}$ & FA \\
\hline CNS & 47 & Agrupadas & amorfas & 0,7 & 12 & Agulhama & $\mathrm{HC}$ & HDA \\
\hline EC & 56 & Agrupadas & puntiformes & 1,5 & 12 & Agulhama & $\mathrm{HC}$ & HDT \\
\hline GA & 50 & Linear & lineares & 1,8 & 12 & Core & $\mathrm{HC}$ & CAD "in situ" \\
\hline GMF & 55 & Agrupadas & $\begin{array}{l}\text { pleomorfas } \\
\text { finas }\end{array}$ & 0,5 & 12 & Core & $\mathrm{HC}$ & CAD "in situ" \\
\hline MCF & 52 & Segmentar & puntiformes & 3,5 & 12 & Core & $\mathrm{HC}$ & CAD Invasivo \\
\hline MIM & 72 & Agrupadas & $\begin{array}{l}\text { heterogêneas } \\
\text { grosseiras }\end{array}$ & 0,5 & 12 & Agulhama & URP & Adenose \\
\hline NPL & 45 & Agrupadas & $\begin{array}{l}\text { pleomorfas } \\
\text { finas }\end{array}$ & 0,5 & 12 & Core & $\mathrm{HC}$ & CAD "in situ" \\
\hline JTG & 35 & Agrupadas & puntiformes & 0,5 & 12 & Agulhama & $\mathrm{HC}$ & HDT \\
\hline
\end{tabular}




\begin{tabular}{|c|c|c|c|c|c|c|c|c|}
\hline Nome & Idade & Distribuição & Morfologia & Área & Quantidade & Método & Origem & AP \\
\hline TARS & 47 & Agrupadas & amorfas & 1,6 & 12 & Core & $\mathrm{HC}$ & CAD Invasivo \\
\hline MFSB & 65 & Agrupadas & amorfas & 1,2 & 12 & Agulhama & $\mathrm{HC}$ & Adenose \\
\hline DRC & 51 & Agrupadas & $\begin{array}{l}\text { pleomorfas } \\
\text { finas }\end{array}$ & 0,8 & 12 & Agulhama & $\mathrm{HC}$ & CAD "in situ" \\
\hline $\mathrm{SH}$ & 42 & Agrupadas & $\begin{array}{l}\text { pleomorfas } \\
\text { finas }\end{array}$ & 0,5 & 12 & Agulhama & $\mathrm{HC}$ & CAD "in situ" \\
\hline CSTRF & 52 & Agrupadas & lineares & 0,5 & 12 & Agulhama & $\mathrm{HC}$ & Adenose \\
\hline MCSS & 49 & Agrupadas & puntiformes & 0,5 & 12 & Agulhama & $\mathrm{HC}$ & Fibroesclerose \\
\hline MNOF & 39 & Agrupadas & $\begin{array}{c}\text { heterogêneas } \\
\text { grosseiras }\end{array}$ & 0,7 & 12 & Agulhama & $\mathrm{HC}$ & HDT \\
\hline MLF & 57 & Linear & $\begin{array}{l}\text { pleomorfas } \\
\text { finas }\end{array}$ & 1,0 & 12 & Core & $\mathrm{HC}$ & CAD "in situ" \\
\hline LBB & 48 & Agrupadas & puntiformes & 0,5 & 12 & Agulhama & $\mathrm{HC}$ & Adenose \\
\hline DVA & 49 & Agrupadas & $\begin{array}{l}\text { pleomorfas } \\
\text { finas }\end{array}$ & 0,7 & 12 & Agulhama & URP & HDT \\
\hline BAC & 54 & Linear & puntiformes & 0,5 & 12 & Agulhama & $\mathrm{HC}$ & $\begin{array}{l}\text { Adenose } \\
\text { esclerosante }\end{array}$ \\
\hline SMGB & 44 & Agrupadas & $\begin{array}{l}\text { heterogêneas } \\
\text { grosseiras }\end{array}$ & 0,5 & 12 & Agulhama & URP & Adenose \\
\hline MNN & 41 & Agrupadas & amorfas & 0,5 & 12 & Agulhama & $\mathrm{HC}$ & Papiloma \\
\hline OSP & 61 & Agrupadas & amorfas & 2,3 & 12 & Agulhama & URP & Adenose \\
\hline LMDLV & 50 & Agrupadas & puntiformes & 0,5 & 12 & Agulhama & $\mathrm{HC}$ & Adenose \\
\hline NAP & 65 & Segmentar & $\begin{array}{l}\text { pleomorfas } \\
\text { finas }\end{array}$ & 3,4 & 12 & Core & $\mathrm{HC}$ & CAD "in situ" \\
\hline EIS & 56 & Agrupadas & amorfas & 0,5 & 12 & Agulhama & $\mathrm{HC}$ & Adenose \\
\hline SMMAA & 48 & Agrupadas & amorfas & 0,5 & 12 & Core & Fleury & Adenose \\
\hline LLE & 59 & Agrupadas & $\begin{array}{l}\text { pleomorfas } \\
\text { finas }\end{array}$ & 2,0 & 12 & Core & $\mathrm{HC}$ & CAD "in situ" \\
\hline AAP & 68 & Agrupadas & $\begin{array}{l}\text { pleomorfas } \\
\text { finas }\end{array}$ & 0,7 & 12 & Core & $\mathrm{HC}$ & CAD "in situ" \\
\hline VLR & 50 & Agrupadas & $\begin{array}{l}\text { pleomorfas } \\
\text { finas }\end{array}$ & 0,5 & 12 & Agulhama & $\mathrm{HC}$ & Papiloma \\
\hline MIS & 55 & Agrupadas & puntiformes & 0,8 & 12 & Agulhama & $\mathrm{HC}$ & Adenose \\
\hline WMC & 57 & Agrupadas & puntiformes & 1,5 & 12 & Agulhama & $\mathrm{HC}$ & Fibroesclerose \\
\hline ALS & 49 & Agrupadas & puntiformes & 2,2 & 12 & Agulhama & $\mathrm{HC}$ & Adenose \\
\hline CF & 52 & Segmentar & puntiformes & 3,5 & 12 & Agulhama & $\mathrm{HC}$ & $\begin{array}{c}\text { Adenose } \\
\text { esclerosante }\end{array}$ \\
\hline LC & 51 & Agrupadas & $\begin{array}{l}\text { pleomorfas } \\
\text { finas }\end{array}$ & 0,7 & 12 & Agulhama & URP & $\begin{array}{c}\text { Adenose } \\
\text { esclerosante }\end{array}$ \\
\hline RLC & 70 & Linear & $\begin{array}{l}\text { pleomorfas } \\
\text { finas }\end{array}$ & 0,5 & 12 & Core & $\mathrm{HC}$ & CAD "in situ" \\
\hline MILB & 55 & Agrupadas & amorfas & 0,6 & 12 & Core & $\mathrm{HC}$ & Adenose \\
\hline $\mathrm{CH}$ & 49 & Agrupadas & amorfas & 0,5 & 12 & Agulhama & $\mathrm{HC}$ & FA \\
\hline LLS & 52 & Agrupadas & amorfas & 0,7 & 12 & Core & $\mathrm{HC}$ & Fibroesclerose \\
\hline LMT & 62 & Agrupadas & $\begin{array}{l}\text { pleomorfas } \\
\text { finas }\end{array}$ & 0,7 & 12 & MAMOTOMIA & Fleury & CAD "in situ" \\
\hline ARDA & 51 & Agrupadas & amorfas & 0,5 & 12 & Core & Fleury & Fibroesclerose \\
\hline CRB & 52 & Agrupadas & $\begin{array}{l}\text { pleomorfas } \\
\text { finas }\end{array}$ & 0,9 & 12 & MAMOTOMIA & Fleury & CAD "in situ" \\
\hline LFL & 52 & Agrupadas & amorfas & 0,8 & 12 & Core & Fleury & Adenose \\
\hline IMR & 75 & Agrupadas & amorfas & 0,5 & 12 & Agulhama & $\mathrm{HC}$ & Adenose \\
\hline YA & 59 & Agrupadas & amorfas & 0,6 & 12 & Core & Fleury & Adenose \\
\hline CPSS & 51 & Agrupadas & amorfas & 0,5 & 12 & Agulhama & $\mathrm{HC}$ & Adenose \\
\hline
\end{tabular}




\begin{tabular}{|c|c|c|c|c|c|c|c|c|}
\hline Nome & Idade & Distribuição & Morfologia & Área & Quantidade & Método & Origem & AP \\
\hline MCS & 56 & Agrupadas & $\begin{array}{l}\text { pleomorfas } \\
\text { finas }\end{array}$ & 0,5 & 12 & Core & $\mathrm{HC}$ & HDT \\
\hline AMAC & 54 & Segmentar & $\begin{array}{l}\text { pleomorfas } \\
\text { finas }\end{array}$ & 3,5 & 12 & MAMOTOMIA & Fleury & CAD Invasivo \\
\hline AMC & 54 & Agrupadas & $\begin{array}{c}\text { heterogêneas } \\
\text { grosseiras }\end{array}$ & 1,5 & 13 & Core & $\mathrm{HC}$ & Papiloma \\
\hline HDB & 64 & Agrupadas & $\begin{array}{l}\text { pleomorfas } \\
\text { finas }\end{array}$ & 0,6 & 13 & Agulhama & URP & CAD Invasivo \\
\hline NA & 73 & Agrupadas & $\begin{array}{l}\text { pleomorfas } \\
\text { finas }\end{array}$ & 0,5 & 13 & Agulhama & $\mathrm{HC}$ & CAD Invasivo \\
\hline VMV & 61 & Agrupadas & puntiformes & 1,2 & 13 & Agulhama & $\mathrm{HC}$ & Adenose \\
\hline SMP & 49 & Agrupadas & $\begin{array}{l}\text { pleomorfas } \\
\text { finas }\end{array}$ & 0,5 & 13 & Core & Fleury & CAD "in situ" \\
\hline $\mathrm{MHCL}$ & 44 & Agrupadas & amorfas & 1,7 & 13 & Core & Fleury & HDA \\
\hline MEL & 59 & Agrupadas & puntiformes & 0,5 & 13 & Agulhama & $\mathrm{HC}$ & Adenose \\
\hline JNM & 40 & Agrupadas & $\begin{array}{l}\text { pleomorfas } \\
\text { finas }\end{array}$ & 0,6 & 13 & MAMOTOMIA & Fleury & CAD Invasivo \\
\hline EMLS & 48 & Agrupadas & amorfas & 0,6 & 13 & Agulhama & $\mathrm{HC}$ & CAD Invasivo \\
\hline NSA & 59 & Linear & amorfas & 0,5 & 13 & Core & $\mathrm{HC}$ & HDT \\
\hline $\mathrm{JBJ}$ & 54 & Agrupadas & amorfas & 1,6 & 13 & Core & $\mathrm{HC}$ & FA \\
\hline MSM & 59 & Agrupadas & amorfas & 0,5 & 13 & MAMOTOMIA & Fleury & Adenose \\
\hline EGAW & 51 & Agrupadas & puntiformes & 1,5 & 13 & Agulhama & $\mathrm{HC}$ & Fibroesclerose \\
\hline BBO & 52 & Agrupadas & puntiformes & 0,8 & 13 & Agulhama & $\mathrm{HC}$ & Adenose \\
\hline RRN & 49 & Agrupadas & amorfas & 0,6 & 13 & Core & $\mathrm{HC}$ & CAD Invasivo \\
\hline TGM & 48 & Agrupadas & puntiformes & 1,0 & 13 & Agulhama & $\mathrm{HC}$ & Fibroesclerose \\
\hline DSM & 52 & Agrupadas & $\begin{array}{c}\text { heterogêneas } \\
\text { grosseiras }\end{array}$ & 0,7 & 13 & Agulhama & $\mathrm{HC}$ & FA \\
\hline MJFA & 45 & Agrupadas & amorfas & 0,5 & 13 & Agulhama & $\mathrm{HC}$ & Papiloma \\
\hline MARG & 50 & Agrupadas & amorfas & 0,5 & 13 & Agulhama & $\mathrm{HC}$ & Adenose \\
\hline MAF & 53 & Agrupadas & amorfas & 2,1 & 13 & Core & $\mathrm{HC}$ & Fibroesclerose \\
\hline TAS & 49 & Agrupadas & puntiformes & 0,5 & 13 & Agulhama & $\mathrm{HC}$ & Adenose \\
\hline GPL & 63 & Linear & puntiformes & 1,6 & 13 & Agulhama & $\mathrm{HC}$ & CAD "in situ" \\
\hline CAGS & 39 & Agrupadas & amorfas & 1,8 & 13 & Agulhama & Fleury & HDT \\
\hline MCP & 51 & Agrupadas & $\begin{array}{l}\text { pleomorfas } \\
\text { finas }\end{array}$ & 0,7 & 13 & Core & $\mathrm{HC}$ & CAD "in situ" \\
\hline $\mathrm{HSO}$ & 44 & Agrupadas & amorfas & 1,9 & 14 & Agulhama & $\mathrm{HC}$ & Adenose \\
\hline JJR & 41 & Agrupadas & amorfas & 2,0 & 14 & Agulhama & URP & CAD "in situ" \\
\hline $\mathrm{HK}$ & 60 & Agrupadas & $\begin{array}{l}\text { pleomorfas } \\
\text { finas }\end{array}$ & 0,4 & 14 & Agulhama & $\mathrm{HC}$ & CAD "in situ" \\
\hline $\mathrm{HSI}$ & 36 & Agrupadas & amorfas & 1,2 & 14 & Agulhama & $\mathrm{HC}$ & HDT \\
\hline MMFB & 60 & Linear & puntiformes & 1,8 & 14 & Agulhama & $\mathrm{HC}$ & Papiloma \\
\hline MBT & 67 & Regional & puntiformes & 0,7 & 14 & MAMOTOMIA & Fleury & Reação CE \\
\hline SMP & 49 & Agrupadas & puntiformes & 0,9 & 14 & Core & Fleury & Fibroesclerose \\
\hline VCO & 41 & Agrupadas & $\begin{array}{l}\text { pleomorfas } \\
\text { finas }\end{array}$ & 0,8 & 14 & Agulhama & URP & CAD "in situ" \\
\hline MHS & 57 & Agrupadas & amorfas & 1,9 & 14 & MAMOTOMIA & Fleury & Adenose \\
\hline $\mathrm{RCM}$ & 35 & Agrupadas & $\begin{array}{c}\text { heterogêneas } \\
\text { grosseiras }\end{array}$ & 0,5 & 14 & Core & Fleury & CAD Invasivo \\
\hline MNS & 61 & Agrupadas & $\begin{array}{l}\text { pleomorfas } \\
\text { finas }\end{array}$ & 1,2 & 14 & Agulhama & $\mathrm{HC}$ & CAD Invasivo \\
\hline AT & 52 & Agrupadas & puntiformes & 1,6 & 14 & Core & $\mathrm{HC}$ & Adenose \\
\hline $\mathrm{CQ}$ & 58 & Agrupadas & amorfas & 0,5 & 14 & Agulhama & $\mathrm{HC}$ & HDT \\
\hline
\end{tabular}




\begin{tabular}{|c|c|c|c|c|c|c|c|c|}
\hline Nome & Idade & Distribuição & Morfologia & Área & Quantidade & Método & Origem & AP \\
\hline RLAC & 70 & Agrupadas & $\begin{array}{c}\text { heterogêneas } \\
\text { grosseiras }\end{array}$ & 0,6 & 14 & Core & Fleury & Papiloma \\
\hline MPE & 49 & Agrupadas & amorfas & 0,8 & 15 & Agulhama & Fleury & HDT \\
\hline SEM & 50 & Agrupadas & amorfas & 0,7 & 15 & Agulhama & $\mathrm{HC}$ & HDT \\
\hline MPA & 40 & Agrupadas & puntiformes & 1,2 & 15 & Core & $\mathrm{HC}$ & Adenose \\
\hline SLA & 48 & Agrupadas & amorfas & 0,8 & 15 & Agulhama & URP & Adenose \\
\hline MJAM & 56 & Agrupadas & amorfas & 0,5 & 15 & Agulhama & $\mathrm{HC}$ & Fibroesclerose \\
\hline $\mathrm{SZ}$ & 65 & Agrupadas & $\begin{array}{c}\text { heterogêneas } \\
\text { grosseiras }\end{array}$ & 0,8 & 15 & MAMOTOMIA & Fleury & Adenose \\
\hline ICF & 42 & Agrupadas & amorfas & 0,8 & 15 & Agulhama & Fleury & HDT \\
\hline SMSTB & 41 & Agrupadas & amorfas & 0,7 & 15 & Agulhama & URP & Adenose \\
\hline TMZ & 59 & Agrupadas & $\begin{array}{l}\text { pleomorfas } \\
\text { finas }\end{array}$ & 0,5 & 15 & Agulhama & $\mathrm{HC}$ & CAD "in situ" \\
\hline MRG & 57 & Agrupadas & amorfas & 1,6 & 15 & Core & $\mathrm{HC}$ & Adenose \\
\hline IMEN & 50 & Agrupadas & $\begin{array}{l}\text { pleomorfas } \\
\text { finas }\end{array}$ & 0,5 & 15 & Agulhama & $\mathrm{HC}$ & CAD "in situ" \\
\hline MAS & 53 & Agrupadas & amorfas & 0,6 & 15 & Agulhama & URP & CAD "in situ" \\
\hline MSTH & 52 & Segmentar & lineares & 3,5 & 15 & Agulhama & URP & CAD Invasivo \\
\hline $\mathrm{GCH}$ & 48 & Linear & $\begin{array}{l}\text { pleomorfas } \\
\text { finas }\end{array}$ & 1,8 & 15 & Agulhama & URP & CAD "in situ" \\
\hline LAC & 48 & Agrupadas & $\begin{array}{l}\text { pleomorfas } \\
\text { finas }\end{array}$ & 0,9 & 15 & Agulhama & URP & CAD "in situ" \\
\hline $\mathrm{ACM}$ & 53 & Segmentar & $\begin{array}{l}\text { pleomorfas } \\
\text { finas }\end{array}$ & 1,8 & 15 & Agulhama & $\mathrm{HC}$ & CAD "in situ" \\
\hline AAS & 43 & Agrupadas & puntiformes & 0,6 & 15 & Agulhama & $\mathrm{HC}$ & HDT \\
\hline $\mathrm{RHA}$ & 54 & Linear & $\begin{array}{c}\text { pleomorfas } \\
\text { finas }\end{array}$ & 1,3 & 15 & Agulhama & URP & CAD "in situ" \\
\hline LV & 75 & Regional & $\begin{array}{c}\text { heterogêneas } \\
\text { grosseiras }\end{array}$ & 3,1 & 15 & Core & Fleury & Esteatonecrose \\
\hline $\mathrm{JFC}$ & 65 & Agrupadas & $\begin{array}{c}\text { heterogêneas } \\
\text { grosseiras }\end{array}$ & 0,9 & 15 & Core & $\mathrm{HC}$ & Adenose \\
\hline $\mathrm{HHR}$ & 37 & Linear & $\begin{array}{l}\text { pleomorfas } \\
\text { finas }\end{array}$ & 1,3 & 15 & Agulhama & URP & CAD Invasivo \\
\hline MPFS & 48 & Agrupadas & $\begin{array}{l}\text { pleomorfas } \\
\text { finas }\end{array}$ & 0,5 & 16 & Core & $\mathrm{HC}$ & Adenose \\
\hline NCBA & 67 & Linear & lineares & 1,6 & 16 & Agulhama & URP & CAD "in situ" \\
\hline EGSS & 64 & Agrupadas & $\begin{array}{l}\text { pleomorfas } \\
\text { finas }\end{array}$ & 3,2 & 16 & Agulhama & URP & CAD "in situ" \\
\hline RS & 50 & Agrupadas & amorfas & 1,6 & 16 & MAMOTOMIA & Fleury & CAD Invasivo \\
\hline APS & 80 & Agrupadas & $\begin{array}{l}\text { pleomorfas } \\
\text { finas }\end{array}$ & 1,2 & 16 & Agulhama & Fleury & CAD Invasivo \\
\hline LHC & 40 & Agrupadas & $\begin{array}{l}\text { pleomorfas } \\
\text { finas }\end{array}$ & 0,7 & 16 & Agulhama & URP & CAD Invasivo \\
\hline $\mathrm{ACA}$ & 68 & Linear & $\begin{array}{l}\text { pleomorfas } \\
\text { finas }\end{array}$ & 1,1 & 16 & Agulhama & URP & CAD Invasivo \\
\hline MGAS & 60 & Agrupadas & $\begin{array}{l}\text { pleomorfas } \\
\text { finas }\end{array}$ & 0,8 & 17 & Agulhama & URP & CAD Invasivo \\
\hline EO & 35 & Agrupadas & $\begin{array}{l}\text { pleomorfas } \\
\text { finas }\end{array}$ & 3,1 & 17 & Agulhama & URP & $\begin{array}{l}\text { Adenose } \\
\text { esclerosante }\end{array}$ \\
\hline STP & 50 & Linear & $\begin{array}{l}\text { pleomorfas } \\
\text { finas }\end{array}$ & 3,4 & 17 & Agulhama & URP & CAD Invasivo \\
\hline AAJM & 65 & Agrupadas & amorfas & 0,5 & 17 & Agulhama & $\mathrm{HC}$ & HDT \\
\hline LMF & 60 & Agrupadas & $\begin{array}{l}\text { pleomorfas } \\
\text { finas }\end{array}$ & 1,3 & 17 & Agulhama & URP & CAD "in situ" \\
\hline
\end{tabular}




\begin{tabular}{|c|c|c|c|c|c|c|c|c|}
\hline Nome & Idade & Distribuição & Morfologia & Área & Quantidade & Método & Origem & AP \\
\hline MLZ & 56 & Agrupadas & $\begin{array}{l}\text { pleomorfas } \\
\text { finas }\end{array}$ & 1,9 & 17 & Agulhama & Fleury & CAD "in situ" \\
\hline $\mathrm{NL}$ & 49 & Linear & $\begin{array}{l}\text { pleomorfas } \\
\text { finas }\end{array}$ & 1,5 & 17 & Agulhama & $\mathrm{HC}$ & Fibroesclerose \\
\hline NS & 71 & Agrupadas & $\begin{array}{l}\text { pleomorfas } \\
\text { finas }\end{array}$ & 1,3 & 17 & Agulhama & URP & CAD "in situ" \\
\hline AVB & 74 & Agrupadas & puntiformes & 0,5 & 17 & Agulhama & $\mathrm{HC}$ & HDT \\
\hline JSTV & 48 & Agrupadas & $\begin{array}{c}\text { heterogêneas } \\
\text { grosseiras }\end{array}$ & 1,3 & 18 & МАMOTOMIA & Fleury & FA \\
\hline SJD & 85 & Agrupadas & $\begin{array}{l}\text { heterogêneas } \\
\text { grosseiras }\end{array}$ & 0,7 & 18 & MAMOTOMIA & Fleury & Adenose \\
\hline MLPS & 49 & Agrupadas & $\begin{array}{l}\text { pleomorfas } \\
\text { finas }\end{array}$ & 1,2 & 18 & MAMOTOMIA & Fleury & CAD "in situ" \\
\hline DRR & 70 & Agrupadas & $\begin{array}{l}\text { heterogêneas } \\
\text { grosseiras }\end{array}$ & 2,5 & 19 & МАМОТОМІА & Fleury & FA \\
\hline ILMM & 66 & Segmentar & $\begin{array}{l}\text { pleomorfas } \\
\text { finas }\end{array}$ & 3,6 & 20 & Agulhama & Fleury & CAD "in situ" \\
\hline RM & 45 & Agrupadas & $\begin{array}{l}\text { pleomorfas } \\
\text { finas }\end{array}$ & 2,5 & 20 & Agulhama & $\mathrm{HC}$ & Adenose \\
\hline EP & 69 & Agrupadas & $\begin{array}{c}\text { heterogêneas } \\
\text { grosseiras }\end{array}$ & 1,4 & 20 & Agulhama & URP & HDT \\
\hline CRS & 56 & Linear & puntiformes & 0,5 & 20 & Agulhama & $\mathrm{HC}$ & Adenose \\
\hline MCG & 59 & Segmentar & $\begin{array}{l}\text { pleomorfas } \\
\text { finas }\end{array}$ & 3,5 & 20 & Core & $\mathrm{HC}$ & CAD "in situ" \\
\hline RSC & 50 & Agrupadas & amorfas & 1,6 & 20 & Agulhama & $\mathrm{HC}$ & CAD "in situ" \\
\hline $\mathrm{RML}$ & 60 & Segmentar & amorfas & 3,0 & 20 & Agulhama & $\mathrm{HC}$ & Fibroesclerose \\
\hline AMJM & 55 & Segmentar & lineares & 3,8 & 20 & Core & $\mathrm{HC}$ & CAD "in situ" \\
\hline NPL & 39 & Segmentar & puntiformes & 3,5 & 20 & Agulhama & $\mathrm{HC}$ & CAD "in situ" \\
\hline LS & 55 & Segmentar & $\begin{array}{c}\text { heterogêneas } \\
\text { grosseiras }\end{array}$ & 3,7 & 20 & Agulhama & $\mathrm{HC}$ & CAD Invasivo \\
\hline GFS & 40 & Agrupadas & $\begin{array}{l}\text { pleomorfas } \\
\text { finas }\end{array}$ & 0,8 & 20 & Agulhama & $\mathrm{HC}$ & CAD "in situ" \\
\hline VLPS & 37 & Segmentar & amorfas & 3,7 & 20 & Agulhama & $\mathrm{HC}$ & HDT \\
\hline SPC & 40 & Linear & $\begin{array}{l}\text { heterogêneas } \\
\text { grosseiras }\end{array}$ & 1,5 & 20 & Agulhama & URP & CAD Invasivo \\
\hline VMA & 53 & Segmentar & $\begin{array}{c}\text { heterogêneas } \\
\text { grosseiras }\end{array}$ & 3,6 & 20 & Core & $\mathrm{HC}$ & CAD "in situ" \\
\hline VBS & 48 & Segmentar & amorfas & 3,5 & 20 & Core & $\mathrm{HC}$ & CAD "in situ" \\
\hline $\mathrm{HM}$ & 77 & Segmentar & $\begin{array}{l}\text { pleomorfas } \\
\text { finas }\end{array}$ & 3,5 & 20 & Core & $\mathrm{HC}$ & CAD "in situ" \\
\hline $\mathrm{JL}$ & 60 & Segmentar & $\begin{array}{l}\text { pleomorfas } \\
\text { finas }\end{array}$ & 3,9 & 20 & Core & $\mathrm{HC}$ & CAD "in situ" \\
\hline TRB & 74 & Agrupadas & $\begin{array}{l}\text { pleomorfas } \\
\text { finas }\end{array}$ & 0,6 & 20 & Agulhama & URP & CAD "in situ" \\
\hline Oco & 72 & Linear & $\begin{array}{l}\text { pleomorfas } \\
\text { finas }\end{array}$ & 1,4 & 20 & Agulhama & URP & CAD "in situ" \\
\hline KMCMC & 36 & Agrupadas & $\begin{array}{l}\text { pleomorfas } \\
\text { finas }\end{array}$ & 0,7 & 20 & Agulhama & URP & CAD Invasivo \\
\hline JCF & 81 & Segmentar & $\begin{array}{l}\text { pleomorfas } \\
\text { finas }\end{array}$ & 3,5 & 20 & Agulhama & $\mathrm{HC}$ & CAD Invasivo \\
\hline MTJCV & 63 & Segmentar & $\begin{array}{l}\text { pleomorfas } \\
\text { finas }\end{array}$ & 3,5 & 20 & Core & $\mathrm{HC}$ & CAD "in situ" \\
\hline MERS & 44 & Agrupadas & amorfas & 1,6 & 20 & Agulhama & $\mathrm{HC}$ & CAD "in situ" \\
\hline MAD & 42 & Segmentar & $\begin{array}{l}\text { pleomorfas } \\
\text { finas }\end{array}$ & 3,5 & 20 & Agulhama & URP & CAD Invasivo \\
\hline
\end{tabular}




\begin{tabular}{|c|c|c|c|c|c|c|c|c|}
\hline Nome & Idade & Distribuição & Morfologia & Área & Quantidade & Método & Origem & AP \\
\hline JM & 56 & Agrupadas & amorfas & 1,5 & 20 & Core & $\mathrm{HC}$ & CAD Invasivo \\
\hline OPP & 67 & Agrupadas & $\begin{array}{l}\text { pleomorfas } \\
\text { finas }\end{array}$ & 1,7 & 20 & Core & $\mathrm{HC}$ & CAD Invasivo \\
\hline ALS & 48 & Segmentar & puntiformes & 3,1 & 20 & Agulhama & $\mathrm{HC}$ & Adenose \\
\hline $\mathrm{KS}$ & 66 & Agrupadas & amorfas & 0,5 & 20 & Agulhama & $\mathrm{HC}$ & CAD "in situ" \\
\hline EIS & 56 & Agrupadas & $\begin{array}{l}\text { heterogêneas } \\
\text { grosseiras }\end{array}$ & 3,2 & 20 & Agulhama & $\mathrm{HC}$ & Adenose \\
\hline MXL & 56 & Segmentar & $\begin{array}{l}\text { pleomorfas } \\
\text { finas }\end{array}$ & 3,5 & 20 & Core & $\mathrm{HC}$ & CAL Invasivo \\
\hline IRS & 57 & Agrupadas & $\begin{array}{l}\text { pleomorfas } \\
\text { finas }\end{array}$ & 1,9 & 20 & Agulhama & $\mathrm{HC}$ & CAD Invasivo \\
\hline LFS & 66 & Segmentar & $\begin{array}{l}\text { pleomorfas } \\
\text { finas }\end{array}$ & 3,6 & 20 & Agulhama & $\mathrm{HC}$ & CAD "in situ" \\
\hline$M X L$ & 56 & Segmentar & amorfas & 3,5 & 20 & Core & $\mathrm{HC}$ & CAD "in situ" \\
\hline MLS & 42 & Agrupadas & amorfas & 0,4 & 20 & Core & $\mathrm{HC}$ & HDT \\
\hline MJFS & 51 & Linear & amorfas & 1,1 & 20 & Core & $\mathrm{HC}$ & CAD "in situ" \\
\hline WPG & 61 & Segmentar & amorfas & 3,5 & 20 & Agulhama & URP & CAD "in situ" \\
\hline MMT & 59 & Linear & $\begin{array}{l}\text { heterogêneas } \\
\text { grosseiras }\end{array}$ & 1,8 & 20 & Core & Fleury & FA \\
\hline EMP & 56 & Agrupadas & $\begin{array}{l}\text { pleomorfas } \\
\text { finas }\end{array}$ & 0,6 & 20 & Core & $\mathrm{HC}$ & CAD "in situ" \\
\hline DMS & 40 & Agrupadas & amorfas & 1,3 & 20 & Agulhama & $\mathrm{HC}$ & CAD "in situ" \\
\hline MGCR & 54 & Agrupadas & $\begin{array}{l}\text { pleomorfas } \\
\text { finas }\end{array}$ & 0,5 & 20 & Core & $\mathrm{HC}$ & $\begin{array}{c}\text { Adenose } \\
\text { esclerosante }\end{array}$ \\
\hline MDSA & 58 & Segmentar & $\begin{array}{l}\text { pleomorfas } \\
\text { finas }\end{array}$ & 4,2 & 20 & Agulhama & $\mathrm{HC}$ & CAD Invasivo \\
\hline$Z G$ & 50 & Agrupadas & puntiformes & 3,1 & 20 & Agulhama & $\mathrm{HC}$ & FA \\
\hline MMA & 42 & Agrupadas & $\begin{array}{l}\text { pleomorfas } \\
\text { finas }\end{array}$ & 0,7 & 20 & Agulhama & URP & CAD "in situ" \\
\hline $\mathrm{MHZ}$ & 36 & Agrupadas & puntiformes & 0,5 & 20 & Core & $\mathrm{HC}$ & Adenose \\
\hline NTM & 64 & Agrupadas & puntiformes & 1,5 & 20 & Agulhama & $\mathrm{HC}$ & HDT \\
\hline MFLS & 49 & Agrupadas & puntiformes & 2,2 & 20 & Agulhama & $\mathrm{HC}$ & Adenose \\
\hline $\mathrm{CCl}$ & 59 & Agrupadas & $\begin{array}{l}\text { heterogêneas } \\
\text { grosseiras }\end{array}$ & 1,6 & 20 & Agulhama & $\mathrm{HC}$ & HDT \\
\hline MSB & 55 & Agrupadas & $\begin{array}{l}\text { pleomorfas } \\
\text { finas }\end{array}$ & 1,2 & 20 & Agulhama & $\mathrm{HC}$ & CAD "in situ" \\
\hline JBG & 53 & Segmentar & $\begin{array}{l}\text { pleomorfas } \\
\text { finas }\end{array}$ & 3,6 & 20 & Agulhama & $\mathrm{HC}$ & CAD Invasivo \\
\hline VLOB & 42 & Regional & amorfas & 3,5 & 20 & Agulhama & $\mathrm{HC}$ & HDT \\
\hline IPG & 40 & Segmentar & $\begin{array}{l}\text { pleomorfas } \\
\text { finas }\end{array}$ & 3,5 & 20 & Agulhama & $\mathrm{HC}$ & CAD "in situ" \\
\hline LRT & 73 & Agrupadas & $\begin{array}{l}\text { pleomorfas } \\
\text { finas }\end{array}$ & 1,1 & 20 & Agulhama & $\mathrm{HC}$ & Esteatonecrose \\
\hline EMA & 66 & Agrupadas & amorfas & 1,1 & 20 & Agulhama & $\mathrm{HC}$ & HDT \\
\hline RBA & 49 & Agrupadas & $\begin{array}{l}\text { pleomorfas } \\
\text { finas }\end{array}$ & 0,6 & 20 & Agulhama & $\mathrm{HC}$ & HDT \\
\hline LMS & 46 & Segmentar & $\begin{array}{l}\text { pleomorfas } \\
\text { finas }\end{array}$ & 3,5 & 20 & Agulhama & $\mathrm{HC}$ & CAD Invasivo \\
\hline LBS & 61 & Agrupadas & $\begin{array}{l}\text { heterogêneas } \\
\text { grosseiras }\end{array}$ & 1,1 & 20 & Agulhama & $\mathrm{HC}$ & HDT \\
\hline VMC & 55 & Agrupadas & $\begin{array}{l}\text { pleomorfas } \\
\text { finas }\end{array}$ & 1,1 & 20 & MAMOTOMIA & Fleury & CAD "in situ" \\
\hline AT & 70 & Linear & $\begin{array}{l}\text { pleomorfas } \\
\text { finas }\end{array}$ & 1,9 & 20 & Agulhama & $\mathrm{HC}$ & CAD "in situ" \\
\hline
\end{tabular}




\begin{tabular}{|c|c|c|c|c|c|c|c|c|}
\hline Nome & Idade & Distribuição & Morfologia & Área & Quantidade & Método & Origem & AP \\
\hline AFZ & 54 & Segmentar & lineares & 3,8 & 20 & Agulhama & $\mathrm{HC}$ & CAD "in situ" \\
\hline VMH & 52 & Segmentar & amorfas & 3,5 & 20 & Core & $\mathrm{HC}$ & CAD "in situ" \\
\hline MDC & 58 & Segmentar & $\begin{array}{l}\text { pleomorfas } \\
\text { finas }\end{array}$ & 3,5 & 20 & Agulhama & $\mathrm{HC}$ & HDT \\
\hline LASA & 43 & Agrupadas & $\begin{array}{l}\text { heterogêneas } \\
\text { grosseiras }\end{array}$ & 1,3 & 20 & Agulhama & $\mathrm{HC}$ & Fibroesclerose \\
\hline MAS & 53 & Linear & lineares & 2,5 & 20 & MAMOTOMIA & Fleury & HDT \\
\hline DT & 46 & Agrupadas & $\begin{array}{l}\text { pleomorfas } \\
\text { finas }\end{array}$ & 1,1 & 20 & Agulhama & $\mathrm{HC}$ & Adenose \\
\hline MS & 55 & Agrupadas & $\begin{array}{l}\text { heterogêneas } \\
\text { grosseiras }\end{array}$ & 0,5 & 20 & Agulhama & $\mathrm{HC}$ & Adenose \\
\hline MLFO & 53 & Segmentar & $\begin{array}{l}\text { pleomorfas } \\
\text { finas }\end{array}$ & 3,6 & 20 & Agulhama & $\mathrm{HC}$ & CAD Invasivo \\
\hline DMS & 66 & Segmentar & $\begin{array}{l}\text { pleomorfas } \\
\text { finas }\end{array}$ & 3,5 & 20 & Agulhama & $\mathrm{HC}$ & HDT \\
\hline ACBM & 43 & Agrupadas & lineares & 1,1 & 20 & Core & $\mathrm{HC}$ & Fibroesclerose \\
\hline AAP & 62 & Segmentar & $\begin{array}{l}\text { pleomorfas } \\
\text { finas }\end{array}$ & 3,5 & 20 & Agulhama & $\mathrm{HC}$ & CAD "in situ" \\
\hline MLRD & 59 & Segmentar & puntiformes & 3,1 & 20 & Agulhama & $\mathrm{HC}$ & CAD Invasivo \\
\hline CMS & 63 & Agrupadas & $\begin{array}{l}\text { heterogêneas } \\
\text { grosseiras }\end{array}$ & 0,7 & 20 & Core & Fleury & Adenose \\
\hline MMP & 39 & Agrupadas & puntiformes & 3,1 & 20 & Agulhama & $\mathrm{HC}$ & Reação CE \\
\hline MLD & 55 & Agrupadas & puntiformes & 3,6 & 20 & Agulhama & $\mathrm{HC}$ & Papiloma \\
\hline MLCM & 55 & Segmentar & $\begin{array}{l}\text { pleomorfas } \\
\text { finas }\end{array}$ & 3,5 & 20 & MAMOTOMIA & Fleury & CAD "in situ" \\
\hline JPCM & 62 & Agrupadas & $\begin{array}{l}\text { pleomorfas } \\
\text { finas }\end{array}$ & 1,1 & 20 & Core & $\mathrm{HC}$ & CAD "in situ" \\
\hline MBS & 46 & Segmentar & amorfas & 3,5 & 20 & Agulhama & $\mathrm{HC}$ & $\begin{array}{c}\text { Adenose } \\
\text { esclerosante }\end{array}$ \\
\hline APSG & 53 & Segmentar & amorfas & 3,5 & 20 & Agulhama & $\mathrm{HC}$ & $\begin{array}{c}\text { Adenose } \\
\text { esclerosante }\end{array}$ \\
\hline NN & 53 & Agrupadas & amorfas & 3,3 & 20 & Agulhama & $\mathrm{HC}$ & Adenose \\
\hline AAP & 53 & Segmentar & amorfas & 3,5 & 20 & Agulhama & $\mathrm{HC}$ & HDT \\
\hline MLP & 73 & Segmentar & $\begin{array}{l}\text { heterogêneas } \\
\text { grosseiras }\end{array}$ & 3,5 & 20 & Core & $\mathrm{HC}$ & Adenose \\
\hline MSR & 57 & Agrupadas & lineares & 0,7 & 20 & Agulhama & $\mathrm{HC}$ & Adenose \\
\hline AMR & 56 & Agrupadas & $\begin{array}{l}\text { pleomorfas } \\
\quad \text { finas }\end{array}$ & 0,7 & 20 & Agulhama & $\mathrm{HC}$ & CAD Invasivo \\
\hline MJM & 53 & Agrupadas & $\begin{array}{l}\text { pleomorfas } \\
\text { finas }\end{array}$ & 1,8 & 20 & Agulhama & $\mathrm{HC}$ & Papiloma \\
\hline APS & 56 & Agrupadas & amorfas & 0,8 & 20 & Core & $\mathrm{HC}$ & HDT \\
\hline $\mathrm{CB}$ & 49 & Agrupadas & amorfas & 1,5 & 22 & Agulhama & $\mathrm{HC}$ & Papiloma \\
\hline FNS & 73 & Agrupadas & $\begin{array}{l}\text { pleomorfas } \\
\text { finas }\end{array}$ & 2,2 & 22 & Core & $\mathrm{HC}$ & CAD "in situ" \\
\hline MCASR & 56 & Segmentar & amorfas & 3,5 & 22 & Agulhama & $\mathrm{HC}$ & CAD "in situ" \\
\hline TMA & 38 & Segmentar & $\begin{array}{l}\text { heterogêneas } \\
\text { grosseiras }\end{array}$ & 3,5 & 22 & Core & $\mathrm{HC}$ & Esteatonecrose \\
\hline MFS & 43 & Segmentar & amorfas & 3,5 & 22 & Agulhama & $\mathrm{HC}$ & $\begin{array}{c}\text { Adenose } \\
\text { esclerosante }\end{array}$ \\
\hline MTJV & 63 & Agrupadas & $\begin{array}{l}\text { pleomorfas } \\
\text { finas }\end{array}$ & 3,1 & 22 & Core & $\mathrm{HC}$ & CAD "in situ" \\
\hline AMDM & 59 & Agrupadas & puntiformes & 0,5 & 23 & Core & $\mathrm{HC}$ & CAD "in situ" \\
\hline os & 46 & Segmentar & $\begin{array}{l}\text { pleomorfas } \\
\text { finas }\end{array}$ & 3,5 & 23 & MAMOTOMIA & Fleury & CAD Invasivo \\
\hline
\end{tabular}




\begin{tabular}{|c|c|c|c|c|c|c|c|c|}
\hline Nome & Idade & Distribuição & Morfologia & Área & Quantidade & Método & Origem & AP \\
\hline DCM & 44 & Agrupadas & $\begin{array}{l}\text { heterogêneas } \\
\text { grosseiras }\end{array}$ & 0,8 & 23 & Agulhama & $\mathrm{HC}$ & CAD "in situ" \\
\hline RMS & 56 & Agrupadas & amorfas & 1,1 & 23 & Agulhama & $\mathrm{HC}$ & Fibroesclerose \\
\hline ALCP & 42 & Agrupadas & $\begin{array}{l}\text { pleomorfas } \\
\text { finas }\end{array}$ & 0,8 & 25 & Agulhama & $\mathrm{HC}$ & $\begin{array}{l}\text { Adenose } \\
\text { esclerosante }\end{array}$ \\
\hline DA & 42 & Segmentar & $\begin{array}{l}\text { pleomorfas } \\
\text { finas }\end{array}$ & 3,6 & 25 & Core & $\mathrm{HC}$ & CAD "in situ" \\
\hline MS & 33 & Agrupadas & $\begin{array}{l}\text { heterogêneas } \\
\text { grosseiras }\end{array}$ & 0,8 & 25 & Agulhama & $\mathrm{HC}$ & $\mathrm{FA}$ \\
\hline NSM & 53 & Agrupadas & $\begin{array}{l}\text { pleomorfas } \\
\text { finas }\end{array}$ & 1,7 & 25 & Agulhama & $\mathrm{HC}$ & CAD "in situ" \\
\hline RCSMS & 41 & Agrupadas & $\begin{array}{l}\text { heterogêneas } \\
\text { grosseiras }\end{array}$ & 3,0 & 25 & Agulhama & $\mathrm{HC}$ & Adenose \\
\hline EMC & 47 & Segmentar & $\begin{array}{l}\text { pleomorfas } \\
\text { finas }\end{array}$ & 3,6 & 25 & Agulhama & URP & CAD "in situ" \\
\hline NMS & 42 & Agrupadas & $\begin{array}{c}\text { heterogêneas } \\
\text { grosseiras }\end{array}$ & 0,8 & 25 & Core & $\mathrm{HC}$ & HDT \\
\hline LCB & 62 & Segmentar & $\begin{array}{l}\text { pleomorfas } \\
\text { finas }\end{array}$ & 3,6 & 25 & Agulhama & $\mathrm{HC}$ & CAD "in situ" \\
\hline LCO & 43 & Agrupadas & $\begin{array}{l}\text { heterogêneas } \\
\text { grosseiras }\end{array}$ & 1,3 & 25 & Core & $\mathrm{HC}$ & Fibroesclerose \\
\hline LAG & 50 & Agrupadas & $\begin{array}{l}\text { heterogêneas } \\
\text { grosseiras }\end{array}$ & 0,5 & 25 & Core & $\mathrm{HC}$ & Fibroesclerose \\
\hline LDS & 40 & Segmentar & amorfas & 3,5 & 25 & Agulhama & URP & CAD "in situ" \\
\hline AAP & 48 & Agrupadas & $\begin{array}{l}\text { pleomorfas } \\
\text { finas }\end{array}$ & 2,1 & 25 & Agulhama & $\mathrm{HC}$ & CAD "in situ" \\
\hline COF & 69 & Segmentar & puntiformes & 3,5 & 25 & Agulhama & URP & CAD "in situ" \\
\hline SCS & 44 & Agrupadas & $\begin{array}{l}\text { pleomorfas } \\
\text { finas }\end{array}$ & 1,5 & 30 & Core & $\mathrm{HC}$ & $\begin{array}{c}\text { Adenose } \\
\text { esclerosante }\end{array}$ \\
\hline $\mathrm{IM}$ & 66 & Segmentar & $\begin{array}{l}\text { pleomorfas } \\
\text { finas }\end{array}$ & 3,4 & 30 & Core & Fleury & CAD Invasivo \\
\hline CSP & 44 & Regional & $\begin{array}{c}\text { heterogêneas } \\
\text { grosseiras }\end{array}$ & 3,0 & 30 & Agulhama & $\mathrm{HC}$ & Adenose \\
\hline ESA & 60 & Segmentar & $\begin{array}{l}\text { heterogêneas } \\
\text { grosseiras }\end{array}$ & 3,5 & 30 & Agulhama & $\mathrm{HC}$ & HDT \\
\hline NGS & 38 & Segmentar & $\begin{array}{l}\text { pleomorfas } \\
\text { finas }\end{array}$ & 3,5 & 30 & Core & $\mathrm{HC}$ & CAD "in situ" \\
\hline MMA & 42 & Segmentar & $\begin{array}{l}\text { pleomorfas } \\
\text { finas }\end{array}$ & 3,0 & 30 & Agulhama & URP & CAD "in situ" \\
\hline CTTU & 46 & Agrupadas & puntiformes & 3,5 & 30 & Agulhama & $\mathrm{HC}$ & Adenose \\
\hline IM & 53 & Agrupadas & $\begin{array}{l}\text { pleomorfas } \\
\text { finas }\end{array}$ & 3,1 & 30 & Agulhama & $\mathrm{HC}$ & CAD "in situ" \\
\hline CNS & 63 & Segmentar & lineares & 4,0 & 30 & Agulhama & URP & CAD Invasivo \\
\hline EM & 59 & Agrupadas & $\begin{array}{l}\text { pleomorfas } \\
\text { finas }\end{array}$ & 2,5 & 30 & Agulhama & $\mathrm{HC}$ & CAD Invasivo \\
\hline MJPB & 64 & Agrupadas & amorfas & 1,9 & 30 & Agulhama & $\mathrm{HC}$ & FA \\
\hline NVA & 47 & Segmentar & puntiformes & 3,5 & 32 & Core & $\mathrm{HC}$ & $\begin{array}{c}\text { Adenose } \\
\text { esclerosante }\end{array}$ \\
\hline MLS & 70 & Regional & $\begin{array}{l}\text { pleomorfas } \\
\text { finas }\end{array}$ & 3,8 & 34 & Agulhama & $\mathrm{HC}$ & Adenose \\
\hline MHBC & 53 & Segmentar & $\begin{array}{l}\text { pleomorfas } \\
\text { finas }\end{array}$ & 3,5 & 35 & Agulhama & $\mathrm{HC}$ & CAD "in situ" \\
\hline MCB & 65 & Segmentar & $\begin{array}{l}\text { pleomorfas } \\
\text { finas }\end{array}$ & 3,1 & 35 & Agulhama & URP & CAD Invasivo \\
\hline RBGS & 49 & Segmentar & amorfas & 3,5 & 35 & Agulhama & URP & CAD Invasivo \\
\hline
\end{tabular}




\begin{tabular}{|c|c|c|c|c|c|c|c|c|}
\hline Nome & Idade & Distribuição & Morfologia & Área & Quantidade & Método & Origem & AP \\
\hline APS & 80 & Segmentar & $\begin{array}{l}\text { pleomorfas } \\
\text { finas }\end{array}$ & 3,6 & 35 & Core & Fleury & CAD "in situ" \\
\hline ZSP & 52 & Segmentar & amorfas & 3,5 & 35 & Core & Fleury & CAD Invasivo \\
\hline NS & 56 & Segmentar & puntiformes & 3,0 & 35 & Agulhama & $\mathrm{HC}$ & Adenose \\
\hline$C Z$ & 55 & Regional & $\begin{array}{l}\text { heterogêneas } \\
\text { grosseiras }\end{array}$ & 3,5 & 35 & Core & Fleury & Adenose \\
\hline LFB & 60 & Agrupadas & $\begin{array}{l}\text { pleomorfas } \\
\text { finas }\end{array}$ & 3,2 & 35 & Agulhama & URP & CAD "in situ" \\
\hline MLPS & 44 & Agrupadas & amorfas & 1,5 & 35 & Agulhama & URP & CAD "in situ" \\
\hline AMN & 38 & Segmentar & $\begin{array}{l}\text { pleomorfas } \\
\text { finas }\end{array}$ & 3,5 & 35 & Agulhama & URP & CAD Invasivo \\
\hline VS & 72 & Agrupadas & $\begin{array}{l}\text { pleomorfas } \\
\text { finas }\end{array}$ & 1,0 & 35 & Agulhama & URP & CAD "in situ" \\
\hline $\mathrm{RCR}$ & 47 & Linear & $\begin{array}{l}\text { pleomorfas } \\
\text { finas }\end{array}$ & 2,3 & 35 & Agulhama & URP & CAD "in situ" \\
\hline NRS & 46 & Segmentar & amorfas & 3,0 & 35 & Agulhama & $\mathrm{HC}$ & Fibroesclerose \\
\hline AMMF & 46 & Agrupadas & $\begin{array}{l}\text { heterogêneas } \\
\text { grosseiras }\end{array}$ & 1,3 & 35 & Agulhama & URP & Adenose \\
\hline AMCM & 56 & Segmentar & $\begin{array}{l}\text { pleomorfas } \\
\text { finas }\end{array}$ & 3,6 & 35 & Agulhama & URP & CAD Invasivo \\
\hline MLS & 49 & Agrupadas & puntiformes & 1,3 & 35 & Agulhama & URP & CAD "in situ" \\
\hline ZFN & 71 & Regional & amorfas & 3,5 & 36 & Agulhama & $\mathrm{HC}$ & Fibroesclerose \\
\hline MARG & 50 & Agrupadas & amorfas & 0,5 & 4 & Agulhama & $\mathrm{HC}$ & Adenose \\
\hline MLS & 50 & Agrupadas & $\begin{array}{l}\text { heterogêneas } \\
\text { grosseiras }\end{array}$ & 0,4 & 4 & Core & $\mathrm{HC}$ & Adenose \\
\hline TRS & 65 & Agrupadas & puntiformes & 0,5 & 4 & Agulhama & $\mathrm{HC}$ & HDT \\
\hline ESS & 58 & Segmentar & $\begin{array}{l}\text { pleomorfas } \\
\text { finas }\end{array}$ & 5,0 & 40 & Core & $\mathrm{HC}$ & CAD "in situ" \\
\hline CCD & 54 & Segmentar & puntiformes & 3,4 & 40 & Agulhama & URP & CAD Invasivo \\
\hline NPGA & 63 & Segmentar & $\begin{array}{l}\text { pleomorfas } \\
\text { finas }\end{array}$ & 3,5 & 40 & Agulhama & URP & CAD "in situ" \\
\hline AHFCCM & 40 & Segmentar & $\begin{array}{l}\text { pleomorfas } \\
\text { finas }\end{array}$ & 3,6 & 45 & Agulhama & URP & CAD "in situ" \\
\hline JBS & 59 & Agrupadas & puntiformes & 0,5 & 5 & Agulhama & $\mathrm{HC}$ & HDT \\
\hline MS & 54 & Agrupadas & amorfas & 0,5 & 5 & Agulhama & $\mathrm{HC}$ & CAD "in situ" \\
\hline TP & 58 & Agrupadas & amorfas & 0,5 & 5 & Agulhama & $\mathrm{HC}$ & Adenose \\
\hline IOSB & 52 & Agrupadas & puntiformes & 0,5 & 5 & Core & Fleury & Adenose \\
\hline MRN & 49 & Agrupadas & amorfas & 0,5 & 5 & Agulhama & $\mathrm{HC}$ & $\begin{array}{c}\text { Adenose } \\
\text { esclerosante }\end{array}$ \\
\hline OC & 70 & Agrupadas & $\begin{array}{l}\text { heterogêneas } \\
\text { grosseiras }\end{array}$ & 0,5 & 5 & Core & Fleury & Adenose \\
\hline CRBE & 51 & Agrupadas & amorfas & 0,5 & 5 & Core & Fleury & Adenose \\
\hline MEVV & 59 & Agrupadas & amorfas & 0,5 & 5 & Agulhama & $\mathrm{HC}$ & Papiloma \\
\hline LMMAA & 48 & Agrupadas & amorfas & 0,5 & 5 & Core & Fleury & Fibroesclerose \\
\hline MLCB & 55 & Agrupadas & $\begin{array}{c}\text { pleomorfas } \\
\text { finas }\end{array}$ & 0,5 & 5 & MAMOTOMIA & Fleury & Adenose \\
\hline RBNC & 43 & Agrupadas & $\begin{array}{l}\text { pleomorfas } \\
\text { finas }\end{array}$ & 0,5 & 5 & MAMOTOMIA & Fleury & Adenose \\
\hline MLP & 53 & Agrupadas & $\begin{array}{l}\text { heterogêneas } \\
\text { grosseiras }\end{array}$ & 0,5 & 5 & MAMOTOMIA & Fleury & FA \\
\hline TAM & 44 & Agrupadas & $\begin{array}{l}\text { pleomorfas } \\
\text { finas }\end{array}$ & 0,8 & 5 & Core & $\mathrm{HC}$ & Adenose \\
\hline SCY & 66 & Agrupadas & $\begin{array}{l}\text { heterogêneas } \\
\text { grosseiras }\end{array}$ & 0,5 & 6 & Core & Fleury & Reação CE \\
\hline
\end{tabular}




\begin{tabular}{|c|c|c|c|c|c|c|c|c|}
\hline Nome & Idade & Distribuição & Morfologia & Área & Quantidade & Método & Origem & AP \\
\hline MA & 42 & Agrupadas & amorfas & 0,5 & 6 & Core & Fleury & Adenose \\
\hline MSB & 47 & Linear & $\begin{array}{l}\text { pleomorfas } \\
\text { finas }\end{array}$ & 0,5 & 6 & MAMOTOMIA & Fleury & Papilomatose \\
\hline $\mathrm{JBH}$ & 45 & Agrupadas & $\begin{array}{l}\text { pleomorfas } \\
\text { finas }\end{array}$ & 0,5 & 6 & Core & $\mathrm{HC}$ & $\begin{array}{c}\text { Adenose } \\
\text { esclerosante }\end{array}$ \\
\hline ICA & 45 & Agrupadas & amorfas & 0,4 & 6 & Agulhama & $\mathrm{HC}$ & Papiloma \\
\hline $\mathrm{SF}$ & 37 & Agrupadas & lineares & 0,5 & 6 & Agulhama & URP & CAD "in situ" \\
\hline $\mathrm{MCNC}$ & 52 & Agrupadas & $\begin{array}{l}\text { pleomorfas } \\
\text { finas }\end{array}$ & 0,5 & 6 & Agulhama & $\mathrm{HC}$ & HDA \\
\hline ARLS & 56 & Agrupadas & amorfas & 0,5 & 6 & Core & Fleury & Fibroesclerose \\
\hline MISJB & 48 & Agrupadas & $\begin{array}{l}\text { pleomorfas } \\
\text { finas }\end{array}$ & 0,5 & 6 & Agulhama & URP & CAD "in situ" \\
\hline FNF & 43 & Agrupadas & $\begin{array}{l}\text { pleomorfas } \\
\text { finas }\end{array}$ & 0,5 & 6 & Agulhama & URP & CAD "in situ" \\
\hline AGO & 43 & Agrupadas & amorfas & 0,5 & 6 & Core & Fleury & Adenose \\
\hline MVTP & 53 & Agrupadas & amorfas & 0,4 & 6 & Agulhama & $\mathrm{HC}$ & Papiloma \\
\hline ATF & 39 & Agrupadas & $\begin{array}{l}\text { pleomorfas } \\
\text { finas }\end{array}$ & 0,5 & 6 & Agulhama & URP & CAD "in situ" \\
\hline OLG & 49 & Agrupadas & amorfas & 0,5 & 6 & Agulhama & URP & CAD "in situ" \\
\hline MCC & 52 & Agrupadas & $\begin{array}{l}\text { pleomorfas } \\
\text { finas }\end{array}$ & 0,3 & 6 & Agulhama & $\mathrm{HC}$ & HDA \\
\hline EFC & 46 & Agrupadas & puntiformes & 0,6 & 6 & Core & Fleury & HDT \\
\hline MAPM & 60 & Agrupadas & $\begin{array}{c}\text { pleomorfas } \\
\text { finas }\end{array}$ & 0,5 & 6 & Agulhama & $\mathrm{HC}$ & HDT \\
\hline $\mathrm{LI}$ & 57 & Agrupadas & $\begin{array}{l}\text { pleomorfas } \\
\text { finas }\end{array}$ & 0,5 & 6 & Agulhama & URP & CAD "in situ" \\
\hline LSB & 57 & Agrupadas & $\begin{array}{l}\text { pleomorfas } \\
\text { finas }\end{array}$ & 0,5 & 6 & Agulhama & $\mathrm{HC}$ & CAD "in situ" \\
\hline $\mathrm{CP}$ & 50 & Agrupadas & puntiformes & 0,6 & 6 & Core & $\mathrm{HC}$ & Adenose \\
\hline DSCS & 43 & Agrupadas & amorfas & 0,5 & 6 & MAMOTOMIA & Fleury & Adenose \\
\hline NMA & 51 & Agrupadas & amorfas & 0,5 & 6 & Agulhama & $\mathrm{HC}$ & Adenose \\
\hline $\mathrm{CCl}$ & 57 & Agrupadas & $\begin{array}{l}\text { pleomorfas } \\
\text { finas }\end{array}$ & 1,3 & 6 & Agulhama & $\mathrm{HC}$ & CAD "in situ" \\
\hline AACC & 48 & Agrupadas & $\begin{array}{l}\text { pleomorfas } \\
\text { finas }\end{array}$ & 0,5 & 6 & Agulhama & URP & $\begin{array}{c}\text { Adenose } \\
\text { esclerosante }\end{array}$ \\
\hline EFS & 40 & Agrupadas & $\begin{array}{l}\text { pleomorfas } \\
\text { finas }\end{array}$ & 0,5 & 6 & Agulhama & $\mathrm{HC}$ & FA \\
\hline MT & 50 & Agrupadas & amorfas & 0,5 & 7 & Agulhama & URP & CAD "in situ" \\
\hline $\mathrm{SP}$ & 58 & Agrupadas & amorfas & 0,5 & 7 & Core & Fleury & Adenose \\
\hline MGVS & 48 & Linear & puntiformes & 0,8 & 7 & Core & $\mathrm{HC}$ & Papiloma \\
\hline MLL & 60 & Agrupadas & puntiformes & 1,8 & 7 & Agulhama & $\mathrm{HC}$ & HDT \\
\hline SAC & 50 & Agrupadas & amorfas & 0,5 & 7 & Agulhama & $\mathrm{HC}$ & Adenose \\
\hline IRGG & 51 & Agrupadas & amorfas & 0,5 & 7 & MAMOTOMIA & Fleury & Adenose \\
\hline MDS & 47 & Agrupadas & amorfas & 0,5 & 7 & Agulhama & $\mathrm{HC}$ & Papiloma \\
\hline CFO & 52 & Agrupadas & $\begin{array}{l}\text { pleomorfas } \\
\text { finas }\end{array}$ & 0,5 & 7 & Core & $\mathrm{HC}$ & $\begin{array}{l}\text { Adenose } \\
\text { esclerosante }\end{array}$ \\
\hline $\mathrm{MFCL}$ & 47 & Agrupadas & puntiformes & 0,5 & 7 & Core & $\mathrm{HC}$ & Fibroesclerose \\
\hline MCFS & 53 & Agrupadas & amorfas & 0,7 & 7 & Agulhama & $\mathrm{HC}$ & CAD "in situ" \\
\hline MJMC & 48 & Segmentar & lineares & 1,2 & 7 & Agulhama & URP & CAD Invasivo \\
\hline MAO & 52 & Agrupadas & $\begin{array}{l}\text { pleomorfas } \\
\text { finas }\end{array}$ & 0,5 & 7 & Agulhama & $\mathrm{HC}$ & CAD Invasivo \\
\hline RHPP & 53 & Agrupadas & $\begin{array}{l}\text { pleomorfas } \\
\text { finas }\end{array}$ & 0,5 & 7 & Core & $\mathrm{HC}$ & CAD "in situ" \\
\hline
\end{tabular}




\begin{tabular}{|c|c|c|c|c|c|c|c|c|}
\hline Nome & Idade & Distribuição & Morfologia & Área & Quantidade & Método & Origem & AP \\
\hline LG & 62 & Agrupadas & $\begin{array}{l}\text { heterogêneas } \\
\text { grosseiras }\end{array}$ & 0,8 & 7 & MAMOTOMIA & Fleury & HDT \\
\hline $\mathrm{MBCL}$ & 38 & Agrupadas & amorfas & 0,5 & 7 & Core & $\mathrm{HC}$ & Adenose \\
\hline $\mathrm{DMJ}$ & 53 & Agrupadas & amorfas & 0,5 & 7 & Agulhama & $\mathrm{HC}$ & HDT \\
\hline MAAMT & 51 & Agrupadas & $\begin{array}{l}\text { pleomorfas } \\
\text { finas }\end{array}$ & 0,5 & 7 & Agulhama & $\mathrm{HC}$ & CAD "in situ" \\
\hline MLST & 61 & Linear & puntiformes & 1,5 & 7 & Agulhama & $\mathrm{HC}$ & Fibroesclerose \\
\hline $\mathrm{CMT}$ & 48 & Agrupadas & amorfas & 0,5 & 7 & Agulhama & $\mathrm{HC}$ & FA \\
\hline MEF & 53 & Agrupadas & lineares & 0,5 & 7 & Agulhama & $\mathrm{HC}$ & Fibroesclerose \\
\hline NS & 55 & Agrupadas & $\begin{array}{l}\text { heterogêneas } \\
\text { grosseiras }\end{array}$ & 0,5 & 7 & Agulhama & $\mathrm{HC}$ & CAD "in situ" \\
\hline AVG & 75 & Agrupadas & amorfas & 0,5 & 7 & Agulhama & $\mathrm{HC}$ & Adenose \\
\hline SEM & 45 & Agrupadas & puntiformes & 0,5 & 7 & Core & Fleury & Adenose \\
\hline LMMST & 62 & Agrupadas & $\begin{array}{l}\text { pleomorfas } \\
\text { finas }\end{array}$ & 0,5 & 7 & MAMOTOMIA & Fleury & CAD "in situ" \\
\hline RCVPC & 52 & Agrupadas & puntiformes & 0,5 & 7 & MAMOTOMIA & Fleury & HDT \\
\hline HBS & 51 & Agrupadas & lineares & 0,5 & 7 & Agulhama & $\mathrm{HC}$ & HDT \\
\hline MGNV & 51 & Agrupadas & amorfas & 0,8 & 7 & Agulhama & $\mathrm{HC}$ & Adenose \\
\hline EC & 39 & Agrupadas & $\begin{array}{l}\text { heterogêneas } \\
\text { grosseiras }\end{array}$ & 0,5 & 7 & MAMOTOMIA & Fleury & Adenose \\
\hline CBY & 75 & Agrupadas & amorfas & 0,7 & 7 & Core & Fleury & Reação CE \\
\hline ICBF & 77 & Agrupadas & $\begin{array}{l}\text { pleomorfas } \\
\text { finas }\end{array}$ & 0,8 & 7 & MAMOTOMIA & Fleury & CAD "in situ" \\
\hline CTC & 50 & Agrupadas & amorfas & 0,5 & 7 & Agulhama & $\mathrm{HC}$ & HDA \\
\hline HFS & 62 & Agrupadas & $\begin{array}{l}\text { heterogêneas } \\
\text { grosseiras }\end{array}$ & 0,9 & 7 & Agulhama & $\mathrm{HC}$ & Adenose \\
\hline MLLF & 40 & Agrupadas & puntiformes & 0,5 & 7 & Core & $\mathrm{HC}$ & Adenose \\
\hline SP & 43 & Agrupadas & $\begin{array}{l}\text { heterogêneas } \\
\text { grosseiras }\end{array}$ & 0,7 & 7 & MAMOTOMIA & Fleury & FA \\
\hline CTP & 53 & Agrupadas & amorfas & 0,8 & 7 & Agulhama & $\mathrm{HC}$ & Adenose \\
\hline LDG & 72 & Agrupadas & puntiformes & 0,5 & 7 & Agulhama & $\mathrm{HC}$ & HDA \\
\hline AMSC & 55 & Agrupadas & amorfas & 0,5 & 7 & Agulhama & URP & Adenose \\
\hline $\mathrm{HC}$ & 49 & Agrupadas & $\begin{array}{l}\text { pleomorfas } \\
\text { finas }\end{array}$ & 0,8 & 7 & Agulhama & URP & CAD Invasivo \\
\hline INF & 52 & Agrupadas & $\begin{array}{l}\text { heterogêneas } \\
\text { grosseiras }\end{array}$ & 0,5 & 7 & MAMOTOMIA & Fleury & Adenose \\
\hline AMSCO & 48 & Agrupadas & amorfas & 0,5 & 7 & Core & Fleury & Fibroesclerose \\
\hline VLVM & 48 & Agrupadas & puntiformes & 0,5 & 7 & Agulhama & $\mathrm{HC}$ & HDT \\
\hline AMM & 38 & Agrupadas & amorfas & 0,5 & 7 & Core & $\mathrm{HC}$ & Adenose \\
\hline MMCN & 37 & Agrupadas & puntiformes & 0,5 & 7 & Core & Fleury & FA \\
\hline AAA & 53 & Agrupadas & amorfas & 0,5 & 7 & Agulhama & $\mathrm{HC}$ & CAD "in situ" \\
\hline MRCM & 51 & Agrupadas & amorfas & 0,5 & 7 & Agulhama & $\mathrm{HC}$ & Papiloma \\
\hline NMG & 60 & Agrupadas & $\begin{array}{l}\text { pleomorfas } \\
\text { finas }\end{array}$ & 0,5 & 7 & Agulhama & URP & CAD "in situ" \\
\hline MXL & 65 & Agrupadas & amorfas & 0,5 & 7 & Core & $\mathrm{HC}$ & CAD Invasivo \\
\hline MSFS & 53 & Agrupadas & $\begin{array}{l}\text { heterogêneas } \\
\text { grosseiras }\end{array}$ & 0,5 & 7 & MAMOTOMIA & Fleury & Adenose \\
\hline MHFO & 45 & Linear & puntiformes & 0,5 & 7 & Core & $\mathrm{HC}$ & CAD "in situ" \\
\hline TAR & 39 & Linear & $\begin{array}{l}\text { pleomorfas } \\
\text { finas }\end{array}$ & 0,5 & 7 & Core & $\mathrm{HC}$ & $\begin{array}{l}\text { Adenose } \\
\text { esclerosante }\end{array}$ \\
\hline$A B$ & 39 & Agrupadas & puntiformes & 0,7 & 7 & Core & $\mathrm{HC}$ & HDT \\
\hline RNO & 49 & Agrupadas & puntiformes & 0,5 & 7 & Core & $\mathrm{HC}$ & Adenose \\
\hline
\end{tabular}




\begin{tabular}{|c|c|c|c|c|c|c|c|c|}
\hline Nome & Idade & Distribuição & Morfologia & Área & Quantidade & Método & Origem & AP \\
\hline DF & 67 & Linear & lineares & 1,9 & 7 & Core & $\mathrm{HC}$ & CAD "in situ" \\
\hline JET & 45 & Agrupadas & $\begin{array}{l}\text { heterogêneas } \\
\text { grosseiras }\end{array}$ & 0,5 & 7 & Core & Fleury & Adenose \\
\hline NAC & 60 & Agrupadas & $\begin{array}{l}\text { heterogêneas } \\
\text { grosseiras }\end{array}$ & 0,5 & 7 & Core & $\mathrm{HC}$ & Adenose \\
\hline SRSL & 37 & Agrupadas & $\begin{array}{l}\text { pleomorfas } \\
\text { finas }\end{array}$ & 1,1 & 7 & MAMOTOMIA & Fleury & CAD "in situ" \\
\hline MLC & 51 & Agrupadas & $\begin{array}{l}\text { pleomorfas } \\
\text { finas }\end{array}$ & 0,5 & 7 & Agulhama & URP & CAD "in situ" \\
\hline RMWR & 41 & Agrupadas & amorfas & 0,5 & 7 & Core & Fleury & Adenose \\
\hline NBD & 52 & Agrupadas & $\begin{array}{l}\text { pleomorfas } \\
\text { finas }\end{array}$ & 0,5 & 7 & Agulhama & URP & CAD "in situ" \\
\hline CNCC & 49 & Agrupadas & puntiformes & 0,5 & 7 & Agulhama & $\mathrm{HC}$ & Adenose \\
\hline LPA & 45 & Agrupadas & amorfas & 0,4 & 7 & Core & $\mathrm{HC}$ & Adenose \\
\hline MRCA & 43 & Agrupadas & amorfas & 0,5 & 7 & Agulhama & URP & CAD "in situ" \\
\hline ECF & 42 & Agrupadas & $\begin{array}{l}\text { heterogêneas } \\
\text { grosseiras }\end{array}$ & 0,5 & 7 & Core & Fleury & FA \\
\hline MNA & 47 & Agrupadas & $\begin{array}{l}\text { heterogêneas } \\
\text { grosseiras }\end{array}$ & 0,5 & 7 & Agulhama & $\mathrm{HC}$ & Adenose \\
\hline CLP & 68 & Agrupadas & puntiformes & 0,5 & 7 & Core & $\mathrm{HC}$ & CAD Invasivo \\
\hline EAS & 61 & Agrupadas & puntiformes & 0,5 & 7 & Core & Fleury & Fibroesclerose \\
\hline MCB & 51 & Agrupadas & amorfas & 0,8 & 7 & Core & $\mathrm{HC}$ & Adenose \\
\hline NAP & 63 & Agrupadas & amorfas & 0,5 & 7 & Core & $\mathrm{HC}$ & Adenose \\
\hline MAFA & 51 & Agrupadas & amorfas & 0,5 & 7 & Agulhama & $\mathrm{HC}$ & Adenose \\
\hline FAZ & 48 & Agrupadas & amorfas & 0,9 & 7 & Core & $\mathrm{HC}$ & Papiloma \\
\hline LN & 53 & Agrupadas & puntiformes & 0,5 & 7 & Agulhama & URP & Adenose \\
\hline EMIV & 45 & Agrupadas & $\begin{array}{l}\text { pleomorfas } \\
\text { finas }\end{array}$ & 0,5 & 7 & MAMOTOMIA & Fleury & $\begin{array}{l}\text { Adenose } \\
\text { esclerosante }\end{array}$ \\
\hline RMR & 43 & Agrupadas & amorfas & 0,5 & 7 & Core & Fleury & Fibroesclerose \\
\hline $\operatorname{ccs}$ & 58 & Agrupadas & $\begin{array}{l}\text { pleomorfas } \\
\text { finas }\end{array}$ & 0,5 & 7 & Agulhama & $\mathrm{HC}$ & $\begin{array}{l}\text { Adenose } \\
\text { esclerosante }\end{array}$ \\
\hline CMSK & 36 & Agrupadas & puntiformes & 0,6 & 7 & Agulhama & URP & Adenose \\
\hline $\mathrm{MHC}$ & 60 & Agrupadas & amorfas & 0,5 & 7 & Core & Fleury & Fibroesclerose \\
\hline ALCP & 51 & Linear & $\begin{array}{l}\text { pleomorfas } \\
\text { finas }\end{array}$ & 0,8 & 8 & Agulhama & $\mathrm{HC}$ & $\begin{array}{c}\text { Adenose } \\
\text { esclerosante }\end{array}$ \\
\hline EFB & 43 & Agrupadas & amorfas & 1,2 & 8 & Core & $\mathrm{HC}$ & Adenose \\
\hline IBM & 53 & Agrupadas & amorfas & 0,5 & 8 & Agulhama & $\mathrm{HC}$ & HDA \\
\hline CPS & 40 & Agrupadas & $\begin{array}{l}\text { heterogêneas } \\
\text { grosseiras }\end{array}$ & 0,5 & 8 & MAMOTOMIA & Fleury & Adenose \\
\hline MJRM & 45 & Agrupadas & $\begin{array}{l}\text { pleomorfas } \\
\text { finas }\end{array}$ & 0,4 & 8 & Agulhama & $\mathrm{HC}$ & Papiloma \\
\hline CMLG & 43 & Agrupadas & puntiformes & 0,5 & 8 & Agulhama & $\mathrm{HC}$ & Adenose \\
\hline AMMA & 56 & Agrupadas & $\begin{array}{l}\text { pleomorfas } \\
\text { finas }\end{array}$ & 0,5 & 8 & Agulhama & $\mathrm{HC}$ & HDA \\
\hline NSM & 47 & Agrupadas & puntiformes & 0,5 & 8 & Agulhama & $\mathrm{HC}$ & Papiloma \\
\hline AAP & 52 & Agrupadas & $\begin{array}{l}\text { pleomorfas } \\
\text { finas }\end{array}$ & 0,5 & 8 & Agulhama & $\mathrm{HC}$ & HDA \\
\hline FMF & 42 & Agrupadas & $\begin{array}{l}\text { heterogêneas } \\
\text { grosseiras }\end{array}$ & 0,7 & 8 & Agulhama & $\mathrm{HC}$ & FA \\
\hline NFG & 62 & Agrupadas & $\begin{array}{l}\text { heterogêneas } \\
\text { grosseiras }\end{array}$ & 0,5 & 8 & MAMOTOMIA & Fleury & FA \\
\hline AIML & 54 & Agrupadas & amorfas & 0,5 & 8 & Agulhama & $\mathrm{HC}$ & HDA \\
\hline IC & 71 & Linear & amorfas & 2,5 & 8 & Agulhama & $\mathrm{HC}$ & HDT \\
\hline
\end{tabular}




\begin{tabular}{|c|c|c|c|c|c|c|c|c|}
\hline Nome & Idade & Distribuição & Morfologia & Área & Quantidade & Método & Origem & AP \\
\hline MCNW & 51 & Agrupadas & puntiformes & 0,5 & 8 & MAMOTOMIA & Fleury & HDA \\
\hline MAS & 51 & Agrupadas & $\begin{array}{l}\text { heterogêneas } \\
\text { grosseiras }\end{array}$ & 0,4 & 8 & Core & $\mathrm{HC}$ & Adenose \\
\hline MLS & 49 & Linear & $\begin{array}{l}\text { pleomorfas } \\
\text { finas }\end{array}$ & 0,8 & 8 & Agulhama & URP & CAD "in situ" \\
\hline $\mathrm{OB}$ & 48 & Agrupadas & $\begin{array}{l}\text { pleomorfas } \\
\text { finas }\end{array}$ & 0,9 & 8 & Agulhama & $\mathrm{HC}$ & Adenose \\
\hline IFC & 61 & Agrupadas & puntiformes & 0,5 & 8 & Core & Fleury & HDT \\
\hline $\mathrm{COM}$ & 53 & Agrupadas & $\begin{array}{l}\text { heterogêneas } \\
\text { grosseiras }\end{array}$ & 0,5 & 8 & Agulhama & $\mathrm{HC}$ & Adenose \\
\hline RCGS & 44 & Agrupadas & $\begin{array}{l}\text { pleomorfas } \\
\text { finas }\end{array}$ & 0,8 & 8 & mamotomia & Fleury & CAL Invasivo \\
\hline TANN & 53 & Agrupadas & $\begin{array}{c}\text { heterogêneas } \\
\text { grosseiras }\end{array}$ & 0,5 & 8 & Agulhama & $\mathrm{HC}$ & CAD Invasivo \\
\hline CMS & 36 & Agrupadas & puntiformes & 0,5 & 8 & Core & Fleury & Adenose \\
\hline SAV & 42 & Agrupadas & amorfas & 0,5 & 8 & Core & Fleury & Adenose \\
\hline ATON & 48 & Agrupadas & amorfas & 0,6 & 8 & Agulhama & $\mathrm{HC}$ & Adenose \\
\hline JBS & 59 & Agrupadas & puntiformes & 0,5 & 8 & Agulhama & $\mathrm{HC}$ & HDT \\
\hline JNM & 50 & Agrupadas & puntiformes & 0,5 & 8 & Agulhama & $\mathrm{HC}$ & HDT \\
\hline $\mathrm{CMGH}$ & 47 & Agrupadas & amorfas & 0,9 & 8 & MAMOTOMIA & Fleury & Fibroesclerose \\
\hline AAP & 60 & Agrupadas & amorfas & 0,9 & 8 & Agulhama & $\mathrm{HC}$ & Adenose \\
\hline $\mathrm{MLCC}$ & 45 & Agrupadas & puntiformes & 0,5 & 8 & Agulhama & $\mathrm{HC}$ & Adenose \\
\hline $\mathrm{MCM}$ & 61 & Linear & $\begin{array}{l}\text { heterogêneas } \\
\text { grosseiras }\end{array}$ & 1,8 & 8 & Agulhama & URP & $\begin{array}{l}\text { Adenose } \\
\text { esclerosante }\end{array}$ \\
\hline JLP & 78 & Agrupadas & amorfas & 0,5 & 8 & Agulhama & $\mathrm{HC}$ & Adenose \\
\hline $\mathrm{MCM}$ & 39 & Agrupadas & amorfas & 0,5 & 8 & Agulhama & $\mathrm{HC}$ & Papiloma \\
\hline VLGO & 55 & Agrupadas & $\begin{array}{l}\text { pleomorfas } \\
\text { finas }\end{array}$ & 0,5 & 8 & Core & $\mathrm{HC}$ & CAD "in situ" \\
\hline AMSF & 49 & Agrupadas & $\begin{array}{l}\text { pleomorfas } \\
\text { finas }\end{array}$ & 0,5 & 8 & Agulhama & $\mathrm{HC}$ & HDT \\
\hline MCGB & 56 & Agrupadas & $\begin{array}{l}\text { heterogêneas } \\
\text { grosseiras }\end{array}$ & 0,6 & 8 & MAMOTOMIA & Fleury & HDT \\
\hline AS & 50 & Agrupadas & amorfas & 0,5 & 8 & Agulhama & $\mathrm{HC}$ & HDA \\
\hline ERP & 53 & Agrupadas & puntiformes & 0,8 & 8 & MAMOTOMIA & Fleury & Adenose \\
\hline MHOS & 44 & Agrupadas & puntiformes & 0,5 & 8 & Core & $\mathrm{HC}$ & Adenose \\
\hline FTS & 56 & Agrupadas & amorfas & 0,5 & 8 & Agulhama & $\mathrm{HC}$ & HDT \\
\hline AMN & 53 & Agrupadas & puntiformes & 0,6 & 8 & Core & $\mathrm{HC}$ & Adenose \\
\hline ICP & 64 & Agrupadas & $\begin{array}{l}\text { heterogêneas } \\
\text { grosseiras }\end{array}$ & 0,9 & 8 & Core & Fleury & Fibroesclerose \\
\hline MSN & 46 & Linear & puntiformes & 0,5 & 8 & Agulhama & $\mathrm{HC}$ & CAD "in situ" \\
\hline MLG & 48 & Agrupadas & puntiformes & 0,5 & 8 & Agulhama & $\mathrm{HC}$ & Papiloma \\
\hline LLS & 49 & Agrupadas & puntiformes & 0,4 & 8 & Agulhama & $\mathrm{HC}$ & Adenose \\
\hline NAB & 51 & Agrupadas & $\begin{array}{l}\text { heterogêneas } \\
\text { grosseiras }\end{array}$ & 0,5 & 8 & Agulhama & $\mathrm{HC}$ & Fibroesclerose \\
\hline SMP & 49 & Agrupadas & $\begin{array}{l}\text { pleomorfas } \\
\text { finas }\end{array}$ & 0,7 & 8 & Agulhama & Fleury & CAD "in situ" \\
\hline NTP & 58 & Agrupadas & $\begin{array}{l}\text { heterogêneas } \\
\text { grosseiras }\end{array}$ & 0,8 & 8 & Agulhama & $\mathrm{HC}$ & Fibroesclerose \\
\hline ASM & 49 & Agrupadas & $\begin{array}{l}\text { pleomorfas } \\
\text { finas }\end{array}$ & 0,5 & 8 & Core & $\mathrm{HC}$ & $\begin{array}{c}\text { Adenose } \\
\text { esclerosante }\end{array}$ \\
\hline CMG & 56 & Agrupadas & $\begin{array}{l}\text { heterogêneas } \\
\text { grosseiras }\end{array}$ & 0,5 & 8 & Agulhama & $\mathrm{HC}$ & HDA \\
\hline APL & 53 & Agrupadas & puntiformes & 0,5 & 8 & Agulhama & $\mathrm{HC}$ & Adenose \\
\hline
\end{tabular}




\begin{tabular}{|c|c|c|c|c|c|c|c|c|}
\hline Nome & Idade & Distribuição & Morfologia & Área & Quantidade & Método & Origem & AP \\
\hline IMG & 56 & Linear & puntiformes & 0,8 & 8 & Agulhama & $\mathrm{HC}$ & Fibroesclerose \\
\hline MS & 45 & Linear & lineares & 0,5 & 8 & Agulhama & $\mathrm{HC}$ & Papilomatose \\
\hline SÃO & 53 & Agrupadas & lineares & 0,5 & 8 & Agulhama & $\mathrm{HC}$ & Papiloma \\
\hline MLS & 48 & Agrupadas & puntiformes & 0,5 & 8 & Agulhama & $\mathrm{HC}$ & Adenose \\
\hline SBAP & 46 & Agrupadas & amorfas & 0,5 & 8 & Agulhama & $\mathrm{HC}$ & Adenose \\
\hline LER & 56 & Agrupadas & $\begin{array}{c}\text { heterogêneas } \\
\text { grosseiras }\end{array}$ & 0,8 & 9 & MAMOTOMIA & Fleury & FA \\
\hline$A R$ & 61 & Agrupadas & $\begin{array}{l}\text { heterogêneas } \\
\text { grosseiras }\end{array}$ & 0,5 & 9 & Agulhama & $\mathrm{HC}$ & HDA \\
\hline RMS & 54 & Segmentar & $\begin{array}{l}\text { pleomorfas } \\
\text { finas }\end{array}$ & 0,5 & 9 & Core & $\mathrm{HC}$ & CAD "in situ" \\
\hline EVD & 46 & Agrupadas & $\begin{array}{c}\text { heterogêneas } \\
\text { grosseiras }\end{array}$ & 0,7 & 9 & Core & $\mathrm{HC}$ & Papiloma \\
\hline MELS & 51 & Agrupadas & puntiformes & 0,9 & 9 & Core & $\mathrm{HC}$ & Adenose \\
\hline MHF & 61 & Agrupadas & $\begin{array}{c}\text { heterogêneas } \\
\text { grosseiras }\end{array}$ & 0,5 & 9 & Core & $\mathrm{HC}$ & Adenose \\
\hline MLC & 49 & Agrupadas & $\begin{array}{l}\text { pleomorfas } \\
\text { finas }\end{array}$ & 0,5 & 9 & Agulhama & URP & CAD "in situ" \\
\hline MMLZFL & 51 & Agrupadas & puntiformes & 1,0 & 9 & Core & Fleury & Adenose \\
\hline JNM & 52 & Agrupadas & puntiformes & 0,5 & 9 & Agulhama & $\mathrm{HC}$ & HDT \\
\hline SRG & 46 & Agrupadas & puntiformes & 0,6 & 9 & Core & Fleury & Adenose \\
\hline LRR & 54 & Agrupadas & $\begin{array}{c}\text { heterogêneas } \\
\text { grosseiras }\end{array}$ & 0,9 & 9 & Core & $\mathrm{HC}$ & Adenose \\
\hline MAMS & 47 & Agrupadas & amorfas & 0,5 & 9 & Agulhama & $\mathrm{HC}$ & Adenose \\
\hline MLA & 49 & Agrupadas & puntiformes & 0,8 & 9 & Core & $\mathrm{HC}$ & Adenose \\
\hline SSC & 41 & Agrupadas & $\begin{array}{c}\text { heterogêneas } \\
\text { grosseiras }\end{array}$ & 0,8 & 9 & MAMOTOMIA & Fleury & Adenose \\
\hline IRM & 64 & Agrupadas & $\begin{array}{c}\text { heterogêneas } \\
\text { grosseiras }\end{array}$ & 0,5 & 9 & Core & $\mathrm{HC}$ & Adenose \\
\hline LBS & 39 & Agrupadas & $\begin{array}{l}\text { heterogêneas } \\
\text { grosseiras }\end{array}$ & 1,0 & 9 & Core & $\mathrm{HC}$ & Adenose \\
\hline TMM & 51 & Agrupadas & amorfas & 0,5 & 9 & Core & $\mathrm{HC}$ & Adenose \\
\hline DSC & 79 & Agrupadas & puntiformes & 0,8 & 9 & MAMOTOMIA & Fleury & FA \\
\hline MLFA & 52 & Agrupadas & amorfas & 0,5 & 9 & Core & Fleury & Fibroesclerose \\
\hline
\end{tabular}


1. Jemal A, Tiwari RC, Murray T, Ghafoor A, Samuels A, Ward E et al. Cancer statistics, 2004. CA Cancer J Clin. 2004 Jan-Feb;54(1):8-29.

2. INCA. Instituto Nacional de Câncer; Ministério da Saúde. Câncer no Brasil: dados dos registros de câncer de base populacional. Rio de Janeiro: INCA; 2003. v.3.

3. Tabar L, Vitak B, Chen HH et al. The Swedish Two-County Trial Twenty Years Later. Radiol Clin North Am. 2000;38(4):625-37.

4. Poplack S, Wells W. Ductal carcinoma "in situ" of the breast: mammographic-pathologic correlation. AJR AM J Roentgenol. 1998;170:1543-9.

5. Tabar L, Dean P, Tot T. Radiology of minimal breast cancer. In: Haus A, Yaffe M, editors. Syllabus; categorical course in diagnostic radiology physics: physical aspects of breast imaging-current and future considerations. Oak Brook, III: Radiological Society of North America; 1999. p.9-18.

6. Liberman L, Abramson AF, Squires FB, Glassman JR, Morris EA, Dershaw DD. The breast imaging reporting and data system: positive predictive value of mammographic features and final assesment categories. Am J Roentgenol. 1998;171(1):35-40.

7. ACR BI-RADS - Breast Imaging and Data System Mammography. 1st ed. 1993.

8. ACR BI-RADS - Breast Imaging and Data System Mammography. 3rd ed. 2003. 
9. AMERICAN CANCER SOCIETY. Breast cancer facts and figures 20012002. Atlanta, Georgia; 2002. p.23.

10. Tchou J, Morrow M. Avaiable models for breast cancer risk assesment:how accurate are they? J Am Coll Surg. 2003;197:1029-35.

11. Moskowitz M. Breast cancer: age-specific growth rates and screening strategies. Radiology. 1986;161:37-41.

12. Seidman TI. "Optimal Filtering" for some ill - posed problems wave propagation and invasion (Fitzgibbon, Wheeler). Philadelphia: SIAM; 1992. p.108-123.

13. Moss, S. A trial to study the effect on breast cancer mortality of annual mammographic screening in women starting at age 40. Trial Steering Group. J Med Screen. 1999;6:144-8.

14. Feig SA, D'Orsi CJ, Hendrick RE, Jackson VP, Kopans DB, Monsees B, Sickles E, Stelling CB, Zinnoninger M, Wilcox-Buchalla P. American College of Radiology guidelines for breast cancer screening. AJR Am. J. Roentgenol. 1998; 171: 29-33.

15. Humphrey LL, Helfand M, Chan BK, Woolf SH. Breast cancer screening: a summary of the evidence for the U.S. Preventive Services Task Force. Ann Intern Med. 2002;137:347-60.

16. Feig SA. Estimation of currently attainable benefit from mammographic screening of women aged 40-49 years. Cancer. 1995;75:2412-9.

17. Feig SA. Increased benefit from shorter screening mammography intervals for women ages 40-49. Cancer. 1997;80:2035-9.

18. Feig SA. Screening mammography: effect of image quality on clinical outcome. AJR Am J Roentgenol. 2002;178:805-7. 
19. Hendrick RE, Smith RA, Rutledge JH III, Smart CR. Benefit of screening mammography in women aged 40-49: a new meta-analysis of randomized controlled trials. J Natl Cancer Inst Monogr. 1997;22:87-92.

20. Kopans DB. Breast imaging. 2nd ed. Philadelphia-New York: LippincottRaven; 1998. Caph. 7.

21. Kopans DB, Feig SA. The Canadian National Breast Screening Study: a critical review. AJR Am J Roentgnenol. 1993;161:755-60.

22. Pisano ED, Constantine A, Gatsonis MJ, Yaffe R, Hendrick E, Tosteson ANA, Fryback DG, Bassett LW, Baum JK, Conant EF, Jong RA, Rebner M, D'Orsi CJ. American College of Radiology Imaging Network Digital Mammographic Imaging Screening Trial: objectives and methodology. Radiology. 2005;236:04-412.

23. O'Shaughnessy K, Castellino R, Muller S, et al. Computer aided detection (CAD) on 90 biopsy -proven breast cancer cases acquired on a full field digital mammography (FFDM) system. Radiology. 2001;221:471.

24. Sickles, EA. Mammographic detectability of breast calcification. Am J Roentgenol. 1982;139:913-8.

25. Jackson VP, Lex AM, Smith DJ. Patiente discomfort during screen-film mammography. Radiology. 1988;168:421-3.

26. Basset LW, Bunnel DH, Jahanshahi R, Gold RH, Arndt RD, Linsman J. Breast cancer detection: one versus two views. Radiology. 1987;165:957.

27. Jackson VP, Reynolds HE, Hawes DR. Sonography of the breast. Semin Ultrasound CT MRI. 1996;177(5):460-75. 
28. Teh WL, Wilson ARM, Evans AJ, Burrel H, Pinder SE, Ellis IO. Ultrasound guided core biopsy of suspicious mammography calcifications using high frequency and power Doppler ultrasound. Clin Radiol. 2000;55:390-4.

29. Sickles EA. Probably benign breast lesions: when chould follow up be recommended and what is the optimal follow up protocol? Radiology. 1999;219:11-4.

30. Sickles EA. Breast imaging: from 1965 to the present. Radiology. 2000;215:1-16.

31. Varas X, Leborgne F, Leborgne JH. Nonpalpable, probably benign lesions: role of follow up mammography. Radiology. 1992;184(2):409-14.

32. Vizcaíno I, Gadea L, Andreo L, Salas D, Ruiz-Perales F, Cuevas D, Herranz C, Bueno F. Short-term follow-up results in 795 nonpalpable probably benign lesions detected at screening mammography. Radiology. 2001;219:475.

33. Sickles EA. Breast calcifications: mammographic evaluation. Radiology. 1986;160:289.

34. Sickles EA. Management of probably benign lesions. The Radiologic Clinics of North America. 1995 Nov.:1123-9.

35. Orel SG, Kay N, Reynolds C, Sullivan DC. BI-RADS categorization as a predictor of malignancy. Radiology. 1999;211(3):845-50.

36. Hall FM. Nonpalpable breast lesion. Radiology. 1988;167:353-61.

37. Kopans DB. The Canadian screening program: a different perspective. AJR. 1990;155:748-9. 
38. Egan RL, McSweeney MB, Sewell CW. Intramammary calcifications without an associated mass in benign and malignant diseases. Radiology. 1980;137:1.

39. Jackman RJ, Burbank F, Parker SH, Evans WP, Lechner MC, Richardson TR, Smid AA, Borofsky HB, Lee CH, Goldstein HM, Schilling KJ, Wray AB, Brem RF, Helbich TH, Lehrer DE, Adler SJ. Stereotactic breast biopsy of nonpalpable lesions: determinants of ductal carcinoma "in situ" underestimation rates. Radiology. 2001;218:497-502.

40. Gershon-Cohen J, Ingleby H, Berger SM, Forman M, Curcio BM. Mammographic screening for breast cancer. Radiology. 1967;88:663-7.

41. Rogers JV Jr, Powell RW. Mammographic indications for biopsy of clinically normal breasts: correlation with pathologic findings in 72 cases. Am J Roentgenol Radium Ther Nucl Med. 1972 Aug;115(4):794-800.

42. Millis RR, Davis R, Stacey AJ. The detection and significance of calcifications in the breast: a radiological and pathological study. The British Journal of Radiology. 1976;49(577):12-26.

43. Le Gal M, Durand JC, Laurent M, Pellier D. Management following mammography revealing grouped microcalcifications without palpable tumor. Nouv Presse Med. 1976 Jun;26;5(26):1623-7.

44. Le Gal M, Chavanne G, Pellier D. Valeur diagnostic des microcalcifications groupées decouverts par mammographies. Bull Cancer (Paris). 1984;71(1):57-64.

45. Tabar L, Fagerberg CJ, Gad A et al. Reduction in mortality from breast cancer after mass screening with mammography: randomised trial from the Breast Cancer Screening Working Group of the Swedish National Board of Health and Welfare. Lancet. 1985;1. 
46. Vianna AD, Marchiori E. Calcificações malignas da mama: correlação mamografia-anatomia patológica. Radiol bras. 2002;35(3):131-7.

47. Basset LW. Standardized report for mammography: BI-RADS. Breast J. 1997;5:207-10.

48. Monsees BS. Evaluation of breast microcalcifications. Radiol Clin North Am. 1995;33:1109-21.

49. Wolfe JN, Saftlas AF, Salane M. Mammographic parenchymal patterns and quantitative evaluation of mammographic densities: a case control study. Am J Roentgenol. 1987;148:1087-92.

50. Liberman L. Clinical management issues in percutaneous core breast biopsy. Radiol Clin North Am. 2000;38:791-807.

51. Ciatto S, Cataliotti L, Distante V. Nonpalpable lesions detected with mammography: review of 512 consecutive cases. Radiology. 1987;165:99-102.

52. Pisano ED, Fajardo LL, Caudry DJ, Sneige NS et al. Fine-Needle Aspiration Biopsy of Nonpalpable Breast Lesions in a Multicenter Clinical Trial: Results from the Radiologic Diagnostic Oncology Group V. Radiology. 2001;219:785-92.

53. Parker SH, Lovin JD, Luethke JM, Hopper KD, Yakes WF, Burke BJ. Stereotatic breast biopsy with a biopsy gun. Radiology. 1990;176:741-7.

54. Meyer JE, Lester SC, Frenna TV, White FV. Occult breast calcifications sampled with large-core biopsy: confirmation with radiography of the specimen [published erratum appears in Radiology 1993 Nov;189(2):625]. Radiology. 1993;188:581-2.

55. Liberman L, Fahs MC, Dershaw DD et al. Impact of stereotaxic core biopsy on cost of diagnosis. Radiology. 1995;195:633-7. 
56. Parker SH, Jobe WE, Dennis MA. Guided automated large-core biopsy. Radiology. 1993;187:507-11.

57. Burbank F. Stereotactic breast biopsy of atypical ductal hyperplasia and ductal carcinoma "in situ" lesions: improved accuracy with a directional, vacuum-assisted biopsy instrument. Radiology. 1997;202:843-7.

58. Burbank F, Parker SH, Fogarty TJ. Stereotactic breast biopsy: improved tissue harvesting with the mammotome. Am Surg. 1996;62:738-44.

59. Agresti A. Categorical data analysis. New York: John Wiley \& Sons; 2002. p.558.

60. Conover WJ. Practical nonparametric statistics. New York: John Wiley \& Sons; 1987.

61. Hosmer DW, Lemeshow S. Applied logistic regression. New York: John Wiley \& Sons. 2000. p.375.

62. Neter J, Wasserman W, Kutner MH. Applied linear statistical models. 3rd ed. Homewood (Illinois): Irwin; 1990. p.127.

63. Siegel S. Estatística não-paramétrica (para as ciências do comportamento). São Paulo: McGraw-Hill; 1975. p.350.

64. Berg WA, Campassi C, Langenberg P, Sexton MJ. Breast Imaging Reporting and Data System: inter and intraobserver variability in feature analysis and final assessment. AJR. 2000;174(6):1769-77.

65. Georgian-Smith D, Lawton TJ. Calcification of lobular carcinoma "in situ" of the breast: radiologic-pathologic correlation. AJR Am J Roentgenol. 1991;176(5):1255-9.

66. Berg WA, Arnouldus CL, Teferra E, Bhargavan M. Biopsy of amorphous breast calcifications: pathologic outcome and yield at stereotactic biopsy. Radiology. 2001;221:495-503. 
67. Burnside ES, Madison WI, Sisney GA, Rubin DL, Ochsner JE, Fowler K. The ability of microcalcification descriptors in the BIRADS 4th edition to stratify the risk of malignancy. RSNA 2005.

68. Orel SG, Kay N, Reynolds C, Sullivan DC. BI-RADS categorization as a predictor of malignancy. Radiology. 1999;211(3):845-50.

69. Lacquement MA, Mitchell D, Hollingsworth AB. Positive predictive value of the breast imaging reporting and data system. J American College of Surgeons. 1999;189(1):34-40.

70. Liberman L, Gougotas CA, Zakowski MF, La Trenta LR, Abramson AF, Morris EA, Dershaw DD. Calcifications highly suggestive of malignancy of breast biopsy methods. AJR AM J Roentgenol. 2001;177(1):165-72.

71. Ball CG, Butchart M, MacFarlane JK. Effect on biopsy technique of breast imaging reporting and data system (BI-RADS) for nonpalpable mammographic abnormalities. Cn J Surg. 2002;45(4):259-63.

72. Gülsün M, Demirkazik FB, Ariyurek M. Evaluation of breast microcalcifications according to breast imaging, reporting and data system criteria. Radiology. 2003 Sep;47(3):227-31. 